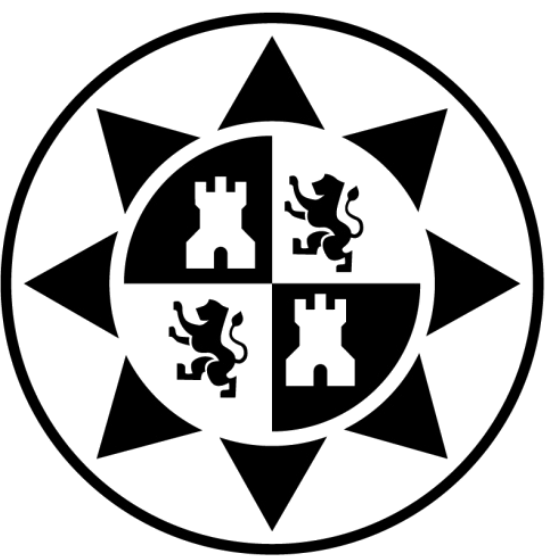

UNIVERSIDAD POLITÉCNICA DE CARTAGENA

Departamento de Economía Financiera y Contabilidad

Programa de Doctorado Administración y Dirección de Empresas

TESIS DOCTORAL

\title{
CULTURA, INNOVACIÓN, INTRAEMPRENDIMIENTO Y RENDIMIENTO EN LAS MIPYME DE COLOMBIA
}

\author{
AUTOR: \\ D. EDGAR JULIÁN GÁLVEZ ALBARRACÍN \\ DIRIGIDA POR: \\ DR. D. DOMINGO GARCÍA PÉREZ DE LEMA
}

CARTAGENA 2011 


\section{Agradecimientos}

Doy gracias en primer lugar a Dios por permitirme terminar exitosamente esta importante etapa de mi formación profesional y personal.

A las directivas de la Facultad de Ciencias de la Empresa de la Universidad Politécnica de Cartagena UPCT, mis sinceros agradecimientos por permitir que me integrara a su programa de doctorado en Administración y Dirección de Empresas; al equipo de colaboradores del Departamento de Economía Financiera y Contabilidad y del Negociado del Doctorado de la UPCT, gracias también por todo el soporte lógistico que me brindaron.

Mención especial merece mi director y tutor el Dr. Domingo García Pérez de Lema, a él mi eterna admiración por sus conocimientos y su capacidad de trabajo, y mi sincera gratitud por su interés en ayudarme a seguir sus pasos en esta ardua senda de la investigación.

Gracias a las directivas de la Universidad del Valle en Cali - Colombia, especialmente a las de su Facultad de Ciencias de la Administración, y a la Asociación Iberomericana Universitaria de Postgrado AUIP, por apoyarme decididamente en este proyecto académico.

Por último, y no por ello de menos importancia son mis agredecimientos para mi esposa María Clara, por su comprensión, paciencia y apoyo incondicional durante las largas horas de intenso trabajo que ha significado la realización de esta tesis. 


\section{Resumen}

Las micro, pequeñas y medianas empresas (MIPYMES) representan a nivel mundial la mayor parte de la demografía empresarial, por lo que se constituyen en actores centrales para el bienestar económico y social de las regiones y los paises. Por esta razón generan en los gobiernos y en la comunidad académica gran interés por conocer más y mejor su naturaleza, sus potencialidades y problemas, y por apoyar su desarrollo y competitividad.

Cuando se analizan los factores que favorecen o dificultan el éxito de las empresas, es necesario observar sus recursos y capacidades. En este sentido, la cultura organizacional y la innovación son tópicos de indudable interés, al igual que el comportamiento intraemprendedor, que se ha constituido en los últimos años en uno de los elementos claves a evaluar y fomentar. Esta tesis doctoral, tomando como marco de referencia la teoría de recursos y capacidades, analiza las relaciones existentes entre la cultura organizacional, el intraemprendimiento, la innovación y el rendimiento en las MIPYME de Colombia.

Los resultados obtenidos en esta tesis son relevantes y con importantes implicaciones para las MIPYME en Colombia. Por una parte, la cultura organizacional se muestra como un factor decisivo que influye significativamente en el rendimiento y en el comportamiento innovador de la empresa, y por otra, las práctcas asociadas con la cultura de intraemprendimiento no están suficientenmente extendidas entre las MIPYME colombianas, aunque cuando las desarrollan generan un importante impacto positivo sobre la innovacion y el rendimiento. Estos resultados son de utilidad y tienen claras implicaciones tanto para los propietarios y los directivos de las empresas, como para los entes gubernamentales para la toma de decisiones sobre las ayudas públicas, también para los profesores e investigadores de las entidades de educación superior en la orientación de programas educativos, de asesoría y de apoyo general a las MIPYME. 


\begin{abstract}
The micro, small and medium enterprises (SMEs) represent around the world the majority of business demography, so that actors are central to social and economic welfare of the regions and countries. For this reason generate in the academic community and governments great interest in knowing more and better about their nature, potential and problems, and for support their development and competitiveness.

When analyzing the factors that help or hinder the success of companies, it's necessary to observe their resources and capabilities. In this sense, organizational culture and innovation are certainly topics of interest, the same way intrapreneurship, which has become in recent years one of the key elements to evaluate and promote. This thesis, on the theory framework of resources and capabilities, analyzes the relationships between organizational culture, intrapreneurship, innovation and performance in SMEs of Colombia.

The results obtained in this thesis are relevant and have important implications for MSMEs in Colombia. On the one hand, organizational culture is shown as a factor that influences significantly the performance and innovative behavior of the company, and on the other, the practices associated with intraempreneurial culture are not enough widespread among MSMEs of Colombia, although when developing, generate a significant positive impact on innovation and performance. These results are useful and have clear implications for both owners and managers of companies, to government agencies for taking decisions on public aid, for teachers and researchers of higher education institutions, to orient educational, counseling and general support to MSMEs.
\end{abstract}


INDICE

INTRODUCCIÓN 8

\section{CAPITULO 1}

CULTURA OGANIZACIONAL, INNOVACIÓN Y RENDIMIENTO EN LAS MIPYME DE MEDIANA Y ALTA TECONOLOGÍA DE COLOMBIA ......................14

\subsection{INTRODUCCIÓN.} 15

1.2. MARCO TEÓRICO Y ESTUDIOS PREVIOS. 17

1.2.1. La Teoria de Recursos y Capacidades ......................................................................... 17

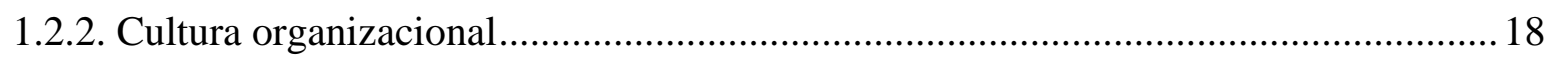

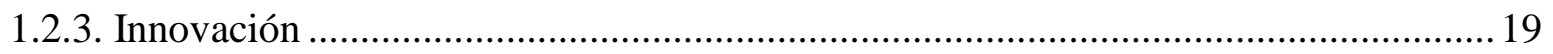

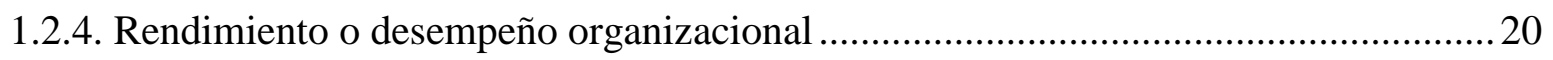

1.2.5. Estudios empíricos sobre cultura organizacional y rendimiento …………………......2 21

1.2.6. Estudios empíricos sobre innovación y rendimiento....................................................22

1.3. METODOLOGÍA DE LA INVESTIGACIÓN........................................................25

1.3.1. Obtención de la muestra y recolección de datos..........................................................25

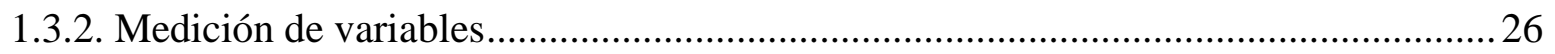

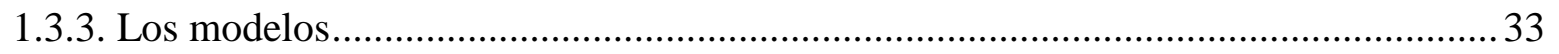

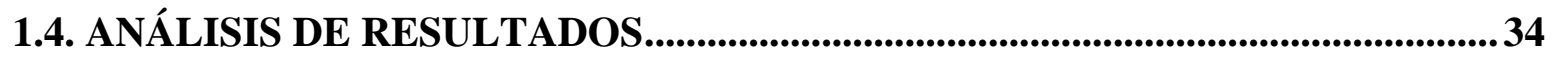

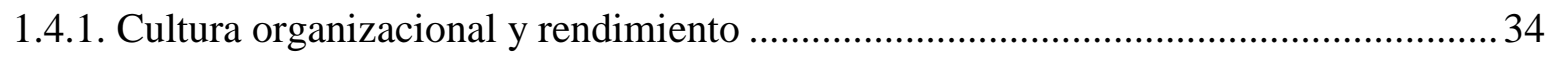

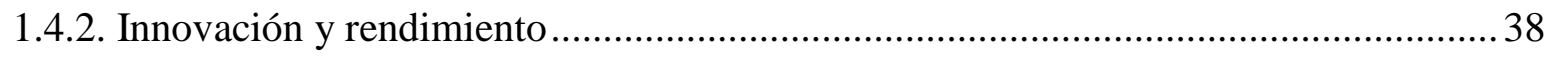

1.5. CONCLUSIONES .............................................................................................................40 


\section{CAPITULO 2}

CULTURA DE INTRAEMPRENDIMIENTO Y SU EFECTO SOBRE EL RENDIMIENTO Y LA INNOVACIÓN DE LAS MIPYMES TURISTICAS DE COLOMBIA

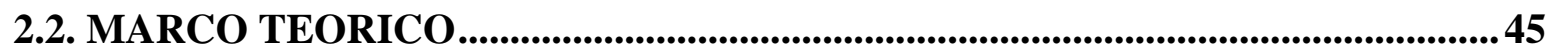

2.2.1. Intraemprendimiento y cultura de intraemprendimiento ................................... 45

2.3. ESTUDIOS EMPÍRICOS PREVIOS ..................................................................4 46

2.3.1. Cultura de intraemprendimiento y rendimiento ................................................ 46

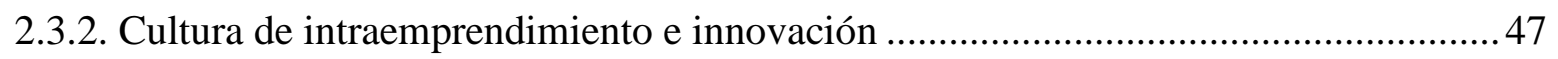

2.4. METODOLOGÍA DE LA INVESTIGACIÓN.............................................................49

2.4.1. Obtención de la muestra y recolección de datos...................................................49

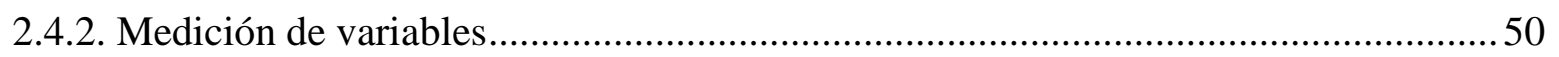



2.5. ANALISIS DE RESULTADOS...................................................................55

2.5.1. Cultura de intraemprendimiento y rendimiento ...................................................55

2.5.2. Cultura de intraemprendimiento e innovación .....................................................57

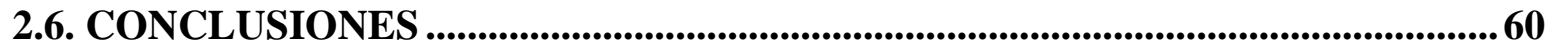

\section{CAPITULO 3}

CULTURA ORGANIZACIONAL, INNOVACIÓN Y RENDIMIENTO EN LAS MIPYMES TURISTICA DE COLOMBIA. UN ESTUDIO MULTIPLE DE

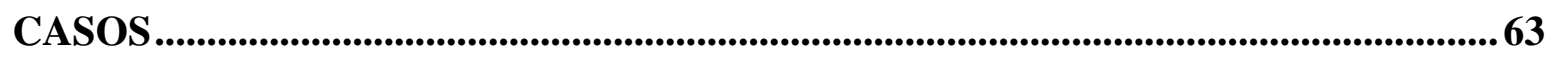

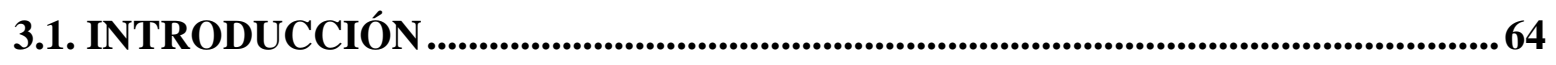


3.3. METODOLOGÍA DE LA INVESTIGACIÓN...........................................................68

3.3.1. Diseño y protocolo del estudio múltiple de casos ...................................................... 68

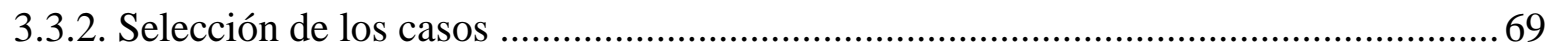

3.3.3. Procedimientos e instrumentos para recolección y medición cualitativa de los datos69

3.3.4. Procesamiento de la información ............................................................................. 71

3.4. ANALISIS DE RESULTADOS.....................................................................................71

3.4.1. Descripción de antecedentes y evolución de los casos..................................................71

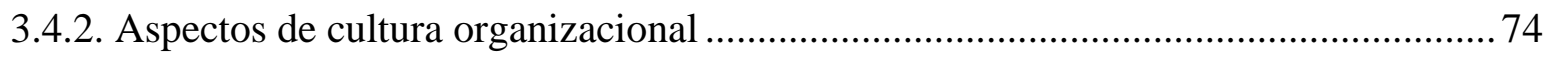

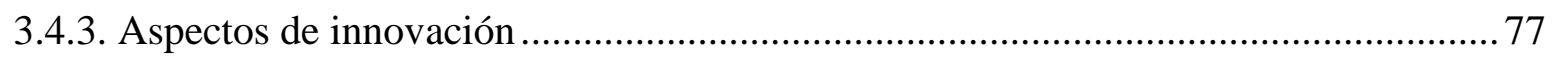

3.4.4. Aspectos de rendimiento ..................................................................................... 79

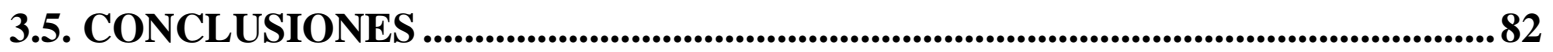



REFERENCIAS BIBLIOGRAFICAS .....................................................................................90

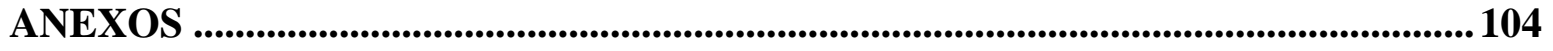

Anexo 1. Encuesta primera investigación..................................................................................105

Anexo 2. Encuesta segunda investigación ............................................................................109

Anexo 3. Protocolo de entrevista tercer investigación .........................................................113

Anexo 4. Guía de observación tercera investigación .............................................................117 


\section{INTRODUCCIÓN}


La presente tesis doctoral tiene como propósito fundamental caracterizar y analizar las relaciones existentes entre la cultura organizacional, la cultura de intraemprendimiento, la innovación y el rendimiento o desempeño de las Micro, Pequeñas y Medianas Empresas (MIPYME) de Colombia. En este trabajo se aporta evidencia teórica y empírica al respecto, desde un enfoque multidisciplinar y énfasis en la teoría de recursos y capacidades.

La teoría de recursos y capacidades ha sido ampliamente utilizada para entender y explicar las diferencias entre la productividad, la competitividad y el rendimiento de las empresas. Cada firma tiene sus propias capacidades humanas y gerenciales, recursos tecnológicos, financieros, humanos y estructuras organizacionales que combinados estratégicamente se pueden convertir en factores claves de diferenciación (Wade y Hulland, 2004; Grant, 1996; Barney, 1991; Wernerfelt, 1984, Penrose, 1962).

La cultura organizacional define en gran medida la forma en que las empresas realizan sus procesos internos y sus relaciones con el mundo exterior, lo que es crítico para determinar su rendimiento (Arango y Urrea, 2000). Si la cultura se trata como una variable, puede ser tomada como un recurso o medio para alcanzar objetivos, y si ese recurso agrega valor, es diferente en sus características a la cultura de otras organizaciones y no es fácilmente imitable por los competidores, puede convertirse en ventaja competitiva y en un activo estratégico que sustente el éxito (Barney, 1986).

La innovación, al igual que la cultura es una construcción social, las personas en cuanto a los valores, las actitudes y los conocimientos que poseen, actúan como eje central de la innovación organizacional (Gasalla, 1999). Se sostiene también que las empresas innovadoras son más flexibles y esto les permite adaptarse mejor a los cambios en el entorno, responder más rápido y mejor a las necesidades cambiantes de la sociedad en su conjunto (Drucker, 1985; Miles y Snow, 1978), y obtener así mejores resultados, también que el éxito creciente y sostenido de las empresas está en función de su capacidad para identificar y aprovechar de manera emprendedora e innovadora las oportunidades del entorno (Hernández, Yescas y Dominguez, 2007; Garzón, 2004).

El intraemprendimiento también denominado emprendimiento corporativo $u$ organizacional es un requerimiento para retomar el espíritu innovador al interior de las empresas, se constituye de aquellas actividades emprendedoras llevadas a cabo dentro de la organización (Trujillo y Guzmán, 2008; Antonic y Hsrich, 2003), y que tienen potencial para traducirse en proyectos empresariales innovadores, y nuevos negocios para la empresa (Varela e Irizar, 2009).

Es por lo anterior que la cultura organizacional, la innovación y el intraemprendimiento son considerados factores realacionados, y críticos para la supervivencia y el éxito de las empresas sin importar su tamaño (Formichella, 2005; Garzón, 2004; Camelo, Romero y Valle, 2000; Damanpour y Gopalakrishnan 2001; Rogers, 1983), siendo dichas interacciones interés central de este trabajo. 
La relación entre cultura organizacional y rendimiento ha sido objeto de un buen número de trabajos empíricos que la han observado de manera independiente o relacionada con otras variables y en diferentes contextos geográficos o temporales, entre otros se pueden señalar los trabajos de Tseng (2010), James y Connolly (2009), Van Auken, Madrid, y García, 2008), Zhang, Li y Wei (2008), Naranjo, Sanz, y Jiménez (2008), O'cass y Ngo (2007), Henri (2006), Kim, Lee y Yu (2004), Deshpande y Farle (2004) Sonrensen (2002), Ogbonna y Harris (2000), Huges (2001), Kotter y Heskett (1992) y Gordon y Di Tomaso (1992).

En la literatura encontramos también estudios empíricos alrededor de la relación existente entre la innovación y el rendimiento de las empresas. En el ámbito de la MIPYME pueden señalarse los trabajos de Fernández y Peña (2009), Lin y Chen (2007), Bhaskaran (2006), Darroch (2005), Hsueh y Tu (2004), Huges (2001), Freel (2000), Yamin, Gunasekaran y Mavondo (1999), y Heunks (1998).

En cuanto a la cultura de intraemprendimiento y sus relaciones con la innovación y el rendimiento organizacional, se pueden señalar para el primer caso investigaciones como las de Kuz (2010), Manimala (2006), Samuelsson y Dahlqvist (2005), Teece et al. (1997), Bamey (1991), y la de Ross (1987). Para el segundo caso las de Benitez-Amado et al. (2010), Veysel et al. (2009), Bieto (2008), López, (2008), Foba y De Villiers (2007), Antoncic (2003), Kuratko et al. (2005), Rhoads (2005), Kyriakopoulos et al. (2004), Marcus y Zimmerer (2003) y la de Morris et al.(1993).

Múltiples estudios han demostrado, que a nivel mundial las pequeñas unidades empresariales generan un alto porcentaje del empleo y realizan una considerable parte de la producción y el comercio (Julien, 2003), así mismo que son actores estrategicos en la generación de innovación empresarial (Moreno, Munuera y García, 2011). En Colombia las MIPYME, conforman el 99.9\% de las empresas (96.4\% micros, 3.5\% Pymes) y generan el $63 \%$ del empleo y el $37 \%$ de la producción (DANE, 2005) ${ }^{1}$; estas cifras demuestran su importancia económica y social.

Es de mencionar que si bien el documento 3484 de 2.007 del CONPES $^{2}$ denominado "Política nacional para la transformación productiva y la promoción de las micro, pequeñas y medianas empresas”, hace un importante esfuerzo para desde el ámbito gubernamental señalar la generalidad de las características y problemas de las MIPYME en Colombia, son aún escasos los estudios científicos que en forma empírica profundizan en las realidades de este tipo de organizaciones en el país.

Este trabajo doctoral es congruente con en el interés existente a nivel mundial y concretamente en Colombia por conocer mejor las MIPYME y por apoyar su desarrollo, por ello busca contribuir a llenar el vacio de información mencionado anteriormente. El

\footnotetext{
${ }^{1}$ El DANE es el Departamento Nacional de Estadística de Colombia.

${ }^{2}$ El CONPES es el Consejo Nacional de Política Económica y Social de Colombia.
} 
objetivo de la tesis es en el marco de la teoría de recursos y capacidades analizar los siguientes aspectos en las MIPYME:

- El efecto de la cultura organizacional y la innovación sobre su rendimiento. Para esto se realizó una investigación cuantitativa con 60 empresas de mediana o alta tecnología de la ciudad de Cali.

- El efecto de la cultura de intraemprendimiento en su innovación y rendimiento. Para esto se realizó una investigación cuantitativa con 68 empresas del sector turistico en Colombia.

- La forma en que manifiestan su cultura organizacional y el impacto que ello tiene en su innovación y rendimiento. Para esto se llevó a cabo un trabajo cualitativo mediante un estudio multiple de casos, a partir de la información recogida en cuatro hoteles de la ciudad de Cali.

El documento se compone de tres capítulos que corresponden a los estudios empíricos adelantados durante el desarrollo de la tesis, cada cápitulo incluye su respectiva introdución, marco teórico, estudios empiricos previos, metodología de investigación, discusión de resultados, conclusiones, implicaciones, limitaciones y futuras líneas de investigación. El trabajo termina con la presentación de las conclusiones e implicaciones generales, obtenidas a través de la amplia revisión de la literatura existente y los estudios empíricos realizados.

El capitulo primero aborda el estudio del efecto de la cultura organizacional sobre la innovación y el rendimiento de la MIPYME de media y alta tecnología, distinguiendo entre culturas de tipo clan, adhocrática, jerárquica, de mercado, y entre innovación en productos, procesos y de gestión. Para ello se realizó un estudio cuantitativo de corte transversal en la ciudad de Cali sobre 60 MIPYME. Las empresas objeto del estudio pertenecen a los sectores del software, la ingeniería eléctrica, las artes gráficas, y los plásticos, ya que son de considerable importancia económica para la región y tienen un buen nivel general de desarrollo. Las preguntas que guiaron el estudio fueron las siguientes: ¿Cómo afecta el tipo de cultura organizacional implantado en la empresa a su rendimiento? y ¿son las empresas más innovadoras las que obtienen un mayor rendimiento?

El capitulo segundo presenta un estudio cuantitativo de corte transversal sobre 68 empresas, el cual analiza el efecto de la cultura de intraemprendimiento sobre la innnovación y el rendimiento de la MIPYME turistica colombiana. Se abordó este sector de actividad ya que se ha constituido en el tercer renglón de exportaciones del país, después del petróleo y el carbón (MINCOMERCIO, 2010) y por que en él las MIPYME son las principales prestadoras de servicios (CONPES, 2005). El intraemprendimiento es un factor que impulsa el desarrollo de nuevos negocios y la innovación dentro de las organizaciones y se mide a través de variables como la autonomía de los empleados, la tolerancia al riesgo y a los errores, la compensación y el reconocimiento, el soporte de la gerencia y la 
flexibilidad en la estructura organizacional. El estudio fue guiado por las siguiente preguntas de investigación: ¿La cultura intraemprendedora conduce a un mayor rendimiento de la MIPYME? y ¿Las MIPYME con mayor cultura intraemprendedora son más innovadoras?

El capitulo tercero presenta una investigación cualitativa realizada mediante un estudio múltiple de casos. Este método se combinó con otros elementos de estudios exploratorios y descriptivos. El objeto de este capitulo es profundizar con un mayor detalle cualitativo, sobre las carácteristicas de la cultura organizacional y sus relaciones con la innovación y el rendimiento. Para guiar el proceso se plantearon las siguientes preguntas: ¿qué elementos caracterizan la cultura organizacional de las empresas?, ¿Cómo influye la cultura organizacional en la innovación y el rendimiento de estas organizaciones? La investigación se llevó a cabo con una muestra no probabilística de cuatro empresas colombianas cuya actividad es la hotelería. Las empresas se seleccionaron en función de su cultura empresarial (clan, adhocrática, jerárquica y de mercado).

La presente tesis es relevante por factores como la importancia de las MIPYME en la demografía empresarial y en la economía mundial y colombiana, por el interés de los gobiernos y la academia en apoyar su desarrollo, y por la escaséz de información empírica a su alrededor en Colombia. Este trabajo proporciona a empresarios y gerentes información reciente que les permitirá entender mejor cómo la cultura organizacional, el intraemprendimiento y la innovación se relacionan, se constituyen en recursos o capacidades estratégicas, y pueden ayudar al remdimiento y éxito de sus empresas. También es útil para el sector gubernamental ya que le permite tener más claridad respecto a las acciones que debe adelantar para impulsar la sostenibilidad de este tipo de organizaciones. De igual manera a la comunidad académica le proporciona nuevas luces respecto a la orientación que puede dar a sus actividades de investigación, docencia y extensión en lo referente a la promoción y apoyo de las MIPYME.

Para concluir esta introducción, es importante resaltar algunos de los elementos y aportes que esta tesis presenta:

a) Temas de investigación novedosos: aborda temáticas y relaciones que han sido poco abordadas de manera empírica en economías emergentes cómo la colombiana.

b) Combinación de metodologías cuantitativas y cualitativas: se utilizaron para los dos primeras investigaciones metodos cuantitativos a través de estudios empíricos de corte transversal y los métodos estadisticos univariantes y multivariantes más adecuados. La tercera investigación, es de tipo cualitativo y se realizó aplicando el estudio múltiple de casos. 
c) Utilización de diversas fuentes de información: en cada una de las investigaciones realizadas se utilizaron bases de datos construidas a través del trabajo de campo del investigador, ya sea através de la aplicación de encuestas o de la información recogida minuciosamente en cada uno de los casos abordados.

d) Medidas e instrumentos ampliamente validados: se han utilizado en el trabajo medidas e instrumentos probados en diferentes estudios internacionales tales cómo el OCAI para medir la cultura organizacional (Cameron y Quinn, 1999), el CVF para analizar el rendimiento (Quinn y Rohrbaugh, 1983), y la metodología propuesta por Hornsby, Kuratko y Zahra (2002), que se tomó como base para diseñar el instrumento empleado pra medir la cultura intraemprendedora.

e) Implicaciones empresariales, académicas y socioeconómicas: los resultados que se presentan, plantean una serie de implicaciones tanto para los propietarios y los directivos de las empresas, como para los entes gubernamentales y los profesores e investigadores de las entidades de educación superior y en generalde apoyo a la MIPYME. 


\section{CAPITULO 1}

CULTURA OGANIZACIONAL, INNOVACIÓN Y RENDIMIENTO EN LAS MIPYME DE MEDIANA Y ALTA TECONOLOGÍA DE COLOMBIA 


\subsection{INTRODUCCIÓN}

Cuando se desea saber por qué una sociedad ha alcanzado determinado nivel de desarrollo, su cultura aparece como un elemento importante a analizar (Formichella, 2005), y algo similar ocurre con las empresas, actores centrales para el progreso de las regiones y los países, ya que la cultura organizacional define en gran medida la forma en que realizan sus procesos internos y sus relaciones con el mundo exterior, lo que es crítico para su rendimiento o desempeño (Arango y Urrea, 2000). La cultura es un factor clave que puede ayudar a las compañías a mejorar su rendimiento y es lo que distingue realmente a las organizaciones de alto desempeño (Jeuchter et al. 1998); por ello es un tema de investigación de primer orden.

Por su parte, la innovación es considerada factor crítico para la supervivencia y el éxito de las empresas (Rogers, 1983; Camelo et al. 2000; Damanpour y Gopalakrishnan 2001; Formichella, 2005), las empresas son innovadoras o no existen (Schumpeter, 1935). En concordancia con esto, el Reporte Mundial de Competitividad (informe anual que mide el desempeño de los países en aspectos tales como la eficiencia de la mano de obra y del mercado, y el aprendizaje tecnológico) le da en su escala de medición un importante valor a la innovación que desarrollan las empresas. En el reporte correspondiente al periodo 20092010, Colombia ocupó el puesto número 69 entre 118 países analizados (Foro Económico Mundial, 2009).

La relación entre cultura organizacional y rendimiento ha sido objeto de un buen número de trabajos empíricos que la han observado de manera exclusiva o relacionada con otras variables, en diferentes contextos geográficos y temporales. Algunos autores como Sonrensen (2002), Kotter y Heskett (1992) y Gordon y Di Tomaso (1992) la enfocan desde la fortaleza de la cultura; Zhang et al. (2008) desde la perspectiva de la consistencia y el balance de las culturas; O'cass y Ngo (2007) y Deshpande y Farle (2004) se centran en la cultura de mercado; Henri (2006) resalta los sistemas de medición del desempeño; Kim et al. (2004) la diferencian según el tipo de industria; Ogbonna y Harris (2000) desde los estilos de liderazgo; y Naranjo et al. (2008) desde los tipos de cultura que favorecen u obstaculizan el desempeño. Sin embargo, la mayoría de estos estudios se centran en los países anglosajones (Davidson et al. 2007) y en la gran empresa (Hughes, 2001; Van Auken et al. 2008).

En la literatura hay también abundantes estudios empíricos alrededor de la relación entre la innovación y el desempeño de las firmas (Duréndez y García, 2008), en el ámbito de la MIPYME se han realizado trabajos en diferentes contextos geográficos y temporales, adicionando algunas veces otros factores al análisis, como ejemplos pueden señalarse los siguientes: la relación entre la creatividad, la innovación y el éxito organizacional (Heunks, 1998), innovación organizacional y desempeño en las empresas con mejores prácticas (Yamin et al. 1999), innovación e incremento superior en el rendimiento (Freel, 2000), 
innovación en las empresas en Taiwan y factores innovadores que afectan positivamente su desempeño (Hsueh y Tu 2004), obstáculos para la innovación y rendimiento comparativo de las pequeñas y grandes empresas en UK (Huges, 2001), relación entre el grado de innovación, los sistemas de control y el rendimiento (Bastida y García, 2005), gestión del conocimiento, innovación y resultados (Darroch, 2005), origen y experiencia del empresario y efecto en el tipo de innovaciones que realiza Bhaskaran (2006), distintos tipos de innovación y su efecto en el rendimiento de las PYME de Aguascalientes México (Maldonado, Madrid, Martínez y Aguilera, 2009), estrategia de innovación tecnológica y resultados empresariales (Fernández y Peña, 2009) y naturaleza y tipo de prácticas de innovación diarias y su efecto en el rendimiento de las PYME de Taiwán (Lin y Chen, 2007).

Si bien en el medio colombiano existen trabajos que abordan diferentes tópicos de las Mipymes, por ejemplo su obsolecencia tecnológica y su proceso de modernización (Pérez, Garzón y Nieto, 2009), su papel en el crecimiento económico del país entre los años 1990 y 2000 (Restrepo, 2007), su potencial de investigación y de desarrollo a partir de la gestión organizacional (Castellanos et al.,2006), sus niveles de agremiación y capacidad productiva (Torres et al. 2005), su estrategia, estructura y formas de asociación (Velásquez, 2004), la problemática de la MIPYME a partir de sus influencias internas y externas (Zapata, 2004); no es frecuente encontrar trabajos empíricos que estudien en este tipo de empresas la relación entre cultura organizacional, innovación y rendimiento a partir de técnicas cuantitativas.

Los objetivos de este trabajo son analizar como la cultura organizacional y la innovación influyen en el rendimiento de las MIPYMES colombianas, distinguiendo entre culturas de tipo clan, adhocrática, jerárquica, de mercado y de innovación, y entre innovación en productos, procesos y de gestión. Las preguntas de investigación que se plantearon fueron ¿cómo afecta el tipo de cultura organizacional implantado en la empresa en su rendimiento? y ¿son las empresas más innovadoras las que obtienen un mayor rendimiento? Para responder a estas preguntas se realizó un estudio empírico, con una muestra de 60 MIPYMES de mediana y alta tecnología de la ciudad de Cali.

Esta investigación contribuye al cuerpo de la literatura sobre cultura organizacional e innovación pues las aborda en el campo de las MIPYMES, que a nivel mundial generan un alto porcentaje del empleo y del valor agregado, por lo que se consideran actores centrales para lograr la competitividad de los países, existiendo no obstante a ello una escasa evidencia empírica sobre estas temáticas; y por que se centra en el caso colombiano, donde representan el $99,9 \%$ de las empresas, generan un $63 \%$ del empleo y un $37 \%$ de la producción (DANE, 2005).

El capitulo está estructurado de la siguiente forma: en primer lugar se desarrolla el marco teórico, se presentan estudios empíricos anteriores y se plantean las hipótesis de investigación. En segundo lugar se expone la metodología, incluidas la manera en que se 
obtuvo la muestra, recogieron los datos, y midieron las variables utilizadas. En tercer lugar se realiza el análisis de resultados; por último se exponen las conclusiones, las limitaciones del trabajo y se plantean posibles futuras investigaciones.

\subsection{MARCO TEÓRICO Y ESTUDIOS PREVIOS}

\subsubsection{La Teoria de Recursos y Capacidades}

La teoría de Recursos y Capacidades es atribuida a Penrose (1962) y a autores como Barney (1991) y Wernerfelt (1984) su perfeccionamiento. Está basada en la heterogeneidad o disparidad existente entre las empresas, surgida a raíz de la diferencia en sus recursos, capacidades o competencias básicas y en su posible valor como fuente de ventaja competitiva sostenible (Franco y Urbano, 2010).

Se trata de una teoría surgida en el seno de la dirección estratégica de la empresa que complementa (no sustituye) al análisis de los sectores industriales (Collis, 1991; Kamoche, 1996). Presenta un carácter ecléctico, ya que recoge numerosas aportaciones de no menos numerosas teorías, a la vez que integrador en tanto en cuanto permite un acercamiento entre la economía y la empresa.

Esta teoría plantea que las organizaciones son entes hetereogeneos en idiosincrasia, dificiles de imitar en recursos y capacidades (Esparza, 2010; Wernerfelt, 1984; Barney, 1991; Conner, 1991). La existencia de heterogeneidad entre las empresas respecto a sus recursos, explica las diferencias en terminos de rendimiento (Lippman y Rumelt, 1982; Barney, 1991). Collis y Montgomery (1995) señalan que esta teoría enfatiza la importancia de los recursos y capacidades internos de la empresa en un entorno competitivo.

Los recursos se definen básicamente cómo el conjunto de factores disponibles que posee y/o controla la empresa (Amit y Schoemaker, 1993). Sin embargo, la posesión de tales recursos no explica, por sí sola, la ventaja competitiva de una empresa, es necesario identificar la forma en que la empresa es capaz de explotar los recursos que posee, lo que determinará las propias capacidades de la misma. Por lo tanto, estas capacidades son un concepto dinámico que expresa la conjunción entre recursos y una serie de rutinas organizativas (Nelson y Winter, 1982).

Barney (1991) clasifica los recursos de la firma en tres grupos: recursos de capital físico, recursos de capital humano y recursos organizacionales. Los recursos físicos incluyen los equipos y la tecnología, la localización geográfica y el grado de acceso a las materias primas. Los recursos de capital humano incluyen factores relacionados con los trabajadores y directivos de la empresa tales como la formación y experiencia. Los recursos organizacionales hacen referencia con la estructura organizativa de la empresa, los sistemas 
de planificación, coordinación y control, de igual manera las relaciones informales entre los distintos agentes dentro de la empresa y entre la empresa y su entorno.

Grant (1996) distingue entre recursos tangibles, intangibles y humanos. Esta clasificación es importante pues como señala Hall (1993), los recursos intangibles son más dificiles de imitar al estar generados mediante un proceso lento y basados en información no codificada y conocimientos tácitos, reportando un mayor potencial competitivo a la empresa.

Las capacidades se basan en el conocimiento organizacional con frecuencia no codificado, que se almacena en la memoria organizativa y al igual que ocurre con los individuos, la organización ante determinados estímulos actúa de forma automática (Teece, 1982). Así, la capacidad se puede entender como una rutina o conjunto de rutinas (Fernández, 1993; Grant, 1991), siendo las rutinas organizativas una serie de pautas de actuación regulares y predecibles que indican las tareas a efectuar y la forma de llevarlas a cabo (Nelson y Winter, 1982). Las rutinas comprenden complejos patrones de interacción, entre las personas y entre éstas y los demás recursos (Grant, 1991), que se han formado lentamente como resultado del aprendizaje colectivo de la organización (Prahalad y Hamel, 1991; Winter, 1995) y que definen en cada momento lo que la organización puede o no puede hacer. Esto implica que los recursos empresariales sólo pueden ser utilizados dentro de un ámbito limitado de posibilidades (López y Sabater, 1998).

Existe una estrecha interdependencia entre los recursos y las capacidades de una organización en el sentido de que las segundas descansan sobre los primeros, a la vez, que aquéllas contribuyen a aumentar el stock de recursos (Dierickx y Cool, 1989).

\subsubsection{Cultura organizacional}

La cultura organizacional es la forma en que la empresa ha aprendido a manejar su ambiente, una mezcla compleja de supuestos, conductas, relatos, mitos, metáforas y otras ideas que definen lo que significa trabajar en una organización particular (Schein, 1985). Es una base de presunciones básicas, inventadas, descubiertas o desarrolladas por un grupo al ir aprendiendo a enfrentar sus problemas de adaptación externa e integración interna, que ejercen la suficiente influencia para ser consideradas válidas y, en consecuencia, enseñadas a los nuevos miembros (Schein, 1988). La cultura de una empresa tiene su origen en aspectos como su historia y su entorno; se manifiesta en aspectos como el lenguaje, la comunicación, el sistema de producción de bienes materiales, sociales e inmateriales, las relaciones interpersonales, el liderazgo y las subculturas (Zapata y Rodríguez, 2008). Lo señalado coincide con Davis (1993), quien plantea que las organizaciones, igual que las huellas digitales, son siempre singulares. La fortaleza de la cultura organizacional se puede interpretar como el grado de presión que ejerce sobre los integrantes de la empresa y sobre 
sus comportamientos. La amplitud de la cultura es una medida de su fortaleza, que será mayor si la extensión y aceptación abarca a toda la empresa (Sonrensen, 2002).

En cuanto a las perspectivas analíticas desde las cuales se estudia la cultura organizacional, Morcillo (2007) señala: el liderazgo, los valores, la ética, la sociabilidad y la solidaridad, el éxito, las ventajas competitivas y la innovación. Por otra parte, la teoría económica institucional y la teoría de los recursos y capacidades establecen un marco de referencia para el estudio de la cultura organizacional; el enfoque institucional de North (1990), muestra que los objetivos y acciones de los individuos y de los grupos están fuertemente influidos por las instituciones del entorno, y la teoría de los recursos y capacidades establece que la cultura genera activos intangibles estratégicos inimitables que explican el éxito competitivo empresarial (Barney, 1991; Cuervo, 1993).

La cultura organizacional puede considerarse entonces como un "recurso" o medio para alcanzar objetivos, y si ese recurso añade valor, es diferente a la cultura de otras organizaciones y no es fácilmente imitable por los competidores, puede convertirse en ventaja competitiva y en un "activo estratégico" que sustente el éxito (Barney, 1986). La cultura es así un medio que podría ser administrado para mejorar el desempeño y el logro de los objetivos (Smircich, 1983). La dirección de una organización puede entonces formular una estrategia interna para aumentar la identificación y la cohesión de los integrantes alrededor de los valores claves para la estrategia externa.

\subsubsection{Innovación}

La innovación como proceso que utiliza la tecnología existente para crear o mejorar un producto, un proceso o un sistema, busca generar, asimilar o explotar con éxito una novedad en los ámbitos económico y social (Medina y Espinosa, 1994). Es así cómo el Manual de Oslo (OECD y EUROSTAT, 2005) señala que innovar es introducir un nuevo o significativamente mejorado producto (bien o servicio) al mercado, o un nuevo proceso, método de comercialización o de organización, en las prácticas internas de la empresa o en sus relaciones externas.

El concepto de innovación, ya comenzaba a vislumbrarse en los escritos de los clásicos Adam Smith y David Ricardo, aunque no lo mencionaran explícitamente, siendo el primer economista importante en desarrollar ampliamente el concepto de proceso de innovación el austríaco Joseph Schumpeter (1935), quien estableció la diferencia entre invención, innovación y difusión; a partir de dichos estadios la temática ha venido avanzando de manera significativa (Formichella, 2005). Existe relación entre la cultura que posee una sociedad y una organización y las innovaciones que puede crear, y de manera contraria, las innovaciones son factores que generan un impacto significativo en la creación de los patrones culturales de las sociedades y las empresas (Cornejo y Muñoz, 2009). 
En la organización se pueden presentar tres tipos de innovación: de productos, de procesos y de gestión (AECA, 1995). La innovación en productos se materializa en la comercialización de un nuevo artículo o en la mejora de otro existente, la innovación en procesos dota a la empresa de nuevos equipos o nuevos procesos de producción. Esta clase de innovación tenderá a incrementar la productividad de las empresas y a reducir sus costos. La innovación en métodos de gestión recoge el conjunto de novedades y cambios introducidos en la estructura organizacional de la empresa como es el caso de la comercialización, financiamiento, organización, etc. (Maldonado, et. al. 2009).

Atendiendo al grado de novedad incorporado, las innovaciones pueden clasificarse en radicales e incrementales. Esta distinción tiene una importante repercusión económica (Freeman, 1987). Las innovaciones radicales, también llamadas básicas, primarias o totales, hacen referencia a productos o procesos totalmente nuevos, ya que presentan diferencias significativas en cuanto a su finalidad, prestaciones, características, propiedades teóricas, materias primas o componentes utilizados en su fabricación; por su parte, las innovaciones incrementales, parciales, progresivas o secundarias, son mejoras en productos o procesos ya existentes y consecuentemente aportan menor novedad (INE, 2000).

Existen varios mecanismos a través de los cuales la empresa adquiere conocimientos y los convierte en activos organizativos para desde ellos desarrollar innovación. Con carácter general, se pueden identificar tres importantes fuentes de acceso a la innovación: 1) desarrollo interno, 2) adquisición desde fuentes externas y 3) realización de acuerdos de cooperación (López, Montes y Vázquez, 2003).

\subsubsection{Rendimiento o desempeño organizacional}

La mayoría de las organizaciones consideran su desempeño en términos de aspectos que aseguran su supervivencia, por ejemplo, el cumplimiento de su misión, sus objetivos o sus metas; pero desde los años setenta han surgido otras variables que se agregan al análisis, cómo la moral, la innovación, la adaptabilidad y la orientación al cambio (Lusthaus et al. 2002).

Definir con precisión el rendimiento organizacional es "complejo y aún subjetivo"; además, los indicadores difieren según el aspecto que se esté analizando: los recursos humanos, las finanzas, los procesos operativos, etc. Los buenos resultados contables y el alza de la cotización de las acciones no indican necesariamente que una empresa sea sólida en el sentido de que sea capaz de sostener sus resultados actuales y crear negocios rentables en el futuro; por ello es necesaria una visión más amplia para analizar el rendimiento organizacional (Dobbs y Koller, 2006).

A nivel internacional se han desarrollado diferentes metodologías y herramientas para medir el desempeño de las empresas, las hay de tipo financiero, operativo y de eficacia; algunas son objetivas, es decir, se extraen de cifras o datos, de sistemas contables 
y presupuestales o del sistema de mando integral (balanced score card); otras son subjetivas, es decir, se obtienen explorando la percepción o los puntos de vista de actores involucrados en los procesos de la empresa y, en algunos casos, de obervadores externos. Hasta el momento no existe acuerdo respecto de un indicador generalizable para medir el rendimiento (Estrada y Sánchez, 2009).

\subsubsection{Estudios empíricos sobre cultura organizacional y rendimiento}

La relación entre cultura organizacional y rendimiento ha sido objeto de diversos trabajos empíricos que la han observado de manera exclusiva o relacionada con otras variables, así como en diferentes contextos geográficos y temporales:

Tseng (2010), para desarrollar un marco conceptual que ayude a entender la relación entre cultura organizacional, conversión del conocimiento y desempeño, tomaron una muestra de 131 empresas y encontraron que la cultura adhocrática contribuye a la reconversión del conocimiento y al rendimiento de la firma.

Desde la perspectiva de la consistencia y el balance, Zhang et al. (2008) buscaban constatar el impacto de la cultura organizacional sobre el desempeño, con una muestra de 270 empresas chinas, y encontraron que la consistencia entre la cultura organizacional y el entorno externo, así como el balance entre los diferentes tipos de cultura señalados por Cameron y Quinn (1999), están positivamente relacionados con el rendimiento de la firma.

Duréndez y García (2008) utilizaron una muestra de 89 firmas españolas para conocer el impacto de la cultura de innovación y los sistemas de control sobre el desempeño de las empresas jóvenes, y encontraron que la cultura clan era la predominante, seguida por la jerárquica; las culturas adhocrática e innovadora tienen efectos sobre el desempeño de las empresas, especialmente significativos en los modelos de procesos internos y abierto; la cultura jerárquica es adversa al desempeño de la empresa.

Con una orientación similar, O’cass y Ngo (2007) estudian la cultura organizacional y en especial si la orientación al mercado contribuye al desempeño de las marcas en Australia; los resultados señalan que las empresas con culturas fuertemente innovadoras reconocen que el desarrollo de las marcas depende en gran medida en su capacidad de crear valor para el cliente. La orientación al mercado es en parte responsable de la cultura de innovación en la empresa, pero esta última es más importante que la primera en cuanto al impacto en el desempeño de la organización.

Henri (2006) analizó en Canadá la relación entre la cultura organizacional y el uso que se da en las empresas a los sistemas de medición del rendimiento; el trabajo dio como uno de sus resultados que la cultura organizacional, desde el enfoque de flexibilidad y control, tiene un efecto directo en las diversas medidas de rendimiento. 
Deshpande y Farle (2004) investigan cómo afectan la cultura de mercado y la innovación sobre el desempeño de las empresas, para ello tomaron una muestra de empresas B2B de diferentes países; sus hallazgos muestran que la orientación al mercado y la innovación tienen un impacto positivo en el rendimiento, y que en general una orientación externa conduce a mejores rendimientos que una orientación interna.

Para verificar cómo afecta la cultura organizacional sobre el rendimiento de la organización en Singapur, Kim et al., (2004) estudiaron una muestra de 723 empresas, hallando entre otros aspectos que los valores compartidos en los diferentes tipos de industrias tienen impacto sobre su dinámica, y que la fortaleza de la cultura en algunos casos influye en el desempeño de las empresas.

Por su parte, Sonrensen (2002), siguiendo la línea de trabajo de autores como Kotter y Heskett (1992) y Gordon y Di Tomaso (1992), estudió cómo afectan las culturas fuertes a la variabilidad del rendimiento en las empresas, encontrando que en entornos relativamente estables la facilitan, pero que a medida que aumenta su volatilidad, las ventajas decrecen dramáticamente.

Ogbonna y Harris (2000) examinaron la relación entre cultura organizacional, estilos de liderazgo y rendimiento en mil empresas medianas y grandes del Reino Unido, encontrando que el estilo de liderazgo está apenas indirectamente ligado al rendimiento, pero que los rasgos y valores competitivos e innovadores están ligados directamente, y que contrariamente a lo esperado los rasgos clan y burocráticos o jerárquicos no estaban directamente relacionados con el desempeño de las empresas.

Tomando en cuenta los estudios anteriores se plantearon para esta relación las siguientes hipótesis:

H1: La cultura clan influye de manera positiva en el rendimiento de la MIPYME

H2: La cultura adhocrática influye de manera positiva en el rendimiento de la MIPYME

H3: La cultura de mercado influye de manera positiva en el rendimiento de la MIPYME

H4: La cultura jerárquica influye de manera negativa en el rendimiento de la MIPYME

H5: La cultura de innovación influye de manera positva en el rendimiento de la MIPYME

\subsubsection{Estudios empíricos sobre innovación y rendimiento}

La relación entre la innovación y el rendimiento de las empresas es un tema que por su importancia, ha convocado también el esfuerzo investigativo empírico de destacados autores, de los cuales se enuncian algunos a continuación:

En una investigación que buscaba analizar el efecto que provocan los distintos tipos de innovación en el rendimiento de las PYME de Aguascalientes México, Maldonado et al. 
(2009), mediante una muestra de 400 empresas, encontraron que las empresas que innovaron en sus productos, obtuvieron una mayor eficiencia (procesos internos), mejores capacidades para satisfacer a sus clientes y adaptarse a sus necesidades (sistema abierto) y elevaron su rentabilidad y adaptabilidad (sistema racional). También encontraron que las empresas que innovaron en procesos mejoraron su eficiencia en la organización de tareas (procesos internos); y las que innovaron en cuanto a sistemas de gestión, mejoraron su posición en la cuota de mercado y rentabilidad (sistema racional). Por consiguiente, el tipo de innovación que influye en un mayor número de dimensiones del rendimiento es la innovación en productos.

Fernández y Peña (2009), en un estudio sobre el efecto en los resultados de la estrategia de innovación tecnológica, en una muestra de 62 cooperativas vinícolas de Castilla La-Mancha en España, encontraron evidencia del efecto positivo y significativo que la estrategia de innovación tiene sobre los resultados empresariales, además, determinaron que el desarrollo de una estrategia formal de innovación tecnológica es de gran importancia para la obtención de ventajas competitivas para la empresa.

Van Auken et al. (2008), al analizar la relación entre el grado de innovación y el rendimiento en 1091 empresas manufactureras españolas, hallaron que la innovación impacta positivamente el rendimiento de las PYME de baja y alta tecnología, pero que es más importante en las de alta para el logro de ventajas competitivas; concluyen también que la innovación se convierte en una ventaja competitiva sostenible para las empresas.

En un estudio que tuvo por objetivo conocer la naturaleza y el tipo de prácticas de innovación diarias de las PYME de Taiwán, Lin y Chen (2007), demostraron que tanto las innovaciones radicales como las incrementales tienen efecto positivo sobre el rendimiento de la empresa; la innovación posee una débil relación con las ventas de la empresa; las innovaciones administrativas han emergido como el factor más crucial para explicar las ventas, aún más que las innovaciones tecnológicas.

En un trabajo realizado en México con empresas del sector artesanal, Hernandez, Yescas y Domínguez (2007) encontraron que entre los factores que influyen en los resultados de estas organizaciones se encuentra la innovación administrativa.

Por su parte Menéndez et al. (2007), en un estudio realizado con empresas españolas, verifican que las innovaciones en procesos ligadas al uso de nuevas tecnologías y en particular de TIC en las relaciones con clientes y proveedores, afectan positivamente el desempeño de las empresas.

Bhaskaran (2006), al analizar el efecto de aspectos cómo el origen del empresario y su experiencia en el tipo de innovaciones generadas, en una muestra de 337 empresas de Australia confirman que la innovación incremental aporta sustantivas ventajas competitivas a las PYME y que este tipo de innovación puede ser adaptado por empresarios de diferente 
nivel cultural. Las PYME que se enfocan en innovaciones en marketing y ventas pueden ser rentables y enfrentarse éxitosamente a las grandes empresas.

Bastida y García (2005), al verificar empíricamente la relación entre el grado de innovación, los sistemas de control gerencial (SCG), y el rendimiento de las empresas, mediante una muestra de 1170 PYMES industriales españolas, encontraron que el uso de SCG y la innovación influyen de forma positiva en el rendimiento, especialmente en las empresas pequeñas y de baja tecnología, pero en las medianas y de alta tecnología no se observa evidencia significativa.

Al tratar de aportar evidencia empírica que le de soporte al rol de la gestión del conocimiento en las empresas, Darroch (2005), encuentra en una muestra de 443 empresas de Nueva Zelanda, que aquellas con capacidad de gerenciar el conocimiento, utilizan más eficientemente sus recursos, son más innovativas y obtienen mejores resultados.

Con el objetivo de encontrar que tan innovadoras son las empresas en Taiwan y los factores innovadores que afectan positivamente su desempeño, Hsueh y Tu (2004), en una muestra de 1047 firmas encontraron que la acción innovadora tuvo un mayor impacto en el incremento de las ventas y la generación de una atmósfera innovadora; la habilidad para innovar en la organización tienen el mayor impacto en las utilidades; y que la mayoría de las empresas de Taiwan ya no sólo se limitan a copiar sino que innovan.

Hughes (2001), en su búsqueda de identificar los obstáculos para la innovación, comparó el rendimiento de las pequeñas empresas con el de las grandes, en una muestra en Reino Unido y encontró que uno de los principales problemas para la innovación de las empresas es la falta de competencias administrativas; así mismo que las empresas del Reino Unido son más rápidas para desarrollar nuevos productos que las de países cómo Japón, pero que se demoran mucho más para alcanzar el mismo nivel de calidad.

Yamin et al. (1999), examinaron la relación entre la innovación organizacional y el desempeño en las empresas con mejores prácticas en Australia, y encontraron que efectivamente la innovación tiene impacto en el desempeño organizacional, pero que las empresas no necesitan ser altamente innovadoras, para llegar a tener buenos desempeños.

Heunks (1998), al analizar la forma en que la creatividad y la innovación se interrelacionan en el camino del éxito organizacional, con una muestra de 200 empresas de seis países, encontró que: la innovación de cualquier tipo fomenta el desempeño en las pequeñas empresas pero que sólo la innovación en procesos estimula la productividad de las mismas. Asi mismo que en las medianas empresas la innovación no es muy importante para lograr el éxito , y que las empresas jóvenes no son menos innovativas que las de mayor edad.

Tomando en cuenta los aportes señalados, en esta relación se plantearon las siguientes hipótesis de trabajo: 
H6: La innovación en productos desarrollada por la MIPYME influye de manera positiva en su rendimiento.

H7: La innovación en procesos desarrollada por la MIPYME influye de manera positiva en su rendimiento.

H8: La innovación en gestión desarrollada por la MIPYME influye de manera positiva en su rendimiento.

\subsection{METODOLOGÍA DE LA INVESTIGACIÓN}

\subsubsection{Obtención de la muestra y recolección de datos}

Las empresas objeto de este estudio fueron las MIPYMES de mediana o alta tecnología de la ciudad de Cali pertenecientes a los sectores de software, ingeniería eléctrica, artes gráficas, y plásticos. Se identificó una población de 312 firmas a partir de las bases de datos del Observatorio de Prospectiva Tecnológica Industrial OPTICOR de la Universidad del Valle, de la Asociación Colombiana de Ingenieros ACIEM capítulo Valle, de la Caja de Compensación Familiar COMFANDI ${ }^{3}$ y de la Cámara de Comercio de Cali. Las empresas se seleccionaron de manera aleatoria, se pidieron 82 citas y 60 firmas aceptaron participar en la investigación. Para validar la representatividad estadística de la muestra determinamos el error muestral con respecto a la población de empresas: 9.5 puntos con un margen de confianza del 95\%. Los datos se recolectaron mediante una encuesta, estructurada a partir de la literatura disponible, y aplicada directamente por los miembros del equipo a los directivos. El trabajo de campo se realizó entre el 15 de abril y el 20 de mayo del 2010. La tabla 1 presenta la distribución de la muestra utilizada.

\section{Tabla 1. Distribución de la muestra}

\begin{tabular}{|l|c|c|c|c|c|}
\hline Sector de actividad & $\begin{array}{c}\text { Micro de } \\
1 \text { a } 10\end{array}$ & $\begin{array}{c}\text { Pequeña de } \\
11 \text { a } 50 \\
\text { trabajadores } \\
\text { trabajadores }\end{array}$ & $\begin{array}{c}\text { Mediana } \\
51 \text { a } 200 \\
\text { trabajadores }\end{array}$ & $\begin{array}{c}\text { Número } \\
\text { de } \\
\text { empresas }\end{array}$ & $\begin{array}{c}\% \text { del } \\
\text { Total }\end{array}$ \\
\hline Software & 7 & 1 & 0 & 8 & 13.3 \\
\hline Ingeniería eléctrica & 2 & 12 & 4 & 18 & 30 \\
\hline Artes gráficas & 6 & 3 & 1 & 10 & 16.7 \\
\hline Plásticos & 5 & 4 & 2 & 11 & 18.3 \\
\hline Metalmecánica & 3 & 6 & 4 & 13 & 21.7 \\
\hline Total & $\mathbf{2 3}$ & $\mathbf{2 6}$ & $\mathbf{1 1}$ & $\mathbf{6 0}$ & $\mathbf{1 0 0}$ \\
\hline
\end{tabular}

Fuente: elaboración propia.

${ }^{3}$ Las cajas de compensación familiar son organizaciones de carácter privado reglamentadas por la ley colombiana que brindan servicios tales como recreación, capacitación y salud a empleados de las empresas del país; para ello administran recursos que éstas aportan mensualmente. 


\subsubsection{Medición de variables}

Variable de rendimiento o desempeño organizacional

Para medir el rendimiento de las MIPYMES se utilizaron indicadores construidos a partir de la percepción del gerente de la empresa sobre su posición competitiva, frente a la opción de usar indicadores procedentes de la información contable, porque si se usa información contable se pueden omitir activos intangibles, valiosos y vitales para el éxito competitivo de las empresas Kaplan y Norton (1993) y Camisón (1997); además, el éxito competitivo es un término relativo (AECA, 1988), de modo que la posición de la empresa frente a la competencia es uno de los indicadores determinantes del éxito o el fracaso.

Para medir esta variable utilizamos la metodología de Quinn y Rohrbaugh (1983), una de las más aceptadas a nivel internacional, para correlacionar el rendimiento con variables cómo la innovación (Maldonado et al., 2009; Van Auken et al., 2008 y Bastida y García, 2005), la transferencia de conocimientos y la cultura organizacional Tseng (2010) y Duréndez y García (2008).

Esta metodología se basa en el marco de valores en competencia (CVF, por sus siglas en inglés), que señala que en las empresas hay intereses y valores luchando entre la flexibilidad y el control, así como por conseguir objetivos internos y externos, y lograr el equilibrio que toda organización debe tener (Rodríguez, 2007).

El modelo establece un marco para el análisis organizacional y tiene tres ejes o dimensiones. El primero se relaciona con el enfoque de la organización, que va desde un punto de vista interno (basado en una visión micro del buen entendimiento y el desarrollo del personal) a uno externo (énfasis macro en el éxito de la empresa). El segundo se centra en la estructura organizacional, desde la estabilidad hasta la flexibilidad, y el tercero se relaciona con los medios y fines organizacionales. De la combinación de estas tres dimensiones surgen los cuatro modelos que se muestran en la gráfica 1:

- Modelo de procesos internos: analiza el rendimiento de la empresa desde el punto de vista interno, da especial importancia al control, la estabilidad y la comunicación de información. Pone especial atención a la evolución de factores cómo la organización en las tareas del personal, la eficiencia de los procesos operativos internos y la calidad de los productos o servicios.

- Modelo de sistema abierto: analiza el rendimiento de la empresa enfocándose en la evolución de su flexibilidad desde un punto de vista externo, plantea cómo principales objetivos el crecimiento, la adquisición de recursos y el apoyo externo. Centra su atención en aspectos tales como la satisfacción de los clientes, la rapidez de adaptación a los cambios del entorno, el cambio en la imagen de la empresa y sus productos o servicios.

- Modelo racional: analiza el rendimiento de la empresa prestando atención al control desde un punto de vista externo, da especial importancia a los criterios de eficiencia y 
productividad. Analiza la variación de aspectos cómo la cuota de mercado, la rentabilidad y la productividad de la empresa.

- Modelo de relaciones humanas: analiza el rendimiento de la empresa centrándose en la flexibilidad desde un punto de vista interno, plantea como objetivo principal el desarrollo de los recursos humanos. Toma en cuenta la evolución de criterios tales como la satisfacción de los trabajadores, la rotación y el ausentismo del personal.

Gráfica 1. Modelo para medición del rendimiento organizacional

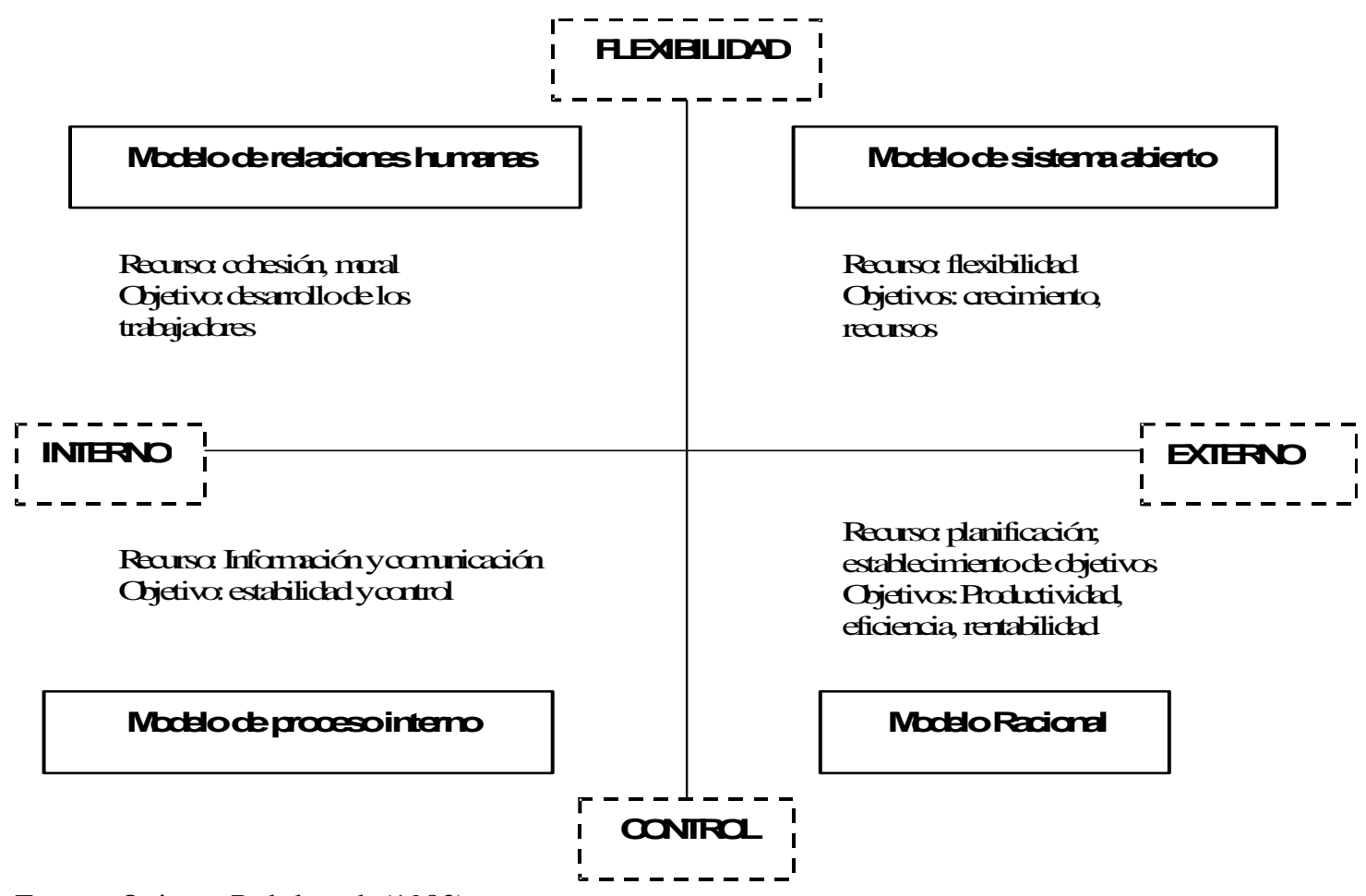

Fuente: Quinn y Rohrbaugh (1983).

Para valorar los modelos se utilizaron 12 ítems (tres por cada uno), con una escala Likert de 1 a 5. La variable que representa cada modelo se construye a partir de la media aritmética de los tres ítems, con lo cual resulta un rango teórico de 1 a 5. Para validar estas medidas se verifica la confiabilidad de las escalas mediante el estadístico Alpha de Cronbach, utilizado habitualmente en conjuntos de dos o más ítems. En la tabla 2 se detallan los ítems utilizados y los valores de validación de las escalas para cada modelo de rendimiento. Los valores parciales y totales de los estadísticos indican la validez de las escalas. 


\section{Tabla 2. Variables de rendimiento}

\begin{tabular}{|l|l|l|}
\hline & $\begin{array}{l}\text { Indique cuál ha sido la evolución de los siguientes } \\
\text { aspectos en su empresa en los dos últimos años: }(1= \\
\text { situación muy desfavorable, 5 situación muy } \\
\text { favorable) }\end{array}$ & Validación escalas \\
\hline $\begin{array}{l}\text { Modelo de } \\
\text { procesos internos }\end{array}$ & $\begin{array}{l}\text { Mejora en la calidad del producto } \\
\text { Mejora en la coordinación de procesos internos } \\
\text { Mejor organización de las tareas del personal }\end{array}$ & $\alpha$ de Cronbach $=0,646$ \\
\hline $\begin{array}{l}\text { Modelo de } \\
\text { sistema abierto }\end{array}$ & $\begin{array}{l}\text { Aumento de la satisfacción de los clientes } \\
\text { Incremento de la habilidad de adaptación a las } \\
\text { necesidades de los mercados } \\
\text { Mejora de la imagen de empresa y de sus productos }\end{array}$ & $\alpha$ de Cronbach $=0,692$ \\
\hline $\begin{array}{l}\text { Modelo } \\
\text { racional }\end{array}$ & $\begin{array}{l}\text { Incremento de la cuota de mercado } \\
\text { Incremento de la rentabilidad de la productividad }\end{array}$ & $\alpha$ de Cronbach $=0,793$ \\
\hline $\begin{array}{l}\text { Modelo de } \\
\text { relaciones } \\
\text { humanas }\end{array}$ & $\begin{array}{l}\text { Reducción de la rotación de personal (abandono } \\
\text { voluntario de los trabajadores) } \\
\text { Reducción del ausentismo laboral }\end{array}$ & $\alpha$ de Cronbach $=0,736$ \\
\hline Modelo total & \begin{tabular}{l} 
Ane Cronbach $=0,816$ \\
\hline
\end{tabular}
\end{tabular}

Fuente: elaboración propia.

\section{Variable de cultura organizacional}

En este trabajo la cultura organizacional se mide a través del instrumento OCAI (Organizational Culture Assessment Instrument) desarrollado por Cameron y Quinn en 1999. Este instrumento se eligió teniendo en cuenta que ha sido probado internacionalmente en numerosas investigaciones por ejemplo, las de Naranjo et al. (2008), Stock et al. (2007), Igo y Skitmore (2006), Deshpandé y Farle (2004), Obenchain y Johnson (2004) y la de Lau y Ngo (2004); y porque, igual que la herramienta que usamos para medir el rendimiento, se basa en el CVF de Quinn y Rohrbaugh (1983), lo que da más coherencia e integralidad metodológica a la investigación.

El OCAI propone analizar la cultura organizacional desde dos dimensiones: primera, estabilidad versus flexibilidad, revisando si la organización considera más importante el orden y el control (estabilidad) o el dinamismo y la discreción; es decir si tiende a ser cambiante y adaptable, o estable, predecible y mecanicista. La segunda revisa si la empresa tiene más orientación externa o interna, es decir, hacia los clientes, competidores, proveedores y el entorno en general; o hacia sus colaboradores y procesos.

El instrumento permite identificar cuatro tipos de cultura: clan, adhocrática, jerárquica y de mercado. La tabla 3 presenta estos tipos de cultura de acuerdo con los valores y prácticas competitivas prevalecientes en las empresas. En el cuestionario se 
solicitó a los directivos que distribuyeran 100 puntos entre cuatro posibles respuestas en relación con la "definición de la empresa", el "estilo de dirección en la empresa", los "valores compartidos por el personal" y los "aspectos claves para el éxito de la empresa". La tabla 4 presenta los ítems observados y la verificación de la confiabilidad de las escalas mediante el estadístico Alpha de Cronbach.

\section{Tabla 3.Tipos de culturas en las empresas}

\begin{tabular}{|c|c|}
\hline Clan & Adhocrática \\
\hline $\begin{array}{l}\text { Características: valores y objetivos compartidos, } \\
\text { cohesión, implicación de los empleados, } \\
\text { compromiso, sentido del "nosotros", equipos de } \\
\text { trabajo, consenso } \\
\text { Tarea de gestión: potenciar a los empleados y } \\
\text { facilitar el compromiso, la participación y la lealtad } \\
\text { Espacio de trabajo: amistoso, en el que las personas } \\
\text { comparten mucho de sí mismos } \\
\text { Líderes: mentores, figuras paternas } \\
\text { Meta a largo plazo: beneficio del desarrollo } \\
\text { individual con una moral y cohesión alta }\end{array}$ & $\begin{array}{l}\text { Características: adaptabilidad, flexibilidad, } \\
\text { creatividad, convivencia con la incertidumbre y la } \\
\text { ambigüedad de la información, ausencia de poder } \\
\text { centralizado y de cadenas de mando bien } \\
\text { establecidas, énfasis en la individualidad, el riesgo y } \\
\text { la anticipación } \\
\text { Tarea de gestión: estimular el riesgo, el } \\
\text { conocimiento y la creatividad para estar siempre } \\
\text { adelante. Crear una visión de futuro, gestionar el } \\
\text { caos, disciplinar la imaginación } \\
\text { Espacio de trabajo: dinámico, emprendedor y } \\
\text { creativo } \\
\text { Líderes: visionarios, innovadores, orientados al } \\
\text { riesgo } \\
\text { Meta a largo plazo: crecimiento rápido, adquisición } \\
\text { de nuevos recursos, producir servicios y productos } \\
\text { únicos y originales }\end{array}$ \\
\hline Jerárquica & Mercado \\
\hline $\begin{array}{l}\text { Características: reglas formales, especialización, } \\
\text { meritocracia, jerarquía, impersonalidad, mecanismos } \\
\text { de responsabilidad, control, los procedimientos rigen } \\
\text { lo que las personas hacen } \\
\text { Tarea de gestión: coordinación y aplicación de los } \\
\text { procedimientos } \\
\text { Espacio de trabajo: formalizado y estructurado } \\
\text { Líderes: buenos coordinadores y organizadores } \\
\text { Meta a largo plazo: estabilidad, previsibilidad y } \\
\text { eficiencia }\end{array}$ & $\begin{array}{l}\text { Características: orientación hacia el exterior, el } \\
\text { control viene de los mecanismos del mercado, } \\
\text { énfasis en las transacciones (intercambio, ofertas, } \\
\text { contratos) con agentes externos para crear ventajas } \\
\text { competitivas. La competitividad y productividad son } \\
\text { los valores clave. El entorno es hostil y los clientes } \\
\text { exigentes } \\
\text { Tarea de gestión: dirección por objetivos } \\
\text { Espacio de trabajo: orientación a resultados } \\
\text { Líderes: productores exigentes, competitivos y } \\
\text { demandantes } \\
\text { Meta a largo plazo: logro de objetivos mayores, } \\
\text { buena posición y penetración en el mercado, ser líder }\end{array}$ \\
\hline
\end{tabular}




\section{Tabla 4. Variables de cultura organizacional}

\begin{tabular}{|c|c|c|}
\hline & $\begin{array}{l}\text { Para cada una de las cuatro cuestiones siguientes, reparta } 100 \\
\text { puntos entre las cuatro respuestas de tal manera que reflejen lo } \\
\text { más apegado a la realidad de la cultura actual en su empresa: }\end{array}$ & Validación escalas \\
\hline \begin{tabular}{|l|} 
Defina su \\
empresa
\end{tabular} & $\begin{array}{l}\text { a) Es cómo una gran familia. La gente comparte mucho con los } \\
\text { demás } \\
\text { b) Es una entidad muy dinámica y emprendedora. La gente está } \\
\text { dispuesta a apostar por sus ideas y asumir riesgos } \\
\text { c) Es una entidad orientada a resultados. La gente es muy } \\
\text { competitiva y enfocada fundamentalmente a conseguir los } \\
\text { objetivos } \\
\text { d) Es una entidad muy jerarquizada, formalizada y estructurada. } \\
\text { Para cualquier actividad existen procedimientos y normas } \\
\text { previamente definidos }\end{array}$ & $\begin{array}{lrl}\alpha & \text { de } & \text { Cronbach }= \\
0,742 & \end{array}$ \\
\hline $\begin{array}{l}\text { Defina el estilo } \\
\text { de dirección en } \\
\text { su empresa }\end{array}$ & $\begin{array}{l}\text { a) Se caracteriza por promover el trabajo en equipo, el consenso } \\
\text { y la participación } \\
\text { b) Se caracteriza por promover la iniciativa del individuo, la } \\
\text { asunción de riesgos, la innovación y la singularidad } \\
\text { c) Se caracteriza por promover la competitividad agresiva y la } \\
\text { consecución de objetivos ambiciosos } \\
\text { d) Se caracteriza por promover la seguridad en el empleo, la } \\
\text { permanencia en el puesto y la existencia de poca incertidumbre }\end{array}$ & $\begin{array}{lrl}\alpha & \text { de } & \text { Cronbach }= \\
0,792 & \end{array}$ \\
\hline $\begin{array}{l}\text { Defina los } \\
\text { valores } \\
\text { compartidos por } \\
\text { el personal de su } \\
\text { empresa }\end{array}$ & $\begin{array}{l}\text { a) Los valores compartidos son la lealtad, el compromiso con la } \\
\text { empresa, la confianza mutual y el trabajo en grupo } \\
\text { b) Los valores compartidos son el compromiso con la innovación } \\
\text { y el cambio continuo } \\
\text { c) Los valores compartidos son la agresividad, el espíritu } \\
\text { ganador y la consecución de los objetivos previstos } \\
\text { d) Los valores compartidos con la empresa son el respeto por las } \\
\text { normas y políticas formales y el cumplimiento con la jerarquía }\end{array}$ & $\begin{array}{lrr}\alpha & \text { de } & \text { Cronbach }= \\
0,733 & \end{array}$ \\
\hline $\begin{array}{l}\text { Defina en que se } \\
\text { basa el éxito de } \\
\text { su empresa }\end{array}$ & $\begin{array}{l}\text { a) El éxito se basa en el trabajo en equipo, el compromiso e } \\
\text { interés por los trabajadores } \\
\text { b) El éxito se basa en el desarrollo de productos únicos y } \\
\text { novedosos. Ser líder en productos e innovación } \\
\text { c) El éxito se basa en la penetración en el mercado y la cuota de } \\
\text { mercado. Ser el número uno respecto a los competidores } \\
\text { d) El éxito se basa en la eficiencia. La adecuada programación de } \\
\text { la producción y los bajos costes son aspectos críticos }\end{array}$ & $\begin{array}{lrl}\alpha & \text { de } & \text { Cronbach }= \\
0,694 & \end{array}$ \\
\hline Modelo total & & $\begin{array}{l}\alpha \text { de } \text { Cronbach }= \\
0,821\end{array}$ \\
\hline
\end{tabular}

Fuente: elaboración propia. 
El valor total de la cultura clan se obtiene sumando los puntos atribuidos a las respuestas "a" en las cuatro preguntas; el valor de la cultura adhocrática, de la suma de las repuestas "b"; la cultura de mercado, de la suma de las repuestas "c"; y la cultura jerárquica, de la suma de las respuestas " $d$ ":

Valor de la cultura clan: $(\mathrm{a} 1+\mathrm{a} 2+\mathrm{a} 3+\mathrm{a} 4)=\mathrm{P} 1$

Valor de la cultura adhocrática: $(\mathrm{b} 1+\mathrm{b} 2+\mathrm{b} 3+\mathrm{b} 4)=\mathrm{P} 2$

Valor de la cultura de mercado: $(\mathrm{c} 1+\mathrm{c} 2+\mathrm{c} 3+\mathrm{c} 4)=\mathrm{P} 3$

Valor de la cultura jerárquica: $(\mathrm{d} 1+\mathrm{d} 2+\mathrm{d} 3+\mathrm{d} 4)=\mathrm{P} 4$

\section{Variable de cultura de innovación}

Los valores, normas y prácticas de una cultura de innovación corresponden a los de las culturas adhocrática y de clan. Las empresas innovadoras tienen una orientación clara y flexible, y son propensas a los cambios. Por esta razón, cómo hicieron Duréndez y García (2008), se calculó una nueva variable denominada "cultura de innovación" mediante un algoritmo matemático. De acuerdo con los resultados de un panel de investigadores, este algoritmo se compone de tres elementos que miden el valor de la cultura de innovación. Esta variable oscila entre 0 y 1 , cuanto más innovadora es la empresa mayor es su valor.

Cultura de innovación $=\left(Z_{1}+Z_{2} \times 100+Z_{3} \times 100\right) / 300$

Donde:

$Z_{1}$ representa la importancia total de las culturas clan $\left(\mathrm{P}_{1}\right)$ y adhocrática $\left(\mathrm{P}_{2}\right) \cdot \mathrm{Z}_{1}=\mathrm{P}_{1}+\mathrm{P}_{2}$.

$Z_{2}$ mide la importancia de la cultura adhocrática en relación con la suma de las culturas que conforman la cultura de innovación (adhocrática y clan). Este componente es necesario porque el panel consideró que la cultura adhocrática es más importante que la cultura clan en la definición de cultura de innovación. $\mathrm{Z}_{2}=\mathrm{P}_{2} /\left(\mathrm{P}_{1}+\mathrm{P}_{2}\right)$.

$Z_{3}$ considera la diferencia entre la importancia que se da a ambas culturas, clan y adhocrática. Según el panel de expertos, cuanto más pequeña es la diferencia entre las culturas adhocrática y clan más innovadora es la compañía. $\mathrm{Z}_{3}=1-\left[\left(\left|\mathrm{P}_{2}-\mathrm{P}_{1}\right|\right) /\left(\mathrm{P}_{1}+\mathrm{P}_{2}\right)\right]$

\section{Variable de innovación}

Para medir el grado de innovación de la empresa existen dos enfoques (Hughes, 2001), uno objetivo que mide a partir de datos de tipo cuantitativo, como número de patentes o datos específicos de la innovación en productos (cantidad de nuevos productos) o procesos (costes de inversión). Y un enfoque subjetivo, basado en la percepción del gerente o propietario de la empresa sobre su actividad innovadora. En el caso de la MIPYME resulta más apropiado el enfoque subjetivo, dado que el objetivo tiende a subestimar la actividad innovadora de las MIPYME (Hughes, 2001). Este enfoque, por 
ejemplo, es el que se utiliza en el Estudio de la Innovación Armonizada de la Unión Europea (2004).

Para estudiar este factor en la investigación, se tuvo en cuenta los diferentes conceptos recopilados en la revisión de trabajos realizada, y en especial la de AECA (1995), que señala que la innovación puede clasificarse en tecnológica y organizacional. Las innovaciones tecnológicas incluyen las novedades significativas en productos y en procesos; la innovación organizacional por su parte, corresponde a los cambios introducidos a la estructura administrativa de la empresa, a la comercialización, etc. Esta misma clasificación ha sido usada en diferente trabajos (Van Auken et al. 2008; Naranjo et al. 2008; Maldonado et al. 2009).

Para medir el grado de innovación, en productos, procesos y gestión, se utilizó una medida multicriterio de varios ítems por cada tipo de innovación, con una escala Likert de cinco puntos $(1=$ grado de innovación poco importante a $5=$ grado de innovación muy importante. La variable innovación en productos está compuesta por la media aritmética de dos ítems (1) cambios o mejoras en productos o servicios existentes, y (2) comercialización de nuevos productos. La variable innovación en procesos está compuesta por la media aritmética de dos ítems: (1) mejoras o cambios en los procesos productivos, y (2) adquisición de nuevos equipos. Y la variable innovación en gestión está compuesta por la media aritmética de tres ítems: (1) gestión de dirección, (2) compras y aprovisionamientos, y (3) comercial y ventas.

Para validar estas medidas se verifica la fiabilidad de las escalas a través del estadístico Alpha de Cronbach (tabla 5). Los valores parciales y total de los estadísticos indican la validez de las escalas utilizadas.

\section{Tabla 5. Variables de innovación}

\begin{tabular}{|l|l|l|}
\hline & $\begin{array}{l}\text { Indique cuál ha sido el grado de innovación realizado en su empresa en } \\
\text { los dos últimos años: (1= Poco importante, 5= Muy importante) }\end{array}$ & Validación escalas \\
\hline $\begin{array}{l}\text { Innovación } \\
\text { en productos }\end{array}$ & $\begin{array}{l}\text { (1) Cambios o mejoras en productos o servicios existentes, y } \\
\text { (2) Comercialización de nuevos productos. }\end{array}$ & $\alpha$ de Cronbach $=0.822$ \\
\hline $\begin{array}{l}\text { Innovación } \\
\text { en procesos }\end{array}$ & $\begin{array}{l}\text { (1) Mejoras o cambios en los procesos productivos, y } \\
\text { (2) Adquisición de nuevos equipos }\end{array}$ & $\alpha$ de Cronbach $=0.635$ \\
\hline $\begin{array}{l}\text { Innovación } \\
\text { en gestión }\end{array}$ & $\begin{array}{l}\text { (1) Gestión de dirección, } \\
\text { (2) Compras y aprovisionamientos, y } \\
\text { (3) Comercial y ventas }\end{array}$ & $\alpha$ de Cronbach $=0.705$ \\
\hline Innovación total & & $\alpha$ de Cronbach $=0.807$ \\
\hline
\end{tabular}

Fuente: elaboración propia.

\section{Variables de control}

Tamaño: Esta variable se midió a través del número medio de empleados del año 2009, en forma logarítmica. El número de empleados ha sido utilizado como medida de 
tamaño en este tipo de trabajos, entre otros: Bruns y Waterhouse (1975), Merchant (1984), Malmi (1999), BjØrnenak (1997).

Edad: Medida a través del número de años transcurridos desde la constitución o inicio de la actividad. Esta variable ha sido utilizada por Holmes y Nicholls (1989) y Yasuda (2005).

\subsubsection{Los modelos}

Para contrastar las hipótesis planteadas en la primera relación se consideró el siguiente modelo:

$Y_{i}=b_{0}+b_{1}$ Cultura $_{i}+b_{2}$ Tamaño $_{i}+b_{3}$ Edad $_{i}+\varepsilon_{i}$

Dependiente $\mathrm{Y}_{\mathrm{i}}$

Rpi Rendimiento procesos internos

Rsa Rendimiento sistema abierto

$\mathrm{Rr} \quad$ Rendimiento racional

Rrh Rendimiento recursos humanos

Rgl Rendimiento global

\section{Control}

Tamaño

Logaritmo del número de empleados

Edad

Número de años transcurridos desde la constitución o el inicio de la actividad

Explicativas

Cclan Cultura clan

Cadh Cultura adhocrática

Cmer Cultura de mercado

Cjer Cultura jerárquica

Cinnov Cultura de innovación 
Para contrastar las hipótesis planteadas en la segunda relación, se considera el siguiente modelo de investigación:

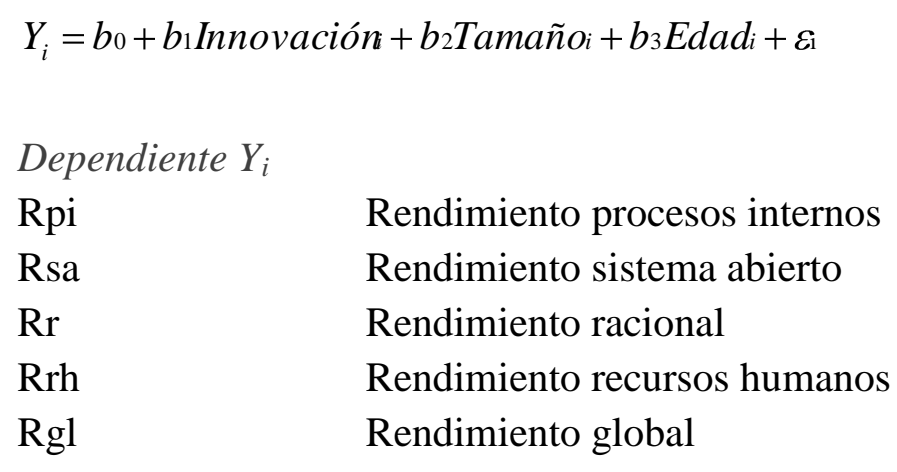

Control

Tamaño Logaritmo del número de empleados

Edad Número de años transcurridos desde la constitución o inicio de actividad

Explicativas

Iprod

Innovación en productos

Iproc

Innovación en procesos

Iges

Innovación en gestión

\subsection{ANÁLISIS DE RESULTADOS}

\subsubsection{Cultura organizacional y rendimiento}

La tabla 6 muestra los resultados de las estimaciones realizadas, examinando las relaciones entre los cinco tipos de cultura (clan, adhocrática, mercado, jerárquica y de innovación), y los cinco sistemas de rendimiento (procesos internos, sistema abierto, racional, relaciones humanas y rendimiento global). Las estimaciones se realizaron mediante regresiones lineales múltiples por MCO. Inicialmente comprobamos en todos los modelos que los regresores presentan un factor de inflación de la varianza (VIF) menor que 1,299, por lo que descartamos la presencia de multicolinealidad.

Efectos de la cultura clan sobre el rendimiento

La cultura de tipo clan tiene asociados coeficientes positivos y significativos, para los modelos de rendimiento en relaciones humanas y en rendimiento global, $(0.388 * * *$, 
$0.296^{* *}$ respectivamente). Esto implica que los valores y prácticas de la cultura clan (trabajo en equipo, consenso, participación, etc.): 1) motivan y satisfacen a los colaboradores, reducen el ausentismo y la rotación de personal, y 2) mejoran el desempeño general de la organización. En este sentido confirmamos la primera hipótesis, pero parcialmente, pues la cultura de tipo clan no tiene un impacto significativo sobre el rendimiento de la empresa en términos de su eficacia (modelo racional), de sus relaciones con el entorno (sistema abierto), ni de sus recursos humanos (modelo de relaciones humanas). Estos resultados difieren de los que obtuvieron Ogbonna y Harrris (2000) y Duréndez y García (2008), que encontraron que la cultura clan no tenía efectos significativos sobre el rendimiento de la organización.

En cuanto a la validez global de los modelos, sólo se encontró validez para el de relaciones humanas, con un valor significativo de $\mathrm{F}\left(\mathrm{F}=3,165^{* *}\right)$.

\section{Efectos de la cultura adhocrática sobre el rendimiento}

Este tipo de cultura no tiene asociados coeficientes significativos para ningún modelo de rendimiento, de modo que se debe rechazar la segunda hipótesis. Esta falta de relación (no esperada), puede deberse a que las empresas abordadas son de alta o media tecnología y los valores y prácticas asociadas a la cultura adhocrática son comunes en ellas; por ello pueden no ser percibidas por sus directivos cómo factores que generan diferencias de rendimiento. También puede obedecer al limitado tamaño de la muestra. Los resultados difieren de los que obtuvieron Duréndez y García (2008), y Tseng (2010), que indicaban una fuerte influencia positiva de la cultura adhocrática sobre el desempeño de las firmas.

\section{Efectos de la cultura de mercado sobre el rendimiento}

Los resultados para este tipo de cultura son similares a los de la cultura adhocrática, y se debe rechazar la tercera hipótesis. Estos hallazgos son opuestos a los resultados de las investigaciones de Deshpandé y Farle (2004), y O'cass y Ngo (2007) en las cuales la cultura de mercado tener un fuerte impacto positivo sobre el rendimiento organizacional.

\section{Efectos de la cultura jerárquica sobre el rendimiento}

La cultura jerárquica tiene asociados coeficientes significativos y negativos para el modelo de procesos internos y para el modelo de sistema abierto $\left(-0.274^{*},-0.300^{* *}\right.$ respectivamente); esto implica que los valores y prácticas asociadas a este tipo de cultura (formalismos, control, impersonalidad, etc.): 1) reducen la eficiencia interna de la empresa, y 2) desmejoran la satisfacción de los clientes, la adaptación a las necesidades del mercado, así como la imagen de la empresa y sus productos. Se confirma entonces la cuarta hipótesis, pero parcialmente, pues la cultura jerárquica no muestra un impacto significativo sobre el 
rendimiento de las empresas en términos de su eficacia (modelo racional), sus recursos humanos (modelo de relaciones humanas), ni su rendimiento global. Estos resultados confirman los de Duréndez y García (2008) quienes también encontraron que la cultura jerárquica afecta negativamente el rendimiento de las firmas.

\section{Efectos de la cultura de innovación sobre el rendimiento}

Como ya señalamos, definimos una nueva forma de cultura que corresponde a una mezcla de las culturas clan y adhocrática, a través de un algoritmo matemático utilizado en otras investigaciones, cómo la de Duréndez y García (2008).

La cultura de innovación tiene asociados coeficientes positivos y significativos para los modelos de rendimiento en procesos internos, sistema abierto, relaciones humanas y rendimiento global $\left(0.265^{*}, 0.272^{*}, 0.294^{* *}, 0.286^{* *}\right.$ respectivamente). Los resultados indican que la cultura de innovación: 1) aumenta la eficiencia interna de la organización, medida en términos de calidad de sus productos y servicios, procesos operativos internos, y organización de las tareas del personal; 2) mejora la satisfacción de los clientes, la rapidez de adaptación a las necesidades del mercado, y la imagen de la empresa y sus productos o servicios; 3) aumenta su cuota de mercado, su rentabilidad y su productividad y 4) mejora su rendimiento general. Se confirma entonces parcialmente la quinta hipótesis en cuanto al rendimiento global, pues la cultura de innovación no tiene un impacto significativo sobre el rendimiento de la empresa en términos de su eficacia (modelo racional).

Estos resultados confirman los de Tseng (2010), Duréndez y García (2008) y O’cass y Ngo (2007), en cuyas investigaciones la cultura de innovación influye positivamente y de manera muy significativa en el desempeño de las empresas.

En cuanto a la validez global de los modelos, sólo se encontró validez para el modelo de procesos internos, con un valor de $\mathrm{F}$ significativo $\left(\mathrm{F}=2.327^{*}\right)$.

Por último, en cuanto a las variables de control, hay que señalar que sólo para la edad surgieron estadísticos significativos, en el modelo de procesos internos, en su relación con las cultura clan y jerárquica $\left(0.251^{*}\right.$ y $0.296 *$ respectivamente). Esto indica que a medida que las MIPYMES tienen más años de funcionamiento, valores o prácticas cómo el trabajo en equipo, el consenso y la participación (cultura clan); y en otros casos los formalismos, el control y la impersonalidad (cultura jerárquica), mejoran su eficiencia interna medida en términos de calidad de sus productos y servicios, procesos operativos internos, y organización de las tareas del personal. 
Tabla 6. Cultura y rendimiento

\begin{tabular}{|c|c|c|c|c|c|}
\hline & \multicolumn{4}{|c|}{ Modelos de rendimiento } & \multirow[b]{2}{*}{ Rendimiento global } \\
\hline & $\begin{array}{l}\text { Procesos } \\
\text { internos }\end{array}$ & $\begin{array}{c}\text { Sistema } \\
\text { abierto }\end{array}$ & Racional & $\begin{array}{c}\text { Relaciones } \\
\text { humanas }\end{array}$ & \\
\hline $\begin{array}{l}\text { Cultura } \\
\text { Clan } \\
\text { Tamaño } \\
\text { Edad }\end{array}$ & $\begin{array}{l}0.083 \\
(0.616) \\
-0.038 \\
(-0.264) \\
0.251 * \\
1.731\end{array}$ & $\begin{array}{l}0.212 \\
(1.564) \\
0.104 \\
(0.709) \\
0.006 \\
(0.042)\end{array}$ & $\begin{array}{l}0.175 \\
(1.275) \\
0.125 \\
(0.856) \\
0.051 \\
(0.347)\end{array}$ & $\begin{array}{l}0.388 * * * \\
(3.026) \\
-0.008 \\
(-0.061) \\
0.041 \\
(0.298)\end{array}$ & $\begin{array}{l}0.296 * * \\
(2.225) \\
0.065 \\
(0.460) \\
0.116 \\
(0.821)\end{array}$ \\
\hline $\begin{array}{l}\text { VIF más alto } \\
\text { F } \\
\text { R2 ajustado }\end{array}$ & $\begin{array}{l}1.172 \\
1.235 \\
0.013\end{array}$ & $\begin{array}{l}1.172 \\
0.969 \\
-0.002\end{array}$ & $\begin{array}{c}1.154 \\
0.918 \\
-0.005\end{array}$ & $\begin{array}{l}1.172 \\
3.165^{* *} * \\
0.106\end{array}$ & $\begin{array}{l}1.154 \\
2.131 \\
0.059\end{array}$ \\
\hline $\begin{array}{l}\text { Cultura } \\
\text { Adhocrática } \\
\text { Tamaño } \\
\text { Edad }\end{array}$ & $\begin{array}{l}0.202 \\
(1.452) \\
-0.053 \\
(-0.354) \\
0.238 \\
(1.573)\end{array}$ & $\begin{array}{l}0.170 \\
(1.175) \\
0.042 \\
(0.270) \\
0.018 \\
(0.114)\end{array}$ & $\begin{array}{l}-0.138 \\
(-0.946) \\
0.088 \\
(0.564) \\
0.079 \\
(0.502)\end{array}$ & $\begin{array}{l}0.062 \\
(0.424) \\
-0.068 \\
(-0.429) \\
0.060 \\
(0.376)\end{array}$ & $\begin{array}{l}0.092 \\
(0.633) \\
0.010 \\
(0.064) \\
0.135 \\
(0.859)\end{array}$ \\
\hline $\begin{array}{l}\text { VIF más alto } \\
\text { F } \\
\text { R2 ajustado }\end{array}$ & $\begin{array}{l}1.197 \\
1.751 \\
0.043\end{array}$ & $\begin{array}{l}1.197 \\
0.530 \\
-0.029\end{array}$ & $\begin{array}{l}1.179 \\
0.560 \\
-0.028\end{array}$ & $\begin{array}{l}1.197 \\
0.148 \\
-0.054\end{array}$ & $\begin{array}{l}1.179 \\
0.486 \\
-0.032\end{array}$ \\
\hline $\begin{array}{l}\text { Cultura } \\
\text { Mercado } \\
\text { Tamaño } \\
\text { Edad }\end{array}$ & $\begin{array}{l}-0.105 \\
(-0.664) \\
-0.059 \\
(-0.329) \\
0.152 \\
(0.846)\end{array}$ & $\begin{array}{l}0.058 \\
(0.365) \\
0.097 \\
(0.538) \\
-0.117 \\
(-0.647)\end{array}$ & $\begin{array}{l}-0.108 \\
(-0.676) \\
0.166 \\
(0.923) \\
-0.077 \\
(-0.428)\end{array}$ & $\begin{array}{l}-0.162 \\
(-1.028) \\
-0.055 \\
(-0.305) \\
0.081 \\
(0.451)\end{array}$ & $\begin{array}{l}-0.115 \\
(-0.712) \\
0.057 \\
(0.313) \\
0.018 \\
(0.097)\end{array}$ \\
\hline $\begin{array}{l}\text { VIF más alto } \\
\text { F } \\
\text { R2 ajustado }\end{array}$ & $\begin{array}{l}1.299 \\
0.403 \\
-0.045\end{array}$ & $\begin{array}{l}1.299 \\
0.208 \\
-0.060\end{array}$ & $\begin{array}{l}1.272 \\
0.450 \\
-0.042\end{array}$ & $\begin{array}{l}1.299 \\
0.431 \\
-0.042\end{array}$ & $\begin{array}{l}1.272 \\
0.237 \\
-0.059\end{array}$ \\
\hline $\begin{array}{l}\text { Cultura } \\
\text { Jerárquica } \\
\text { Tamaño } \\
\text { Edad }\end{array}$ & $\begin{array}{l}-0.274^{*} \\
(-1.868) \\
-0.060 \\
(-0.382) \\
0.296^{*} \\
(1.909)\end{array}$ & $\begin{array}{l}-0.300^{*} \\
(-1.990) \\
0.053 \\
(0.332) \\
0.30 \\
(0.190)\end{array}$ & $\begin{array}{l}0.145 \\
(0.927) \\
0.073 \\
(0.439) \\
0.063 \\
(0.380)\end{array}$ & $\begin{array}{l}-0.035 \\
(-0.222) \\
-0.076 \\
(-0.455) \\
0.156 \\
(0.943)\end{array}$ & $\begin{array}{l}-0.135 \\
(-0.869) \\
0.000 \\
(0.001) \\
0.181 \\
(1.103)\end{array}$ \\
\hline $\begin{array}{l}\text { VIF más alto } \\
\text { F } \\
\text { R2 ajustado }\end{array}$ & $\begin{array}{l}1.155 \\
2.219 * \\
0.077\end{array}$ & $\begin{array}{l}1.155 \\
1.328 \\
0.022\end{array}$ & $\begin{array}{l}1.133 \\
0.518 \\
-0.035\end{array}$ & $\begin{array}{c}1.155 \\
0.313 \\
-0.049\end{array}$ & $\begin{array}{l}1.133 \\
0.648 \\
-0.025\end{array}$ \\
\hline $\begin{array}{l}\text { Cultura de } \\
\text { Innovación } \\
\text { Tamaño } \\
\text { Edad }\end{array}$ & $\begin{array}{l}0.265^{*} \\
(1.931) \\
-0.025 \\
(-0.165) \\
0.231 \\
(1.548)\end{array}$ & $\begin{array}{l}0.272 * \\
(1.921) \\
0.072 \\
(0.469) \\
0.006 \\
(0.038)\end{array}$ & $\begin{array}{l}0.026 \\
(0.179) \\
0.093 \\
(0.587) \\
0.060 \\
(0.380)\end{array}$ & $\begin{array}{l}0.294 * * \\
(2.098) \\
-0.035 \\
(-0.228) \\
0.032 \\
(0.213)\end{array}$ & $\begin{array}{l}0.286 * * \\
(2.028) \\
0.040 \\
(0.263) \\
0.112 \\
(0.738)\end{array}$ \\
\hline $\begin{array}{l}\text { VIF más alto } \\
\text { F } \\
\text { R2 ajustado }\end{array}$ & $\begin{array}{l}1.197 \\
2.327^{*} \\
0.074\end{array}$ & $\begin{array}{l}1.197 \\
1.304 \\
0.018\end{array}$ & $\begin{array}{c}1.181 \\
0.268 \\
-0.047\end{array}$ & $\begin{array}{l}1.197 \\
1.563 \\
0.033\end{array}$ & $\begin{array}{l}1.181 \\
1.752 \\
0.044\end{array}$ \\
\hline
\end{tabular}

Debajo de cada coeficiente estandarizado, entre paréntesis, valor del estadístico t-student. ${ }^{*} \mathrm{p} \leq 0.1 ;{ }^{* *} \mathrm{p} \leq 0.05 ; * * * \mathrm{p} \leq 0.01$

Fuente: elaboración propia. 


\subsubsection{Innovación y rendimiento}

La Tabla 7 muestra los resultados de las estimaciones realizadas, sobre las relaciones entre los tres tipos de innovación (productos, procesos y gestión), y los cinco sistemas de rendimiento examinandos (procesos internos, sistema abierto, racional, relaciones humanas y rendimiento global). Los cálculos se realizan a partir de regresiones lineales múltiples por MCO. Inicialmente se comprobó en todos los modelos que los regresores presentan un factor de inflación de la varianza (VIF) menor a 1.59, por lo que se descartó la presencia de multicolinealidad.

\section{Efectos de la innovación en productos sobre el rendimiento}

La innovación en productos tiene asociados coeficientes positivos y significativos para los modelos de rendimiento en proceso internos, sistema abierto y rendimiento global $\left(0.254^{*}, 0.328^{* *}, 0.265^{* *}\right)$ respectivamente. Esto indica que la innovación en productos (cambios o mejoras en productos o servicios existentes o la comercialización de nuevos productos) genera en las MIPYME un mayor rendimiento en aspectos relacionados con: (1) incrementos en su eficiencia interna, medida en términos de calidad de sus productos y servicios, procesos operativos internos, y organización de las tareas del personal; (2) mejora en la satisfacción de los clientes, en la rapidez de adaptación a las necesidades del mercado, y en imagen de la empresa y sus productos o servicios; y (3) incremento en su rendimiento general. En este sentido se puede confirmar la primera hipótesis planteada en cuanto al rendimiento global, pero parcialmente, dado que la innovación en productos no tiene un impacto significativo sobre el rendimiento de la empresa en términos de su eficacia (modelo racional), ni de sus recursos humanos (modelo de relaciones humanas).

En cuanto a la validez global de los modelos, ésta se encuentra solo para el de procesos internos y el de sistema abierto, puesto que los valores de las $\mathrm{F}$ resultaron significativos $\left(\mathrm{F}=2.513^{*}, \mathrm{~F}=2.347^{*}\right)$. 


\section{Tabla 7. Innovación y rendimiento}

\begin{tabular}{|c|c|c|c|c|c|}
\hline & \multicolumn{4}{|c|}{ Modelos de Rendimiento } & \multirow[b]{2}{*}{$\begin{array}{c}\text { Rendimiento } \\
\text { Global }\end{array}$} \\
\hline & $\begin{array}{l}\text { Procesos } \\
\text { internos }\end{array}$ & $\begin{array}{c}\text { Sistema } \\
\text { abierto }\end{array}$ & Racional & $\begin{array}{l}\text { Relaciones } \\
\text { humanas }\end{array}$ & \\
\hline $\begin{array}{l}\text { Innovación } \\
\text { Productos } \\
\text { Tamaño } \\
\text { Edad }\end{array}$ & $\begin{array}{l}\mathbf{0 . 2 5 4} * \\
(1.991) \\
-0.067 \\
(-0.492) \\
0.294 * * \\
(2.132)\end{array}$ & $\begin{array}{l}0,328 * * \\
(2,559) \\
0,074 \\
(0,541) \\
0,063 \\
(0,453)\end{array}$ & $\begin{array}{l}0.098 \\
(0.720) \\
0.089 \\
(0.620) \\
0.088 \\
(0.606)\end{array}$ & $\begin{array}{l}0.132 \\
(0.978) \\
-0.063 \\
(-0.437) \\
0.079 \\
(0.541)\end{array}$ & $\begin{array}{l}0.265^{* *} \\
(2.022) \\
0.017 \\
(0,119) \\
0.175 \\
(1.247)\end{array}$ \\
\hline $\begin{array}{l}\text { VIF más alto } \\
\mathrm{F} \\
\mathrm{R}^{2} \text { ajustado }\end{array}$ & $\begin{array}{l}1.186 \\
2.513^{*} \\
0.073\end{array}$ & $\begin{array}{l}1.186 \\
2.347 * \\
0.065\end{array}$ & $\begin{array}{l}1.171 \\
0.517 \\
-0.026\end{array}$ & $\begin{array}{l}1.186 \\
0.400 \\
-0.032\end{array}$ & $\begin{array}{l}1.171 \\
1.779 \\
0.039\end{array}$ \\
\hline $\begin{array}{l}\text { Innovación } \\
\text { Procesos } \\
\text { Tamaño } \\
\text { Edad }\end{array}$ & $\begin{array}{l}0.048 \\
(0.369) \\
-0.061 \\
(-0.435) \\
0.256^{*} \\
(1.815)\end{array}$ & $\begin{array}{l}\text { O.262** } \\
(2.020 \\
0.075 \\
(0.535) \\
0.019 \\
(0.133)\end{array}$ & $\begin{array}{l}0.358 * * * \\
(2.846) \\
0.090 \\
(0.669) \\
0.088 \\
(0.650)\end{array}$ & $\begin{array}{l}0.179 \\
(1.349) \\
-0.065 \\
(-0.456) \\
0.063 \\
(0.438)\end{array}$ & $\begin{array}{l}0.300 * * \\
(2.338) \\
0.022 \\
(0.162) \\
0.147 \\
(1.068)\end{array}$ \\
\hline $\begin{array}{l}\text { VIF más alto } \\
\mathrm{F} \\
\mathrm{R}^{2} \text { ajustado }\end{array}$ & $\begin{array}{l}1.163 \\
1.160 \\
0.008\end{array}$ & $\begin{array}{l}1.163 \\
1.518 \\
0.026\end{array}$ & $\begin{array}{l}1.149 \\
3.093 * * \\
0.099\end{array}$ & $\begin{array}{l}1.163 \\
0.689 \\
-0.016\end{array}$ & $\begin{array}{l}1.149 \\
2.247^{*} \\
0.062\end{array}$ \\
\hline $\begin{array}{l}\text { Innovación } \\
\text { Gestión } \\
\text { Tamaño } \\
\text { Edad }\end{array}$ & $\begin{array}{l}0.158 \\
(1.038) \\
-0.106 \\
(-0.724) \\
0.344 * * \\
(2.097)\end{array}$ & $\begin{array}{l}0.237 \\
(1.530) \\
0.014 \\
(0.095) \\
0.145 \\
(0.874)\end{array}$ & $\begin{array}{l}0.135 \\
(0.851) \\
0.054 \\
(0.363) \\
0.149 \\
(0.883)\end{array}$ & $\begin{array}{l}0.144 \\
(0.919) \\
-0.101 \\
(-0.671) \\
0.139 \\
(0.826)\end{array}$ & $\begin{array}{l}0.229 \\
(1.470) \\
-0.040 \\
(-0.268) \\
0.264 \\
(1.586)\end{array}$ \\
\hline $\begin{array}{l}\text { VIF más alto } \\
\mathrm{F} \\
\mathrm{R}^{2} \text { ajustado }\end{array}$ & $\begin{array}{l}1.596 \\
1.493 \\
0.025\end{array}$ & $\begin{array}{l}1.596 \\
0.933 \\
-0.003\end{array}$ & $\begin{array}{l}1.591 \\
0.587 \\
-0.022\end{array}$ & $\begin{array}{l}1.596 \\
0.362 \\
-0.034\end{array}$ & $\begin{array}{l}1.591 \\
1.122 \\
0.006\end{array}$ \\
\hline
\end{tabular}

Debajo de cada coeficiente estandarizado, entre paréntesis, valor del estadístico t-student

* $\mathrm{p} \leq 0.1 ; * * \quad \mathrm{p} \leq 0.05 ; * * * \mathrm{p} \leq 0.01$

Fuente: elaboración propia.

Efectos de la innovación en procesos sobre el rendimiento

La innovación en procesos tiene asociado coeficientes positivos y significativos para los modelos de rendimiento sistema abierto, racional y global $\left(0.262^{* *}, 0.358^{* * *}\right.$, $\left.0.300^{* *}\right)$ respectivamente, esto indica que en la medida que se mejoran los procesos productivos o se adquieren nuevos equipos, en las MIPYMES de mediana y alta tecnología de Cali, mejora significativamente su desempeño en cuanto a: (1) la satisfacción de los 
clientes, la rapidez de adaptación a las necesidades del mercado, y en imagen de la empresa y sus productos o servicios; (2) en cuanto a su cuota de mercado, rentabilidad y productividad; y (3) en cuanto a su rendimiento global. De esta forma, también se confirma la segunda hipótesis planteada en cuanto al rendimiento global, pero parcialmente, dado que la innovación en procesos no tiene un impacto significativo sobre el rendimiento de la empresa en términos de incrementos en su eficiencia interna, medida en términos de calidad de sus productos y servicios (procesos operativos internos) cómo se hubiera esperado, de sus relaciones con el entorno (modelos de sistema abierto), ni de sus recursos humanos (modelo de relaciones humanas).

Respecto a la validez global del modelo, se encuentra validez solo para el sistema racional y el de rendimiento global, puesto que los valores de las $\mathrm{F}$ resultaron significativos $\left(\mathrm{F}=3.093^{*}, \mathrm{~F}=2.247^{*}\right)$.

\section{Efectos de la innovación en gestión sobre el rendimiento}

Este tipo de innovación no tiene asociados coeficientes significativos para ningún modelo de rendimiento planteado. Por lo que se debe rechazar la tercera hipótesis planteada. En este caso el signo esperado sería positivo y significativo. Esta falta de relación (no esperada) puede deberse a que se trata de empresas de alta y media tecnología donde la innovación en gestión resulta una herramienta común y ampliamente establecida en el seno de sus organizaciones. En cualquier caso, también puede obedecer al reducido tamaño de la muestra utilizada.

Finalmente, y en cuanto a las variables de control, sólo para la edad surgieron estadísticos significativos y en particular en el modelo de procesos internos, siendo positivos para todos los tipos de innovación estudiados $\left(0.294 * *, 0.265^{*}, 0.344^{* *}\right)$ respectivamente. Esto indica que en la medida que la MIPYME tiene más años de funcionamiento, los diferentes tipos de innovación que se impulsen en ella generan un mejoramiento en su eficiencia interna, medida en términos de calidad de sus productos y servicios, procesos operativos internos, y organización de las tareas del personal.

\subsection{CONCLUSIONES}

En este trabajo se ha analizado el efecto de la cultura organización y la innovación, en el rendimiento de la MIPYME, mediante la utilización de una muestra de 60 empresas de mediana y alta tecnología de la ciudad de Cali. De esta forma, se contribuye a la literatura sobre el tejido empresarial colombiano, donde los estudios empíricos sobre estas temáticas son muy escasos.

Esta investigación es relevante porque en Colombia, según datos del DANE (2005), las MIPYME representan el 99.9\% de las empresas (96,4\% micro y 3,5\% Pymes), generan un $63 \%$ del empleo y un $37 \%$ de la producción. Además, porque en el intento de mejorar la 
competitividad del país, el cambio de paradigmas culturales por parte de sus empresarios se ha convertido en un objetivo prioritario para el gobierno (CONPES 3484, 2007).

Los resultados del estudio confirman los de otras investigaciones pero en el contexto colombiano, ya que muestran que los valores y prácticas organizacionales asociadas a la cultura de innovación, es decir, aquellas que estimulan la cohesión, el trabajo en equipo, el compromiso, la adaptabilidad, la flexibilidad, la aceptación del riesgo y la incertidumbre, generan importantes mejoras en el desempeño en términos de la calidad de los productos y servicios, en la eficiencia de los procesos internos, en las relaciones humanas internas, y en la relación de la empresa con su entorno inmediato. Este resultado evidencia la sinergia que se genera al combinar adecuadamente prácticas de la cultura clan y de la cultura adhocrática.

De igual manera, esta investigación verifica que el desempeño y la satisfacción de los colaboradores se ven estimulados por un ambiente de trabajo amistoso, por la presencia de líderes que actúen cómo mentores y por la definición consensual de los objetivos de la empresa.

Es importante también señalar que como se encontró en otros trabajos, las estructuras organizacionales demasiado rígidas, el exceso de formalismo y de procedimientos, influyen negativamente en el desempeño, especialmente en aspectos como la baja adaptación a las necesidades del mercado y la poca satisfacción de los clientes.

Se debe resaltar que la experiencia que gana la empresa con el paso del tiempo influye positivamente en el desempeño de sus procesos internos, medidos en términos de la calidad de sus productos y servicios, la eficiencia de los procesos operativos y la organización de las tareas del personal.

Respecto a la innovación y su efecto sobre el rendimiento, se pudo concluir que la innovación en procesos y la innovación en productos son las que mayor impacto positivo generan en la MIPYME, y contrario a lo esperado, la innovación en gestión no muestra un efecto significativo sobre el rendimiento. De otra parte, se verifica que en general la innovación impacta positivamente el desempeño externo de la empresa y en su rendimiento general.

Los resultados de esta investigación son de importancia ya que proporcionan pautas a los empresarios y gerentes acerca de los valores, tipos de liderazgo, ambiente laboral y formas de innovación que deberían impulsar para mejorar el desempeño de sus organizaciones. A las entidades públicas y privadas de fomento de la actividad empresarial les ofrecen nuevas perspectivas para reforzar sus programas de intervención en los aspectos de mayor impacto en el rendimiento de las empresas. La academia puede utilizarlos para orientar sus actividades de investigación, docencia y extensión hacia aquellas que más contribuyan a generar o fortalecer una cultura organizacional y estrategias de innovación que estimulen la competitividad y el desarrollo de las MIPYME. 
El trabajo presenta entre otras las siguientes limitaciones: el tamaño de la muestra es relativamente pequeño, lo que pudo llevar a que algunos estadísticos no resultaran significativos; por otra parte, la encuesta sólo se aplicó a los directivos de las empresas, siendo deseable utilizar informantes de diferente nivel para limitar los posibles sesgos perceptuales (Cameron y Quinn, 1999; Naranjo et al. 2008).

Futuros trabajos podrían retomar esta investigación para abordar elementos que quedan pendientes de analizar, cómo los tipos de cultura y de innovación predominantes en el conglomerado de MIPYME y en cada sector específico de actividad. También se podría revisar y discutir las relaciones estudiadas tomando cómo unidad de análisis cada sector o el tamaño de las empresas (micro, pequeñas o medianas); en próximos estudios se podrían añadir variables de control, cómo el género del gerente, su grado de escolaridad y la condición de ser o no una empresa familiar. 


\section{CAPITULO 2}

CULTURA DE INTRAEMPRENDIMIENTO Y SU EFECTO SOBRE EL RENDIMIENTO Y LA INNOVACIÓN DE LAS MIPYMES TURISTICAS DE COLOMBIA 


\subsection{INTRODUCCIÓN}

El intraemprendimiento también denominado emprendimiento corporativo u organizacional representa una actividad emprendedora llevada a cabo dentro de las organizaciones (Trujillo y Guzmán, 2008; Antoncic y Hsrich, 2003), lo que se puede traducir en el desarrollo de proyectos empresariales innovadores y nuevos negocios para la empresa (Varela e Irizar, 2009). Según Garzón (2004), es necesario pasar de una cultura organizacional tradicional caracterizada por aspectos tales como la rigidez, la centralización y la formalidad, a una intraemprendedora; plantea que "para que el intraemprendedor surja, se requiere que la organización genere una cultura organizacional que ofrezca a los empleados la posibilidad de encontrar las oportunidades de innovación, y a la vez satisfacer los deseos de sentirse propietarios de sus proyectos internos, sin abandonar la organización".

A nivel internacional, un buen número de trabajos empíricos relacionan el emprendimiento corporativo o intraemprendimiento con el rendimiento. En este sentido, destacar los estudios de Benítez-Amado et al. (2010), Agca et al. (2009), Lopez (2008), Foba y De Villiers (2007), Kuratko et al. (2005), Kyriakopoulos et al. (2004), Marcus y Zimmerer (2003), Morris et al. (1993) y Covin y Slevin (1991). De igual manera se han realizado trabajos empíricos que relacionan el intraemprendimiento con la innovación organizacional, pudiéndose destacar los de Kuz (2010), Lee et al. (2008), Khazanchi et al. (2007), Manimala (2006), Amo y Kolvereid (2005), Samuelsson y Dahlqvist (2005), Zhao (2005), Garzón (2004), Martins y Terblanche (2003) y el de Claver et al. (1998).

Sin embargo estos estudios se han centrado en las grandes corporaciones y no han abordado las MIPYMES, no obstante a que "generan un alto porcentaje del empleo y realizan una considerable parte de la producción y el comercio a nivel mundial" (Julien, 2003).

Esta investigación busca contribuir a llenar el vacío de literatura, respondiendo a las siguientes preguntas de investigación: ¿La cultura intraemprendedora conduce a un mayor rendimiento de la MIPYME? y ¿Las MIPYME con mayor cultura de intraemprendimiento son más innovadoras? Para ello se realiza un estudio empírico a partir de la entrevista a 68 gerentes de hoteles, agencias de viaje y restaurantes MIPYME de Colombia. Se ha escogido el sector turístico ya que mundialmente ha tomado gran importancia siendo uno de los de más rápido crecimiento en generación de divisas y empleo (World Economic Forum, 2009), y porque en Colombia se ha constituido en el tercer renglón de 
exportaciones después del petróleo y el carbón, por lo que el gobierno nacional ha decidido apoyarlo a través de sus políticas públicas (CONPES $\left.{ }^{4}, 2005\right)$.

El documento está estructurado de la siguiente forma: en primer lugar se revisan los estudios empíricos previos y se plantea la hipótesis de investigación, en segundo lugar se expone la metodología usado lo cual incluye la obtención de la muestra, la recolección de datos y la medición de las variables utilizadas. En tercer lugar se presentan los resultados, su discusión y finalmente se exponen las conclusiones alcanzadas, las limitaciones del trabajo y se señalan posibles investigaciones futuras.

\subsection{MARCO TEORICO}

\subsubsection{Intraemprendimiento y cultura de intraemprendimiento}

El intraemprendimiento también denominado emprendimiento corporativo $u$ organizacional es definido por Varela e Irizar (2009) como una actividad que tiene como objetivo la generación de nuevos negocios para la empresa matriz, lo cual se puede llevar a cabo por medio del desarrollo de nuevos proyectos empresariales innovadores; a su vez Trujillo y Guzmán (2008) señalan que es la actividad emprendedora llevada a cabo dentro de las organizaciones ya establecidas, por su parte McGinnis y Verney (1987) se refieren al intraemprendimiento cómo un requerimiento para retomar el espíritu emprendedor al interior de las organizaciones.

El intraemprendimiento ha sido abordado desde diferentes perspectivas que pueden recogerse en cuatro grupos principales: los elementos del entorno externo a la empresa que generan en esta respuestas o posturas emprendedoras; el sujeto que lo ejerce al que se le denomina intraemprendedor o empresario interno; los aspectos organizacionales es decir las características procesos o condiciones propias de la firma que favorecen o dificultan el surgimiento de iniciativas emprendedoras entre ellas la estrategia, la estructura y la cultura organizacional; y el efecto que produce el intraemprendimiento en la empresa, por ejemplo en su innovación, (Trujillo y Guzmán, 2008).

La cultura intraemprendedora o de intraemprendimiento es aquella cultura organizacional que a diferencia de una "tradicional", ofrece a los empleados la posibilidad de encontrar oportunidades de innovación, y a la vez de satisfacer los deseos de sentirse propietarios de sus proyectos internos, sin tener que abandonar la empresa (Garzón, 2004).

Para Ross (1987) al crear empresas los individuos son emprendedores, por lo cual al menos durante sus inicios la cultura que prevalece en ellas es igualmente emprendedora; pero que con el tiempo y con la complejidad que toman las actividades, dicha cultura tiende

\footnotetext{
${ }^{4}$ El CONPES es el Consejo Nacional de Política Económica y Social, ente asesor del poder ejecutivo y máxima autoridad en la formulación de políticas públicas en Colombia.
} 
a volverse burocrática. Señala este autor que dentro las características que se encuentran en una firma donde se desarrolla y mantiene una cultura intraemprendedora e innovadora están la autonomía, la tolerancia al riesgos y a los errores, la lealtad, la firmeza y general todas las características atribuidas al espíritu empresarial; indica además el autor que la cultura intraemprendedora debería desarrollarse en todos los colaboradores y no únicamente en los directivos.

Teniendo en cuenta que emprender es un proceso, es factible la creación de una cultura, donde se incite a las organizaciones y en especial a sus colaboradores a emprender nuevos proyectos que produzcan empleo y desarrollo (Varela e Irizar, 2009; MacMillan y McGrath, 2000).

Según Kyriakopoulos et al. (2004), la cultura emprendedora dentro de la organización tiene las siguientes características: actitud de toma de riesgo, liderazgo innovador, mecanismos de relacionamiento y flexibilidad. La mentalidad intraempresarial en la organización incluye elementos como un apropiado sistema de recompensas, disponibilidad de recursos para los proyectos emprendedores, una estructura organizacional de soporte, y tolerancia al riesgo y a los errores (Wood, 2004).

\subsection{ESTUDIOS EMPÍRICOS PREVIOS}

\subsubsection{Cultura de intraemprendimiento y rendimiento}

Benitez-Amado et al. (2010) estudiaron en una muestra de 203 empresas españolas cómo las tecnologías de información y el intraemprendimiento influyen en el rendimiento de las organizaciones, hallando que la cultura de intraemprendimiento es un importante predictor del desempeño comercial de la firma, y que la tecnología de la empresa así como el uso que hace de ella, tienen un efecto positivo sobre el emprendimiento y el rendimiento organizacional.

Agca et al. (2009) publican un trabajo realizado con 331 empresas manufactureras turcas en las cuales a través de un constructo multidimensional, observan las relaciones entre el ambiente externo, el intrapreneurship y el rendimiento. En esta investigación el intraemprendimiento es analizado en términos de innovación, nuevos negocios, renovación organizacional, proactividad y toma de riesgo. Los resultados muestran que los factores ambientales tienen un impacto estadísticamente significativo sobre las actividades intraemprendedoras de estas empresas, siendo negativa su influencia para la relación entre la utilidad financiera y la renovación, y positiva para la toma de riesgos y la innovación.

Explorando el impacto de la creatividad y la experiencia de los mandos medios, en los resultados de los emprendimientos al interior de las corporaciones, López (2008) encuentra en una muestra de 308 funcionarios que estas dos variables tienen una relación 
positiva con la cantidad y calidad de los intraemprendimientos y por lo tanto en el rendimiento de la organización.

Kuratko, et al. (2005) a partir de un estudio realizado en la empresa Middle-Level, desarrollan un modelo conceptual que relaciona el conocimiento, el espíritu empresarial corporativo y el rendimiento de los directivos. En este trabajo los autores muestran que la conducta de los gerentes de nivel medio está relacionada con el éxito del emprendimiento corporativo, lo que les permite plantear un proceso para impulsar el intraemprendimiento cómo un factor de éxito empresarial.

En un estudio longitudinal realizado en diez de las 500 mejores corporaciones de la revista Fortune, Marcus y Zimmerer (2003) encuentran que la incorporación de programas de intraemprendimiento en la estructura de la organización tiene un impacto positivo en el desempeño de la misma en términos del total de ventas, utilidades y rendimiento para los inversores. Lo anterior los lleva a concluir que para las organizaciones es importante que sus colaboradores se formen en las labores propias de sus cargos, pero también en el desarrollo de conductas emprendedoras.

Morris et al. (1993) estudia en una muestra de 84 empresas industriales la relación entre el corte colectivista o individualista en la cultura organizacional y el desarrollo del intraemprendimiento en la empresa. Sus resultados muestran que el espíritu empresarial es más alto en condiciones de colectivismo o individualismo equilibrado, y más deteriorado en ambientes altamente individualistas o colectivistas, y que ello tiene influencia directa en el rendimiento de la organización.

Por otra parte estudios cómo los de Covin y Slevin (1991) muestran que las empresas con mayor capacidad adaptativa y mayor orientación emprendedora tienen un desempeño mejor que las firmas más conservadoras, particularmente en entornos turbulentos y cambiantes.

Partiendo de los aportes mencionados se plantea la siguiente hipótesis:

\section{H1. Las empresas con mayor cultura intraemprendedora tienen mejor desempeño}

\subsubsection{Cultura de intraemprendimiento e innovación}

La relación entre intraemprendimiento e innovación organizacional ha sido de igual manera objeto de diversos trabajos empíricos, que la han estudiado de manera exclusiva o relacionándola con otras variables, en diferentes contextos geográficos y culturales:

En los Estados Unidos de América, Kuz (2010) estudia el intraemprendimiento y la innovación en empresas de alta tecnología, vinculando estos factores al papel desempeñado por sus líderes de mayor rango. Su estudio muestra que para que la empresa sea más 
innovadora el líder debe fomentar prácticas como la generación de ambientes de trabajo colaborativos, apoyar la innovación abierta a través de concursos de ideas, vincular el intraemprendedor a los procesos innovadores, y conducir la empresa hacia negocios de más actualidad.

Lee et al. (2008) en un estudio con empresas de Taiwan relacionan el aprendizaje y los comportamientos organizacionales asociados al intraemprendimiento y la innovación. Hallan una relación positiva y significativa entre la cultura organizacional intraemprendedora y la innovación, demostrando que las empresas con este tipo de cultura son más innovadoras en productos y a nivel gerencial.

Explorando cómo los valores organizacionales impactan en el proceso de innovación y en especial la manufactura tecnológicamente avanzada -AMT, Khazanchi et al. (2007) encontraron que los valores relacionados con la flexibilidad (considerada por muchos autores cómo una de las principales características de la cultura intraemprendedora), afectan positiva y directamente la innovación y que en la medida que los gerentes y operarios comparten dicha percepción de flexibilidad, el rendimiento de la planta mejora después de la implementación de un sistema de -AMT.

Manimala (2006) presentó un estudio realizado en empresas del sector público de la India, cuyo principal objetivo fue identificar las dificultades de la organización para la innovación intraemprendedora. Para cumplir con su propósito revisó 162 proyectos, de los que seleccionó 31 casos altamente innovadores. Entre sus resultados identificó las siguientes dificultades para la innovación intraempresarial: insuficiencia de premios y reconocimiento $(65 \%)$, pobre documentación y mantenimiento de registros $(58 \%)$, y falta de formalidad en la formación del equipo (81\%).

Amo y Kolvereid (2005) aplicaron un modelo orientado a medir el comportamiento intraemprendedor e innovador en graduados de la Escuela de Negocios de la Universidad de Norway. El estudio que incluyó una muestra 634 individuos ocupantes desde gerencias de nivel alto y medio, hasta cargos de menor rango en diferentes organizaciones, arrojó resultados que sustentan la relación entre la orientación hacia el intraemprendimiento y la renovación definida y alcanzada por la organización.

En un estudio empírico realizado en Suecia, Samuelsson y Dahlqvist (2005) analizaron si las innovaciones intraemprendedoras se presentan más en las empresas nuevas o en las ya establecidas; encontraron que en promedio la mayoría de emprendimientos innovadores se desarrollan dentro de organizaciones más antiguas, y que los recursos y capacidades que han logrado acumular estas empresas se constituyen en un factor diferenciador al respecto.

Zhao (2005) buscando aportar al entendimiento de la relación entre emprendimiento y la innovación en las organizaciones, realizó un estudio de casos múltiples con seis 
empresas innovadoras de Australia. Encontró que existe una relación positiva, directa y complementaria entre los factores observados, y que en entornos cambiantes la combinación de ambos es vital para el éxito organizativo, así mismo concluyó que el estilo de dirección y en general la cultura organizacional son factores que influyen en el comportamiento innovador de la firma.

En Colombia Garzón (2004) realizó un trabajo con PYMES de Bogotá para observar el papel de los altos intraemprendedores y la cultura intraemprendedora en los procesos de innovación; encontró que los factores que facilitan el trabajo intraemprendedor en las PYMES son en orden jerárquico: el apoyo a las ideas innovadoras de los colaboradores, la identidad y el sentido de pertenencia con el equipo y la empresa, la autonomía, una estructura organizacional flexible, una adecuada relación desempeñopremio para el colaborador y la tolerancia institucional al conflicto.

Martins y Terblanche (2003) estudiaron los elementos de la cultura organizacional que influyen sobre el desarrollo de la creatividad y la innovación en las empresas, obteniendo cómo resultado que son especialmente el fomento de la generación de ideas y la toma de riesgos, el aprendizaje continuo, el soporte para afrontar el cambio y la competencia, y el apoyo en caso de cometer errores o en casos de conflictos intraorganizacionales.

Claver et al. (1998), en un trabajo que analiza el origen de la innovación tecnológica y las condiciones más importantes para que se produzca en la organización, encuentran que se requiere de: preparación técnica, un factor humano preparado, recursos financieros, pero sobre todo de una cultura organizacional favorable al cambio; y que todos estos factores son determinantes para el éxito de la estrategia innovadora de la firma.

Partiendo de los aportes mencionados se plantean la siguiente hipótesis:

H2. Las MIPYME con mayor cultura de intraemprendimiento son más innovadoras

\subsection{METODOLOGÍA DE LA INVESTIGACIÓN}

\subsubsection{Obtención de la muestra y recolección de datos}

Las empresas objeto de este estudio son hoteles, agencias de viajes y restaurantes, las cuales forman parte del sector turístico de Colombia. Para elaborar el marco muestral se utilizaron las bases de datos de afiliados a las respectivas agremiaciones: COTELCO ${ }^{5}$ para los hoteles, ANATO $^{6}$ para las agencias de viaje y ACODRES $^{7}$ para los restaurantes,

\footnotetext{
${ }^{5}$ COTELCO es la Asociación Hotelera de Colombia. www.cotelco.org

${ }^{6}$ ANATO es la Asociación Colombiana de Agencias de Viaje y Turismo. www.anato.org

${ }^{7}$ ACODRES es la Asociación Colombiana de la Industria Gastronómica. www.acodres.com.co
} 
identificándose un total de 2.012 organizaciones. Las empresas se seleccionaron de manera aleatoria, se solicitaron 300 citas y 68 firmas aceptaron participar de la investigación. Esto representa un margen de error de 9.5 con un margen de confianza del 95\%. La información se recogió entre los meses de noviembre del 2010 y enero del 2011, la metodología utilizada fue la entrevista personal, aplicándose un cuestionario especialmente diseñado para este trabajo. Las 68 encuestas realizadas fueron válidas.

La tabla 1 muestra la distribución de la muestra por sector de actividad y tamaño de la empresa.

\section{Tabla 1. Distribución de la muestra}

\begin{tabular}{|l|c|c|c|c|}
\hline Tamaño de la empresa & $\begin{array}{c}\text { Micro de } \\
\mathbf{1} \text { a } \mathbf{1 0} \\
\text { Sector de actividad }\end{array}$ & $\begin{array}{c}\text { Pequeña de } \\
\mathbf{1 1} \text { a 50 } \\
\text { trabajadores }\end{array}$ & $\begin{array}{c}\text { Mediana } \\
\mathbf{5 1} \text { a 200 } \\
\text { trabajadores }\end{array}$ & $\begin{array}{c}\text { Número de } \\
\text { empresas }\end{array}$ \\
\hline Hoteles & 11 & 15 & 3 & $\mathbf{2 9}$ \\
\hline Agencias de viajes & 10 & 12 & 2 & $\mathbf{2 4}$ \\
\hline Restaurantes & 8 & 6 & 1 & $\mathbf{6 8}$ \\
\hline Total & $\mathbf{2 9}$ & 33 & 6 & $\mathbf{6 8}$ \\
\hline
\end{tabular}

Fuente: elaboración propia.

\subsubsection{Medición de variables}

Variable cultura intraemprendedora

Para medir esta variable en la investigación (véase tabla 2, partiendo de una amplia revisión de trabajos teóricos y empíricos, se desarrolló un cuestionario que contempla cinco elementos: 1) autonomía para los colaboradores, 2) tolerancia al riesgos y a los errores, 3) compensación e incentivos, 4) trabajo en equipo, y 5) soporte de la gerencia y flexibilidad en la estructura corporativa. La tabla 9 presenta el cuestionario aplicado, mostrando cómo cada pregunta se soporta en los aportes de los autores revisados. 


\section{Tabla 2. Elementos de la Cultura Intraemprendedora}

\begin{tabular}{|c|c|c|}
\hline $\begin{array}{c}\text { VARIABLE } \\
\text { CONSIDERADA }\end{array}$ & PREGUNTAS & $\begin{array}{c}\text { AUTORES Y ENFOQUES DE } \\
\text { REFERENCIA }\end{array}$ \\
\hline $\begin{array}{l}\text { Autonomía para los } \\
\text { colaboradores. }\end{array}$ & $\begin{array}{l}\text { ¿En su organización es permitido que los } \\
\text { funcionarios inicien algunos proyectos sin tener } \\
\text { que consultarlo con los directivos? } \\
\text { ¿En su organización se persuade más que se } \\
\text { obliga a los funcionarios para que participen en } \\
\text { nuevos proyectos? } \\
\text { ¿Los colaboradores pueden tomar decisiones } \\
\text { autónomamente en el desarrollo de los proyectos } \\
\text { institucionales? }\end{array}$ & $\begin{array}{l}\text { Varela e Irizar, 2009; Moriano et al. } \\
\text { 2009; Garzón, 2005; Sathe, 2003; } \\
\text { Hornsby et al. 2002; Ross, 1987; } \\
\text { Girard, 1989, Pinchot III, 1985. }\end{array}$ \\
\hline $\begin{array}{c}\text { Tolerancia al riesgo y } \\
\text { a los errores }\end{array}$ & $\begin{array}{l}\text { ¿En su empresa las personas que toman riesgos } \\
\text { son valoradas y bien vistas, aunque algunas } \\
\text { veces se equivoquen? } \\
\text { ¿La empresa estimula que los colaboradores } \\
\text { tomen riesgos calculados? }\end{array}$ & $\begin{array}{l}\text { Varela e Irizar, 2009; Garzón, 2005; } \\
\text { Chen et al. 2005; Kyriakopoulos et } \\
\text { al. 2004; Antoncic, 2003; Morris y } \\
\text { Kuratko, 2002; Wood, 2004; } \\
\text { Hornsby et al. 2002; Girard, 1989; } \\
\text { Ross, 1987; Pinchot III, 1985. }\end{array}$ \\
\hline $\begin{array}{l}\text { Compensación e } \\
\text { incentivos }\end{array}$ & $\begin{array}{l}\text { ¿En la empresa a las personas que generan o } \\
\text { impulsan proyectos novedosos se les reconoce } \\
\text { públicamente? } \\
\text { ¿La empresa recompensa económicamente a los } \\
\text { colaboradores que generan nuevas ideas o } \\
\text { proyectos? }\end{array}$ & $\begin{array}{l}\text { Varela e Irizar, 2009; Moriano et al. } \\
\text { 2009; Van Brusel y Ulijn 2008; } \\
\text { Manimala, 2006; Chrístensen, 2005; } \\
\text { Garzón, 2005; Wood, 2004; } \\
\text { Hornsby et al. 2002; Pinchot III, } \\
1985 \text {. }\end{array}$ \\
\hline Trabajo en equipo & $\begin{array}{l}\text { ¿En la organización está bien vista la generación } \\
\text { espontanea de equipos para asuntos laborales? } \\
\text { ¿La empresa con frecuencia fomenta el trabajo } \\
\text { entre colaboradores de diferentes áreas y/o } \\
\text { niveles jerárquicos? }\end{array}$ & $\begin{array}{l}\text { Varela e Irizar, 2009; Manimala, } \\
\text { 2006; Garzón, 2005; Kyriakopoulos } \\
\text { et al. 2004; Sathe, 2003; Morris et } \\
\text { al. 1993; Ross, 1987; Pinchot III, } \\
\text { 1985. }\end{array}$ \\
\hline $\begin{array}{l}\text { Soporte de la gerencia } \\
\text { y flexibilidad en la } \\
\text { estructura corporativa }\end{array}$ & $\begin{array}{l}\text { ¿Es frecuente que las directivas se la jueguen por } \\
\text { los proyectos de sus colaboradores? } \\
\text { ¿Existe un programa institucional para fomentar } \\
\text { la iniciativa de los colaboradores? } \\
\text { ¿Es frecuente que en la empresa se apoyen } \\
\text { nuevos proyectos así no hayan estado en el plan } \\
\text { estratégico o el presupuesto previamente } \\
\text { aprobado? } \\
\text { ¿Las directivas permiten que los colaboradores } \\
\text { usen parte de su tiempo laboral para la } \\
\text { planeación y/o el desarrollo de los proyectos } \\
\text { auto iniciados? }\end{array}$ & $\begin{array}{l}\text { Varela e Irizar, 2009; Moriano et al. } \\
\text { 2009; Chen et al. 2005; Garzón, } \\
\text { 2005; Wood, 2004; Kyriakopoulos } \\
\text { et al. 2004; Martins y Terblanche, } \\
\text { 2003; Sathe, 2003; Hornsby et al. } \\
\text { 2002; Pinchot III, } 1985\end{array}$ \\
\hline
\end{tabular}

Fuente: elaboración propia.

Las preguntas se presentan en una escala Likert de 5 puntos, donde 1 significa que el encuestado está nada de acuerdo y 5 que está totalmente de acuerdo. De igual manera en 
la tabla señalada se indica cómo el estadistico Alpha de Cronbach valida la escala utilizada. El Alpha de Cronbach es habitualmente utilizado como medida de fiabilidad respecto a un conjunto de dos o más ítems de un constructo (en donde los valores van desde 0 a 1 , considerándose de 0.60 hasta 0.70 el límite inferior de aceptabilidad (Hair et al. 1999).

Variable de rendimiento o desempeño organizacional

Para medir esta variable, cómo se hizo en la investigación presentada en el primer capítulo de la tesis, se utiliza la metodología de Quinn y Rohrbaugh (1983), ya que es una de las más aceptadas a nivel mundial, habiéndose empleado para correlacionar el rendimiento con variables cómo la innovación (Maldonado et al. 2009; Van Auken et al. 2008; Bastida y García, 2005); la transferencia de conocimientos (Rodríguez, 2007); y la cultura organizacional (Tseng, 2010).

Para valorar los distintos modelos se utilizaron 12 ítems ( 3 por cada modelo) con una escala tipo Likert de 1 a 5 . La variable que representa cada modelo se construye a partir de la media aritmética de los tres ítems, resultando un rango teórico de 1 a 5. Para validar estas medidas se verifica la fiabilidad de las escalas a través del estadístico Alpha de Cronbach. En la tabla 3 se expone el detalle de los ítems utilizados así cómo el valor de la validación de la escala.

\section{Tabla 3. Variables de rendimiento}

\begin{tabular}{|l|l|c|}
\hline & $\begin{array}{l}\text { Indique cuál ha sido la evolución de los siguientes } \\
\text { aspectos en su empresa en los dos últimos años: } \\
\text { (1=Situación muy desfavorable, 5= Situación muy } \\
\text { favorable) }\end{array}$ & \\
\hline $\begin{array}{l}\text { Modelo } \\
\text { Procesos Internos }\end{array}$ & $\begin{array}{l}\text {-Mejora en la calidad del producto } \\
\text {-Mejora en la coordinación de procesos internos } \\
\text {-Mejor organización de las tareas del personal }\end{array}$ & \multirow{2}{*}{$\alpha$ de Cronbach $=0.766$} \\
\hline Sistema Abierto & $\begin{array}{l}\text {-Aumento de la satisfacción de los clientes } \\
\text {-Incremento de la habilidad de adaptación a las } \\
\text { necesidades de los mercados } \\
\text {-Mejora de la imagen de empresa y de sus productos }\end{array}$ & \\
\hline $\begin{array}{l}\text { Modelo } \\
\text { Racional }\end{array}$ & $\begin{array}{l}\text {-Incremento de la cuota de mercado } \\
\text {-Incremento de la rentabilidad } \\
\text {-Incremento de la productividad }\end{array}$ & \\
\hline Modelo & $\begin{array}{l}\text {-Aumento de la motivación de los trabajadores } \\
\text { Relaciones Humanas }\end{array}$ & $\begin{array}{l}\text {-Reducción de la rotación de personal } \\
\text {-Reducción del absentismo laboral }\end{array}$ \\
\hline
\end{tabular}

Fuente: elaboración propia. 


\section{Variable de innovación}

Cómo se realizó en la investigación precedente, para medir el grado de innovación se tuvieron en cuenta los diferentes conceptos recopilados en la revisión de trabajos realizada, y en especial en el de AECA (1995) que señala que la innovación puede clasificarse en tecnológica y organizacional. Las innovaciones tecnológicas incluyen las novedades significativas en productos y en procesos; la innovación organizacional por su parte corresponde a los cambios introducidos a la estructura administrativa de la empresa, a la comercialización, a la financiación, etc. Esta misma clasificación ha sido usada en diferente trabajos cómo los de Maldonado et al. 2009; Van Auken et al. 2008; Naranjo et al. 2008.

Para medir esta variable, se utilizó una medida multicriterio de varios ítems por cada tipo de innovación, con una escala Likert de cinco puntos (de 1 = grado de innovación poco importante a $5=$ grado de innovación muy importante). La variable innovación en productos está compuesta por la media aritmética de dos ítems: 1) cambios o mejoras en productos o servicios existentes, y 2) comercialización de nuevos productos. La variable innovación en procesos está compuesta por la media aritmética de dos ítems: 1) mejoras o cambios en los procesos productivos, y 2) adquisición de nuevos equipos. Y la variable innovación en gestión está compuesta por la media aritmética de tres ítems: 1) gestión de dirección, 2) compras y aprovisionamientos, y 3) comercialización y ventas.

Para validar estas medidas se verifica la fiabilidad de las escalas a través del estadístico Alpha de Cronbach (tabla 4). El valor del estadístico indica la validez de la escala utilizada.

\section{Tabla 4. Tipos de innovación}

\begin{tabular}{|l|l|c|}
\hline & $\begin{array}{l}\text { Indique cuál ha sido el grado de innovación realizado en } \\
\text { su empresa en los dos últimos años: (1= Poco } \\
\text { importante, 5= Muy importante) }\end{array}$ & Validación escalas \\
\hline $\begin{array}{l}\text { Innovación } \\
\text { en productos }\end{array}$ & $\begin{array}{l}\text { 1) Cambios o mejoras en productos o servicios existentes, y } \\
\text { 2) Comercialización de nuevos productos. }\end{array}$ & $\alpha$ de Cronbach = 0.771 \\
\hline $\begin{array}{l}\text { Innovación } \\
\text { en procesos }\end{array}$ & $\begin{array}{l}\text { 1) Mejoras o cambios en los procesos productivos, y } \\
\text { 2) Adquisición de nuevos equipos }\end{array}$ & \\
\hline $\begin{array}{l}\text { Innovación } \\
\text { en gestión }\end{array}$ & $\begin{array}{l}\text { 1) Gestión de dirección, } \\
\text { 2) Compras y aprovisionamientos, y } \\
\text { 3) Comercialización y ventas }\end{array}$ & \\
\hline
\end{tabular}

Fuente: elaboración propia.

Las estimaciones se realizan a partir de regresiones lineales múltiples por MCO. Inicialmente se comprobó en todos los modelos que los regresores presentan un factor de inflación de la varianza (VIF) menor a 1.831, por lo que se descartó la presencia de multicolinealidad. 


\subsubsection{Modelos analizados}

Para contrastar las hipótesis planteadas en este trabajo se consideraron los siguientes modelos de investigación:

H1. Las empresas con mayor cultura intraemprendedora tienen mejor rendimiento.

$\operatorname{Re} n \operatorname{dim}_{\text {iento }_{i}}=b_{0}+b_{1}$ Auton $_{i}+b_{2}$ Toler $_{i}+b_{3}$ Comp $_{i}+b_{4} \operatorname{Tr}_{r} b_{i}+b_{5} \operatorname{Sop}_{i}+\varepsilon_{1}$

Dependiente $Y_{i}$

Rpi Rendimiento procesos internos

Rsa Rendimiento sistema abierto

$\mathrm{Rr} \quad$ Rendimiento racional

Rrh Rendimiento recursos humanos

Rgl Rendimiento global

\section{Explicativas (Factores de Intraemprendimiento)}

Auton: Autonomía.

Toler: Tolerancia al riesgo y a los errores.

Comp: Compensación e incentivos.

Trab: Trabajo en equipo.

Sop: Soporte de la gerencia y flexibilidad en la estructura corporativa.

H2. Las MIPYME con mayor cultura intraemprendedora son más innovadoras.

Innovación $_{i}=b_{0}+b_{1}$ Auton $_{i}+b_{2}$ Toler $_{i}+b_{3}$ Comp $_{i}+b_{4}$ Trab $_{i}+b_{5}$ Sop $_{i}+\varepsilon_{i}$

\section{Dependiente Innovación}

Innovación en productos.

Innovación en procesos.

Innovación en gestión.

Innovación global.

\section{Explicativas (Factores de Intraemprendimiento)}

Auton: Autonomía.

Toler: Tolerancia al riesgo y a los errores.

Comp: Compensación e incentivos.

Trab: Trabajo en equipo.

Sop: Soporte de la gerencia y flexibilidad en la estructura corporativa. 


\subsection{ANALISIS DE RESULTADOS}

\subsubsection{Cultura de intraemprendimiento y rendimiento}

La tabla 5 presenta los datos descriptivos de las variables analizadas. En cuanto a las prácticas relacionadas con la cultura intraemprendedora se puede apreciar cómo los factores que presentan mayores valores son los de trabajo en equipo, compensación y tolerancia al riesgo, todos ellos superiores a 3 , mientras que prácticas cómo soporte de la gerencia y autonomía obtienen valores inferiores.

Tabla 5. Descriptivos de las variables

\begin{tabular}{|l|c|c|c|c|}
\hline & Media & $\begin{array}{c}\text { Desviación } \\
\text { Estándar }\end{array}$ & Min & Max \\
\hline CULTURA INTRAEMPRENDEDORA & 2.78 & 0.89 & 1 & 4 \\
Autonomía. & 3.04 & 1.04 & 1 & 5 \\
Tolerancia al riesgo. & 3.26 & 1.24 & 1 & 5 \\
Compensación e incentivos. & 3.28 & 1.03 & 1 & 5 \\
Trabajo en equipo. & 2.56 & 1.06 & 1 & 4 \\
Soporte de la gerencia y flexibilidad en la & & & & \\
estructura corporativa. & & & & \\
\hline RENDIMIENTO & 4.18 & 0.60 & 2 & 5 \\
Procesos internos. & 4.21 & 0.62 & 1 & 5 \\
Sistema abierto. & 3.82 & 0.84 & 1 & 5 \\
Racional. & 3.77 & 0.65 & 2 & 5 \\
Relaciones humanas. &
\end{tabular}

Fuente: elaboración propia.

Respecto a su rendimiento, las empresas analizadas consideran que estuvieron mejor en sus procesos internos, y en su sistema abierto (con medias superiores a 4), que en los aspectos del modelo racional y en los de relaciones humanas, donde obtienen valores inferiores aunque cercanos a dicha cifra.

Por su parte la tabla 6 muestra los resultados de las relaciones entre los factores de cultura intraemprendedora considerados: autonomía, tolerancia al riesgo y a los errores, compensación e incentivos, trabajo en equipo y, soporte y flexibilidad en la estructura organizacional, más su agregado que constituye el intraemprendimiento global; frente a los sistemas de rendimiento observados: procesos internos, sistema abierto, racional, relaciones humanas y su agregado o rendimiento global. 
Tabla 6. Cultura intraemprendedora y rendimiento

\begin{tabular}{|c|c|c|c|c|c|}
\hline \multirow[b]{2}{*}{ Intraemprendimiento } & \multicolumn{4}{|c|}{ Modelos de Rendimiento } & \multirow[b]{2}{*}{$\begin{array}{c}\text { Rendimiento } \\
\text { Global }\end{array}$} \\
\hline & $\begin{array}{l}\text { Procesos } \\
\text { internos }\end{array}$ & $\begin{array}{l}\text { Sistema } \\
\text { abierto }\end{array}$ & Racional & $\begin{array}{l}\text { Relaciones } \\
\text { humanas }\end{array}$ & \\
\hline Autonomía & n.s. & n.s & n.s & n.s & n.s. \\
\hline $\begin{array}{l}\text { Tolerancia al riesgo y a los } \\
\text { errores }\end{array}$ & n.s. & n.s & n.s & n.s & n.s. \\
\hline Compensación e incentivos & n.s. & n.s & n.s & n.s & n.s. \\
\hline Trabajo en equipo & n.s. & n.s & n.s & $\begin{array}{l}0.239 * * \\
(2.000)\end{array}$ & n.s. \\
\hline $\begin{array}{l}\text { Soporte de la gerencia y } \\
\text { flexibilidad en la estructura } \\
\text { corporativa }\end{array}$ & $\begin{array}{l}0.147^{*} \\
(1.808)\end{array}$ & $\begin{array}{l}0.324 * * * \\
(2.779)\end{array}$ & n.s & n.s & $\begin{array}{l}0.254 * * \\
(2.134)\end{array}$ \\
\hline $\begin{array}{l}\mathrm{F} \\
\mathrm{R}^{2} \text { ajustado }\end{array}$ & $\begin{array}{l}2.247 * \\
0.019\end{array}$ & $\begin{array}{l}7.724 * * * \\
0.091\end{array}$ & n.s & $\begin{array}{l}4.002 * * \\
0.43\end{array}$ & $\begin{array}{c}4.553 * * \\
0.050\end{array}$ \\
\hline $\begin{array}{c}\text { Intraemprendimiento } \\
\text { global }\end{array}$ & n.s & $\begin{array}{l}0.245 * * \\
(2.051)\end{array}$ & n.s & n.s & n.s \\
\hline $\begin{array}{l}\mathrm{F} \\
\mathrm{R}^{2} \text { ajustado }\end{array}$ & n.s & $\begin{array}{l}4.209 * * \\
0.046\end{array}$ & n.s & n.s & n.s \\
\hline
\end{tabular}

Regresión Lineal Múltiple por MCO.

Debajo de cada coeficiente estandarizado, entre paréntesis, valor del estadístico t-student

* $\mathrm{p} \leq 0.1 ; * * \quad \mathrm{p} \leq 0.05 ; * * * \mathrm{p} \leq 0.01 ; \mathrm{n}$.s.: no significativo

Fuente: elaboración propia.

Efectos de la autonomía, la tolerancia al riesgo y a los errores, y la compensación e incentivos sobre el rendimiento

No se encuentran estadísticos significativos en estas relaciones. Los hallazgos del trabajo en este aspecto y sus diferencias con los de Agca et al. (2009) quienes encuentran que la tolerancia al riesgo y la toma de riesgos si influyen positivamente en el desempeño de la empresa, pueden obedecerse a que cómo se aprecia en los datos descriptivos que se mostraron previamente, las empresas turísticas en Colombia hacen una relativamente baja aplicación de las practicas asociadas a estos factores de intraemprendimiento; pero también a las diferencias culturales propias entre países y organizaciones de distintos continentes.

\section{Efectos del trabajo en equipo sobre el rendimiento}

Se encuentra impacto positivo y significativo sobre el modelo de rendimiento en relaciones humanas $\left(0.239^{* *}\right)$, este resultado indica que en la medida que se fomenta el trabajo entre personas de diferentes áreas y niveles jerárquicos, se presenta mayor satisfacción y motivación en los colaboradores de la organización, así cómo disminución en 
su ausentismo y rotación. Estos resultados coinciden con los de Morris et al. (1993) en que un ambiente de colectivismo tiene impacto positivo sobre el desempeño de la firma.

Efectos del soporte de la gerencia y la flexibilidad en la estructura corporativa sobre el rendimiento

Se encuentran impactos positivos y significativos sobre los modelos de procesos internos, sistema abierto y rendimiento global $(0.147 *, 0.324 * * *, 0.254 * *$ respectivamente). Estos resultados muestran que cuando en las MIPYME existen programas que fomentan la iniciativa de los colaboradores, se asignan recursos a sus proyectos y se les permite utilizar parte de su tiempo laboral en ellos, mejora el desempeño general de la firma, pero especialmente en cuanto a: 1) la calidad de sus productos y servicios, 2) la eficiencias de sus procesos operativos, 3) la organización de las tareas del personal, 4) la satisfacción de sus clientes, 5) la rapidez de adaptación a las necesidades del mercado y 5) la imagen de la empresa. Estos hallazgos coinciden con los de los de Covin y Slevin (1991) en qué la flexibilidad y adaptabilidad en la estructura corporativa conduce a mejoras en el rendimiento de la empresa.

Se halla validez global de modelos en las relaciones con procesos internos, sistema abierto, relaciones humanas, y rendimiento global, ya que sus F son significativas $\left(2.247^{*}\right.$, $7.724 * * *, 4.002 * *, 4.553 * *$ respectivamente).

\section{Efectos del intraemprendimiento global sobre el rendimiento}

El intraemprendimiento global presenta impacto positivo y significativo sobre el sistema abierto $\left(0.245^{* *}\right)$, hallándose también validez global del mismo modelo ya que el estadístico de su F es significativo (4.209**). Este hallazgo muestra que la sumatoria de prácticas de cultura intraemprendedora utilizadas por las MIPYME, mejora la satisfacción de sus clientes, su rapidez de adaptación a las necesidades del mercado y la imagen de la empresa, coincidiendo con los de Benítez-Amado et al. (2010) y los de Kyriakopoulos et al. (2004), quienes respectivamente encuentran que el intraemprendimiento es un positivo predictor del desempeño comercial de la firma y de su orientación al mercado.

\subsubsection{Cultura de intraemprendimiento e innovación}

La tabla 7 presenta los datos descriptivos de las variables analizadas. Puede observarse que en promedio las MIPYME del sector turístico colombiano son más innovadoras que intraemprendedoras. Y que desarrollan más innovaciones de productos/servicios y menos en gestión, aunque en todos los casos los valores se sitúan por encima de 3 . 
Tabla 7. Descriptivos de las variables

\begin{tabular}{|l|c|c|c|c|}
\hline & Media & $\begin{array}{c}\text { Desviación } \\
\text { Estándar }\end{array}$ & Min & Max \\
\hline CULTURA INTRAEMPRENDEDORA & 2.78 & 0.89 & 1 & 4 \\
Autonomía. & 3.04 & 1.04 & 1 & 5 \\
Tolerancia al riesgo y a los errores. & 3.26 & 1.24 & 1 & 5 \\
Compensación e incentivos. & 3.28 & 1.03 & 1 & 5 \\
Trabajo en equipo. & 2.56 & 1.06 & 1 & 4 \\
Soporte de la gerencia y flexibilidad en la & & & & \\
estructura corporativa. & 3.69 & 1.31 & 0 & 5 \\
\hline INNOVACIÓN & 3.42 & 1.39 & 0 & 5 \\
Productos/servicios. & 3.10 & 1.44 & 0 & 5 \\
Procesos. & & & \\
Gestión. &
\end{tabular}

Fuente: elaboración propia.

Por su parte la tabla 8 muestra la relación entre los cinco factores de cultura de intraemprendimiento: autonomía, tolerancia al riesgo y a los errores, compensación e incentivos, trabajo en equipo, soporte y flexibilidad en la estructura corporativa, más el agregado de dichos factores que constituye el intraemprendimiento global; frente a los tipos de innovación considerados: productos, procesos y gestión, más su agregado que representa la innovación global. Los resultados se describen a continuación:

Efectos de la autonomía, la tolerancia al riesgo y a los errores, y la compensación e incentivos sobre la innovación

No se encontró un impacto significativo de estos tres factores de la cultura intraemprendedora sobre los diferentes tipos de innovación. Estos resultados difieren de los del estudio de Manimala (2006), en el cual la compensación aparece como un factor importante para que se produzcan innovaciones en la empresa, y con los de Garzón (2004) quien encuentra que la compensación y la autonomía tienen el mismo efecto.

Nuestros resultados en este aspecto y sus diferencias con los otros señalados, pueden deberse a que cómo se pudo apreciar en los análisis descriptivos, las MIPYME turísticas de Colombia, hacen una relativamente baja aplicación de las practicas asociadas a estos factores de intraemprendimiento, por lo cual no alcanzan a impactar su desempeño innovador.

\section{Efectos del trabajo en equipo sobre la innovación}

El trabajo en equipo cómo factor de la cultura de intraemprendimiento tiene asociados coeficientes positivos y significativos para sus relaciones con la innovación en 
gestión y la innovación global $(0,347 * * *, 0,286 * *$ respectivamente). Ello indica que en la medida en que se fomenta el trabajo entre personas de diferentes áreas y niveles jerárquicos se genera en la organización una mayor innovación en los sistemas de dirección y gestión, compras y aprovisionamiento, comercialización y ventas; de igual manera que en términos generales, la empresa se vuelve más innovadora. Estos resultados confirman los de Kuz (2010) y los de Garzón (2004), quienes encuentran que un ambiente colaborativo y la identificación del empleado con la empresa y el equipo de trabajo, son fundamentales para que se dé la innovación corporativa.

Efectos del soporte de la gerencia y la flexibilidad de la estructura corporativa sobre la innovación

Este factor de la cultura intraemprendedora tiene asociado un coeficiente positivo y significativo en su relación con la innovación en procesos $\left(0,315^{* * *}\right)$. Esto significa que cuando en las MIPYME se apoyan las iniciativas de los colaboradores, se asignan recursos a los proyectos presentados por estos y se les permite utilizar parte de su tiempo laboral en ellos, mejora la innovación en los procesos de producción, y el aprovechamiento de los equipos adquiridos. Estos hallazgos confirman los de Kuz (2010), los de Garzón (2004) y los de Martins y Terblanche (2003), en cuanto a que este factor de intraemprendimiento fomenta la innovación empresarial; pero en especial ratifican los de Khazanchi et al. (2007) quienes encuentran que la flexibilidad fomenta la innovación en procesos productivos. Por otra parte los resultados de este trabajo difieren de los de Lee et al. (2008) quienes sí encuentran un efecto positivo del soporte de la gerencia y la flexibilidad de la estructura corporativa sobre la innovación en gestión y en productos/servicios.

Se comprueba la validez global de los modelos que relacionan el intraemprendimiento con la innovación en procesos, gestión e innovación global, puesto que sus $\mathrm{F}$ son significativas $(7,262 * *, 9,029 * * *, 5,896 * *$ respectivamente).

\section{Efectos del intraemprendimiento global sobre la innovación}

Para el agregado de los diferentes factores de cultura intraemprendedora o intraemprendimiento global, se encuentran coeficientes positivos y significativos en su relación con la innovación en procesos, en gestión y en innovación global $(0,249 * *$, $0,275^{* *}, 0,254 *$ respectivamente). Esto indica que si la organización es más intraemprendedora, mejora su desempeño innovador en cuanto a procesos de: producción o servicios, aprovechamiento de los equipos adquiridos, dirección, gestión, compras y aprovisionamiento, comercialización y ventas; así cómo a nivel general. Estos resultados confirman los de Amo y Kolvereid (2005) y los de Zhao (2005), quienes hallan que las prácticas asociadas a la cultura intraemprendedora influyen positivamente sobre la renovación corporativa y en el desempeño innovador de la compañía. 
Se encuentra validez global de los modelos para las mismas relaciones: procesos, gestión e innovación global ya que sus $\mathrm{F}$ tienen valores significativos $\left(4,358^{* *}, 5,414 * *, 4,549 * *\right.$ respectivamente).

Tabla 8. Cultura de intraemprendimiento e innovación

\begin{tabular}{|c|c|c|c|c|}
\hline \multirow[b]{2}{*}{ Intraemprendimiento } & \multicolumn{3}{|c|}{ Innovación } & \multirow[b]{2}{*}{$\begin{array}{c}\text { Innovación } \\
\text { Global }\end{array}$} \\
\hline & Productos & Procesos & Gestión & \\
\hline Autonomía & n.s & n.s & n.s & n.s \\
\hline Tolerancia al riesgo & n.s & n.s & n.s & n.s \\
\hline Compensación & n.s & n.s & n.s & n.s \\
\hline Trabajo en equipo & n.s & n.s & $\begin{array}{l}0,347 * * * \\
(3,005)\end{array}$ & $\begin{array}{l}0,286 * * \\
(2,248)\end{array}$ \\
\hline $\begin{array}{l}\text { Soporte de gerencia y } \\
\text { flexibilidad en la estructura } \\
\text { organizacional }\end{array}$ & n.s & $\begin{array}{l}0,315^{* * *} \\
(2,695)\end{array}$ & n.s & n.s \\
\hline $\begin{array}{l}\mathrm{F} \\
\mathrm{R}^{2} \text { ajustado }\end{array}$ & n.s & $\begin{array}{l}7,262 * * * \\
0,085\end{array}$ & $\begin{array}{l}9,029 * * * \\
0,107\end{array}$ & $\begin{array}{l}5,896 * * \\
0,068\end{array}$ \\
\hline $\begin{array}{c}\text { Intraemprendimiento } \\
\text { global }\end{array}$ & n.s & $\begin{array}{l}0,249 * * \\
(2,088)\end{array}$ & $\begin{array}{l}0,275 * * \\
(2,327)\end{array}$ & $\begin{array}{l}0,254 * * \\
(2,133)\end{array}$ \\
\hline $\begin{array}{l}\mathrm{F} \\
\mathrm{R}^{2} \text { ajustado }\end{array}$ & n.s & $\begin{array}{l}4,358 * * \\
0,248\end{array}$ & $\begin{array}{l}5,414 * * \\
0,062\end{array}$ & $\begin{array}{l}4,549 * * \\
0,050\end{array}$ \\
\hline
\end{tabular}

Regresión Lineal Múltiple por MCO.

Debajo de cada coeficiente estandarizado, entre paréntesis, valor del estadístico t-student

* $\mathrm{p} \leq 0,1 ; * * \quad \mathrm{p} \leq 0,05 ; * * * \mathrm{p} \leq 0,01 ; \mathrm{n}$.s.: no significativo

Fuente: elaboración propia

De acuerdo con los resultados presentados, se pueden confirmar las hipótesis planteadas en este trabajo, pero parcialmente, dado que cómo se indicó previamente las prácticas asociadas a la cultura de intraemprendimiento no tuvieron efectos significativos sobre el rendimiento racional ni sobre la innovación en productos.

\subsection{CONCLUSIONES}

Según los hallazgos de esta investigación, las empresas MIPYME del sector turístico en Colombia tienen un promedio apenas aceptable de utilización global de las prácticas asociadas a la cultura intraemprendedora (2,98 sobre 5); no obstante a ello su impacto es significativo en las relaciones con su medio externo, y en su comportamiento innovador global (pero en especial en el de sus procesos productivos y de su gestión). 
Lo señalado demuestra que el emprendimiento corporativo puede ser considerado una herramienta a utilizar por aquellas MIPYME que desean o necesitan mejorar su adaptación a los cambios del mercado y especialmente a las preferencias de sus clientes, así como su nivel global de innovación y en particular el de su operación productiva, gerencial y comercial.

Los resultados de la investigación ponen también de manifiesto que de los factores de cultura intraemprendedora considerados, el soporte de la gerencia y la flexibilidad en la estructura corporativa es el menos implementado en la MIPYME turística colombiana, pero que aún así es el de mayor impacto positivo sobre su rendimiento. Esto muestra claramente que una mayor aplicación de prácticas relacionadas con este factor de intraemprendimiento, podría generarles mejoras realmente importantes en su desempeño.

El hecho de que el trabajo en equipo se presente en esta investigación como el factor de intraemprendimiento con mayor impacto positivo sobre la innovación de las empresas, reafirma la importancia de estimular la sinergia que se produce al combinar la capacidad creativa de los colaboradores de diferentes niveles y/o departamentos.

Por su parte que el intraemprendimiento global haya mostrado impacto positivo en la mayor parte de los tipos de innovación observados, muestra que son justificados los esfuerzos que se hagan para implementar en las MIPYME turísticas las diferentes prácticas asociadas a la cultura de intraemprendimiento, ya que ello mejora su desempeño innovador y por ende su nivel competitivo; teniendo eso si que buscarse nuevas prácticas de intraemprendimiento que logren estimular su innovación en productos/servicios.

La contribución de esta investigación al contexto de la MIPYME es relevante y tiene implicaciones importantes, ya que en Colombia los prestadores turísticos son principalmente micro y pequeñas empresas, que requieren de apoyo para alcanzar mejores estándares de calidad y competitividad (CONPES, 2005). Los resultados muestran a los empresarios MIPYME las ventajas de establecer o fortalecer el intraemprendimiento en su organización. A las entidades públicas y privadas de fomento a la actividad empresarial, les ofrece nuevas perspectivas para reforzar sus programas de intervención en temáticas de mayor impacto en el rendimiento y la innovación de las empresas. A la academia le proporciona ideas para que sus actividades de investigación, docencia y extensión contribuyan de manera más significativa en el fortalecimiento de una cultura de emprendimiento corporativo que estimule la competitividad y el desarrollo empresarial y en consecuencia el de las regiones y los países.

La investigación presenta entre otras las siguientes limitaciones: el tamaño de la muestra es relativamente pequeño lo que conlleva un margen de error de 9.5 con un margen de confianza del $95 \%$. Aunque este margen de error está dentro de un rango aceptable, lo preferible hubiera sido no superar uno de 5 puntos. En este sentido, una muestra más amplia hubiera permitido analizar los resultados discriminándolos según el tamaño de las empresas (micro, pequeñas y medianas) y según su sector específico de actividad (hoteles, 
restaurantes, y agencias de viaje). Por otra parte, la encuesta fue aplicada solamente a los directivos de la empresa, siendo deseable utilizar informantes de diferente nivel para limitar las posibilidades de sesgos perceptuales (Cameron y Quinn, 1999; Naranjo et al., 2008).

Futuros estudios podrían retomar esta línea de investigación para analizar elementos que quedan pendientes, como los factores de la cultura intraemprendedora predominantes según el tamaño de las empresas y en cada actividad específica del sector económico. De igual manera, se podrían añadir variables de control como la edad de la empresa, la condición de ser o no de tipo familiar, el género del gerente y su grado de escolaridad. También se podrían incluir otros actores del turismo, tales como las empresas de transporte terrestre y las de alquiler de vehículos. 
CAPITULO 3

CULTURA ORGANIZACIONAL, INNOVACIÓN Y RENDIMIENTO EN LAS MIPYMES TURISTICA DE COLOMBIA. UN ESTUDIO MULTIPLE DE CASOS 


\subsection{INTRODUCCIÓN}

La presente investigación analiza desde una perspectiva cualitativa la forma en cómo se manifiesta la cultura organizacional en las MIPYME del sector turístico de Colombia, y su efecto sobre la innovación y el rendimiento. La cultura organizacional puede constituirse en un recurso o medio para alcanzar objetivos, y si añade valor, es diferente a la cultura de otras organizaciones y no es fácilmente imitable por los competidores, se convierte en ventaja competitiva y en un "activo estratégico" que sustenta la innovación, el desempeño y el éxito empresarial (Barney, 1986).

La innovación, al igual que la cultura es una construcción social; es importante recordar que las personas en cuanto a los valores, las actitudes y los conocimientos que poseen, actúan como eje central de la innovación organizacional (Gasalla, 1999). Existe, por tanto, relación entre la cultura que tiene una organización y las innovaciones que pueden crear, y de manera contraria, las innovaciones son factores que generan un impacto significativo en la creación de los patrones culturales de las sociedades y las empresas (Cornejo y Muñoz, 2009).

El seguimiento y control del rendimiento es una de las labores más importantes de la gestión empresarial y la mayoría de las organizaciones lo consideran imprescindible para asegurar su supervivencia. Como por ejemplo, el cumplimiento de su misión, sus objetivos o sus metas; sin embargo desde los años setenta han surgido otras variables que se agregan al análisis, cómo la moral, la innovación, la adaptabilidad y la orientación al cambio (Lusthaus et al. 2002).

Diversos trabajos se han realizado acerca de la relación entre la cultura organizacional y diferentes elementos o factores de la empresa, frente a la innovación se pueden mencionar entre otros los de Kuz (2010), Blichfeldt (2009), Naranjo et al. (2008), Khazanchi et al. (2007), Zhao (2005), Lau y Ngo (2004), Malaver y Vargas (2004), Martins y Terblanche (2003), La Rovere y Hasenclever (2003), Claver et al. (1998), Maidique y Zirger (1984). La relación entre la cultura organizacional y el desempeño empresarial también ha sido objeto de trabajos como los de Tseng (2010), James y Connolly (2009); Duréndez y García (2008), Zhang et al. (2008), O'cass y Ngo (2007), Deshpande y Farle (2004), Kim et al. (2004), Sonrensen (2002), Ogbonna y Harris (2000) y Dávila (1999).

No obstante la gran cantidad de investigaciones sobre el efecto de la cultura organizacional en la innovación y el rendimiento, la mayor parte de dichos estudios han tenido como objeto las grandes corporaciones, siendo escaso el número de investigaciones que se centran en las MIPYMES, a pesar de que juegan un importante papel en la economía mundial, especialmente por la contribución al generación de empleo y al desarrollo de la comunidad en donde se ubican (Franco y Urbano, 2010), y que en el caso de Colombia representan el $99,9 \%$ de las empresas, generan un $63 \%$ del empleo y un $37 \%$ de la producción (DANE, 2005). 
Este trabajo busca contribuir a llenar el vacío señalado, y tiene por objetivo caracterizar y describir cualitativamente la cultura organizacional de las empresas MIPYME del sector turístico en Colombia, y analizar su impacto sobre su innovación y rendimiento. Para guiar el proceso se han planteado las siguientes preguntas: ¿Qué elementos caracterizan la cultura organizacional de las empresas del sector turístico en Colombia?, ¿Cómo influye la cultura organizacional en la innovación y el rendimiento de estas organizaciones? Para responder a estas preguntas se realiza un estudio múltiple de casos con cuatro hoteles MIPYME de Cali, Colombia.

En esta investigación se utiliza el estudio de casos ya que se pretende estudiar un fenómeno como un proceso dinámico y dentro de la realidad de su contexto. Este estudio según la tipología de (Yin, 1989) es de tipo exploratorio ya que busca aportar resultados que puedan ser utilizados para la formulación de hipótesis e investigaciones posteriores; y descriptivo por que intenta explicar cómo la cultura organizacional afecta a la innovación y el rendimiento de la MIPYME.

Se ha escogido el sector turístico dado que en los últimos años a nivel mundial es uno de los de más rápido crecimiento en generación de divisas y empleo (World Economic Forum, 2009), constituyendo para Colombia su tercer renglón de exportaciones después del petróleo y el carbón, por lo que el gobierno nacional ha decidido apoyarlo a través de sus políticas públicas de una forma decidida (CONPES, 2005).

El documento está estructurado de la siguiente manera, en primer lugar se presentan los estudios empíricos previos que aplican la metodología de estudio de casos; en segundo lugar se describe la metodología de investigación utilizada; luego se presentan los resultados y su discusión relacionando los conceptos abordados en la revisión teórica con los hallazgos empíricos de la investigación; finalmente se presentan las conclusiones, implicaciones del trabajo y futuras líneas de investigación.

\subsection{ESTUDIOS PREVIOS}

Existe un gran interés por estudiar empíricamente la cultura organizacional, la innovación empresarial, y la relación existente entre estos factores como se puede apreciar en los trabajos de Esparza y García (2011), Kuz (2010), Naranjo et al. (2008), Khazanchi et al. (2007), Lau y Ngo (2004), Martins y Terblanche (2003), Claver et al (1998), en cuanto a estudios de casos que aborden estas temáticas, se pueden señalar los siguientes:

Blichfeldt (2009) desarrolla un estudio de caso con una empresa turística de Dinamarca para conocer cómo se da el proceso de innovación en las PYME, encuentra que aquellas empresas que participan en redes empresariales, son más hospitalarias y buscan diferenciarse, tienden a ser más innovadoras que las que actúan de manera aislada, siendo esto un factor crítico para su desempeño y supervivencia. 
James y Connolly (2009) en un estudio de casos tomando como referencia el rendimiento de los estudiantes, analizan el efecto de la cultura organizacional en el desempeño de los colegios; hallan que la relación entre cultura y desempeño es mutua y no unidireccional.

Zhao (2005) en un estudio de casos múltiple con seis empresas innovadoras de Australia encontró que en general la cultura organizacional y en especial el liderazgo son factores que influyen en el comportamiento innovador de la firma.

Malaver y Vargas (2004) publican un estudio de casos realizado con 17 empresas industriales colombianas el cual tuvo por objeto identificar y describir los principales rasgos de las capacidades tecnológicas y de los procesos de innovación. Los resultados indican que los procesos de innovación se caracterizan por su informalidad, por no inscribirse en procesos planeados ni obedecer a una gestión estratégica de la tecnología y la innovación y por originarse en la solución de problemas de adaptación de tecnologías importadas, en la respuesta a las necesidades de los clientes o en el aprovechamiento de oportunidades de mercado.

La Rovere y Hasenclever (2003) encuentran en un estudio de casos múltiples realizado con PYMES del Brasil que las empresas estudiadas tienen una visión de corto plazo en la definición de estrategias competitivas y que no son capaces de identificar la importancia de la creación de conocimiento y del establecimiento de lazos de cooperación. Como resultado, las empresas utilizan las TICs de un modo muy limitado y sin efectos importantes en la competitividad.

Por su parte, Sonrensen (2002), siguiendo la línea de trabajo de autores como Kotter y Heskett (1992) y Gordon y Di Tomaso (1992), estudió cómo afectan las culturas fuertes la variabilidad del rendimiento en las empresas, encontrando que en entornos relativamente estables la facilitan, pero que a medida que aumenta su volatilidad, las ventajas decrecen dramáticamente.

Dávila (1999) realiza un estudio de caso en un colegio de México con la finalidad de encontrar los valores compartidos que conducen hacia un alto desempeño. Establece que es a través de la dirección, un liderazgo comprometido y el compromiso de los profesores, que se logran la definición y formación de una cultura vigorosa y un mejor desempeño.

Maidique y Zirger (1984), realizan un estudio múltiple de casos con 20 empresas de electrónica en los Estados Unidos de América para evidenciar los factores que influyen en el desempeño de la innovación en productos, encuentran que cómo factores de éxito están un gran entendimiento del consumidor, experticia en marketing, una buen margen de contribución planteado del producto para la empresa, una buena planeación del proceso de investigación y desarrollo, buena coordinación de los procesos de mercadeo, una temprana introducción del producto o tecnología en el mercado, unos buenos beneficios para el consumidor y un alto nivel de soporte gerencial. 
Con base en los elementos teóricos y los estudios previos expuestos, coherentemente con los objetivos de la investigación y en virtud de que los estudios cualitativos no consideran hipótesis por qué no siempre comprueban relaciones o encuentran causas que expliquen un fenómeno o acontecimiento (Stake, 2005), la presente investigación parte de la siguiente proposición general:

Proposición (Pp): La cultura organizacional influye en la innovación y el desempeño de las MIPYME.

Con el fin de poder establecer algunos indicadores que midan el comportamiento, la innovación y el desempeño, se establecen las siguientes proposiciones específicas que son las que se contrastarán con la realidad de la de las MIPYME:

Proposición (P1): la cultura organizacional de la empresa influye en sus prácticas y nivel innovador en cuanto a: productos y servicios, procesos, y gestión.

Proposición (P2): La cultura organizacional influye en el desempeño de las empresas en cuanto a: productos y servicios, procesos internos, relaciones externas, indicadores racionales y relaciones humanas. 


\subsection{METODOLOGÍA DE LA INVESTIGACIÓN}

En este trabajo se utilizó el estudio múltiple de casos por ser uno de los métodos más utilizados en las investigaciones cualitativas (Esparza y García, 2011; Maxwell, 1996; Yin, 1989), debido a que permite comprender el proceso que da origen a ciertos fenómenos, captar adecuadamente la heterogeneidad y el rango de variación existente en una población determinada, y medir empíricamente una teoría o construir una nueva explicación teórica sobre un determinado fenómeno investigado.

El método del caso facilita realizar una generalización analítica de los resultados a través de las técnicas de replicación literal y la selección teórica (o hecha deliberadamente) para trabajar aquellos casos que resultan críticos en la valoración de una teoría ya existente o en desarrollo (Franco y Urbano, 2010). Esto le permite al investigador capturar sutiles diferencias y similitudes entre los diferentes casos estudiados (Eisenhardt, 1.989; Yin, 1989).

El método de estudio de caso se torna apto para el desarrollo de investigaciones a cualquier nivel y en cualquier campo de la ciencia, y es apropiado para la elaboración de tesis doctorales (Martínez, 2006). El empleo del método del caso en ciencias sociales cómo la economía, y su aplicación en ámbitos cómo la creación de empresas y las PYME ha ido creciendo con el tiempo (Urbano y Toledano, 2007).

El tiempo total empleado en esta investigación para la identificación de las empresas, construcción de la guía para las entrevistas, recolección y registro de datos, análisis individual y general de la información, elaboración de las conclusiones y del reporte final fue de aproximadamente ocho meses.

\subsubsection{Diseño y protocolo del estudio múltiple de casos}

El estudio múltiple de casos es una investigación empírica que analiza un fenómeno contemporáneo dentro de su contexto real, cuando las fronteras entre el fenómeno y el contexto no son evidentes, para lo cual utiliza múltiples fuentes de evidencia (Yin, 1989).

Se concreta en la recogida de datos durante un determinado periodo de tiempo para ofrecer un análisis del contexto y los procesos implicados en el fenómeno objeto de estudio (Hartley, 1994). Este trabajo para asegurar su falibilidad y validez cumple con el protocolo y las etapas propuestas por (Yin, 1989) para el desarrollo de este tipo de estudios: identificación del problema a investigar, elaboración del planteamiento teórico, selección de los casos, recolección de los datos, triangulación y análisis de datos e interpretación de resultados. 


\subsubsection{Selección de los casos}

Los casos se seleccionaron de la base de datos de empresas MIPYME del sector turístico colombiano, construida en desarrollo de la investigación presentada en el capitulo anterior. Tomando a las empresas turísticas como unidad de análisis, la investigación se llevó a cabo con una muestra no probabilística de cuatro casos: hoteles de entre 12 y 66 habitaciones y un número de empleados entre 8 y 34, lo que los constituye en pequeños dentro del sector de actividad, prevaleciendo en cada uno la cultura clan, adhocrática, mercado o jerárquica según las tipologías establecidas por Cameron y Quinn (1999). Se considera que los casos presentan problemas comunes por estar ubicados en el mismo sector de actividad y zona geográfica, y por tener tamaños comparables.

Las empresas fueron seleccionadas mediante un muestreo teórico para escoger aquellos casos que ofrecen mayores posibilidades de aprendizaje (Yin, 1989; Eisenhardt, 1989), siendo contactadas de manera personal por el investigador, e invitadas a participar de este nuevo trabajo a través de una carta institucional que formalizó el proceso.

Los casos han sido nombrados empresa A, B, C y D respectivamente con el fin de preservar el anonimato y confidencialidad de la información suministrada (Hernández, Fernández y Baptista, 2006). Los criterios para seleccionar los casos se muestran en la tabla 1 .

Tabla 1. Criterios cualitativos para la selección de los casos

\begin{tabular}{|l|l|}
\hline Criterios & Descripción \\
\hline Sector & Hotelero. \\
\hline Tamaño & Pequeño. \\
\hline Cultura Empresarial & $\begin{array}{l}\text { Tipo Clan, Adhocrática, Mercado o Jerárquica según } \\
\text { la metodología propuesta por Cameron y Quinn } \\
(1999) .\end{array}$ \\
\hline Ubicación geográfica & Zona norte de Cali, Colombia. \\
\hline Personas a entrevistar & $\begin{array}{l}\text { Propietario o gerente, y colaboradores de primer } \\
\text { rango. }\end{array}$ \\
\hline
\end{tabular}

Fuente: elaboración propia.

\subsubsection{Procedimientos e instrumentos para recolección y medición cualitativa de los datos}

En este trabajo se utilizó un enfoque cualitativo y el método de la teoría fundamentada propuesta por Strauss y Corbin (1998), las técnicas de la entrevista y la encuesta. Para las entrevistas en profundidad se utilizó una guía que permitió una mayor facilidad para comparar los datos y que el investigador y el entrevistado no desviaran su atención. 
Una vez que las empresas aceptaron participar de la investigación, en sus respectivas sedes se llevaron a cabo las entrevistas programadas con el propietario o gerente y uno de los colaboradores previamente seleccionados, de igual manera se aprovechó para realizar observación directa; este proceso de triangulación se hizo para evitar sesgos y asegurar la validez de la información (Hernández, et al. 2006). Con el fin de obtener mayor claridad en cada uno de los aspectos analizados, las preguntas se fueron ajustando o complementando en función de las respuestas que se iban obteniendo, y de acuerdo con las reacciones que se observaban. De esta manera se pudo recopilar la información, codificarla, categorizarla, compararla y relacionarla para responder a las preguntas de investigación.

Las escalas e instrumentos utilizados para medir cada variable fueron respectivamente:

\section{Variable de cultura organizacional}

La cultura organizacional se midió a través del OCAI (Organizational Culture Assessment Instrument) desarrollado por Cameron y Quinn en 1999. Este instrumento se eligió teniendo en cuenta que ha sido probado internacionalmente en numerosas investigaciones cómo las de Naranjo et al. (2008), Stock et al. (2007), Igo y Skitmore (2006), Deshpandé y Farle, (2004), Obenchain y Johnson (2004) y la de Lau y Ngo (2004), y porque igual que la herramienta que usamos para medir el rendimiento, se basa en el Competing Values Framework -CVF (marco de valores en competencia) de Quinn y Rohrbaugh (1983), el cual sostiene que en las empresas hay intereses y valores luchando entre la flexibilidad y el control, así como por la consecución de objetivos internos y externos, para lograr el equilibrio que toda organización debe tener (Rodriguez, 2007). De esta manera se busca coherencia e integralidad metodológica.

\section{Variable de innovación}

Para medir el grado de innovación de las empresas existen dos enfoques (Hughes, 2001), uno objetivo que utiliza datos de tipo cuantitativo cómo el número de patentes, la innovación en productos (número de nuevos productos) o en los procesos (costes de inversión); y un enfoque subjetivo basado en la percepción del gerente o propietario de la empresa sobre su actividad innovadora. En el caso de la MIPYME resulta más apropiado el enfoque subjetivo, dado que el enfoque objetivo tiende a subestimar su actividad innovadora (Hughes, 2001). Este enfoque, por ejemplo, es el que se utiliza en el Estudio de la Innovación Armonizada de la Unión Europea.

Para abordar este factor en la investigación, se tuvieron en cuenta los diferentes conceptos recopilados en la revisión de trabajos realizada, y en especial el de AECA (1995) que señala que la innovación puede clasificarse en tecnológica y organizacional. Las 
innovaciones tecnológicas incluyen las novedades significativas en productos o servicios y en procesos; la innovación organizacional por su parte corresponde a los cambios introducidos a la estructura administrativa de la empresa, a la comercialización, a la financiación, etc. Esta misma clasificación ha sido usada en diferente trabajos cómo los de Maldonado et al. 2009; Van Auken et al. 2008; Naranjo et al. 2008.

\section{Variable de rendimiento o desempeño organizacional}

Para medir esta variable, en la investigación se utiliza la metodología de Quinn y Rohrbaugh (1983), ya que es una de las más aceptadas a nivel mundial, habiéndose empleado para correlacionar el rendimiento con variables tales como la innovación (Maldonado et al. 2009; Van Auken et al. 2008; Bastidas y García, 2005); la transferencia de conocimientos (Rodríguez, 2007); y la cultura organizacional (Tseng, 2010).

\subsubsection{Procesamiento de la información}

El objetivo de esta fase es examinar, categorizar, tabular y triangular y analizar la información obtenida, confrontándola de manera directa con las proposiciones de la investigación (Rialp, 1998). Los estudios múltiples de caso generan una gran cantidad de información que puede resultar poco manejable para sistematizarla adecuadamente (Hernández et al. 2006). Sin embargo, lo anterior se ha podido realizar adecuadamente en este trabajo mediante el análisis minucioso de cada uno de los casos.

La interpretación de la información está basada en la descripción y el análisis de toda la evidencia obtenida; a continuación se desarrollan los cuatro casos y se valoran las diferentes variables utilizadas, a partir de la revisión de la literatura y de la información obtenida de cada uno de las empresas.

\subsection{ANALISIS DE RESULTADOS}

\subsubsection{Descripción de antecedentes y evolución de los casos}

A continuación se desarrollan los cuatro casos abordados. La investigación se ha centrado en las percepciones e interpretaciones que los gerentes y colaboradores manifestaron en las entrevistas, así como en la observación directa realizada. Los nombres de las empresas han sido omitidos para preservar el anonimato y la estricta confidencialidad de la información proporcionada (Hernández et al., 2006). En cada caso se presenta la actividad, los antecedentes y evolución de la empresa y se describen algunos rasgos de sus propietarios.

La empresa “ $\boldsymbol{A}$ ” es un hotel de 23 habitaciones fundado en el año 1992, su principal servicio es el alojamiento, ofrece adicionalmente alquiler de espacios y equipos para 
eventos. Su creador, un contador público titulado que trabajó en diferentes empresas y se jubiló en un importante grupo empresarial colombiano, sintiéndose inquieto y motivado por las experiencias que había vivido al hospedarse en hoteles durante su actividad laboral, aprovechó sus contactos para establecer y ofrecer a empresas el servicio de alojamiento para funcionarios que visitan a Cali, bajo un concepto diferenciador de calidez y personalización, al que denominó "huéspedes ilustres".

Inicialmente los servicios fueron prestados exclusivamente a empresas conocidas, modelo que se mantuvo hasta el año 2003. A partir del 2004 se decide dejar de depender de ese reducido número de clientes y ser más asequibles, para lo cual se implementa una página web y diversifican los medios de pago recibidos. Desde el 2006 se fortalece el proceso de "apertura" mediante la implementación de reservas en línea. En el año 2011 el hotel es reconocido por una publicación especializada como uno de los tipo boutique más importantes de Colombia; se vinculan a diferentes portales especializados, a redes sociales y de turismo y se obtiene un certificado de sostenibilidad ambiental.

La dirección de la empresa está a cargo de una junta directiva constituida por el fundador quien la preside, su esposa que se encarga de la preservación del modelo empresarial y por una directora administrativa que no es miembro de la familia y tiene a su cargo los aspectos operativos de la empresa,. El hotel funciona en el norte de la ciudad y proyecta ampliar allí sus instalaciones, abrir una nueva sede en el sur, y seguir consolidando su presencia en los medios virtuales.

La empresa “ $\boldsymbol{B}$ ” es un hotel de 66 habitaciones ubicado en el norte de la ciudad, fundado en el año 2004. Tiene como su principal servicio el alojamiento y ofrece también el alquiler de espacios y equipos para eventos. Es operado desde el 2005 por su actual gerente, un ingeniero industrial con formación de postgrado en mercadeo y experiencia operativa, comercial, gerencial y empresarial en los sectores productivo, bancario, agropecuario y de servicios de alimentación y hospedaje; es además docente en temas relacionados con la hotelería y el turismo y ha desarrollado actividades de consultoría en varias entidades de apoyo a los microempresarios.

El hotel surgió en un momento donde no había mucha competencia en la zona geográfica donde se ubica, situación que ha venido cambiando hasta ser muy fuerte hoy en día; sin embargo se ha posicionado como una opción para aquellas personas que buscan buena calidad en el servicio a tarifas razonables; actualmente es de tres estrellas y pretende llegar pronto a las cuatro, su ubicación es considerada por el gerente una ventaja competitiva. Ha logrado nichos de mercado como el de los artistas que visitan la ciudad durante las festividades decembrinas. Actualmente está culminando un proceso de certificación de calidad.

La empresa “C” es un hotel de 38 habitaciones que abrió operaciones en el 2008, su servicio principal es el alojamiento y ofrece adicionalmente el de restaurante y alquiler de un salón para eventos. Es operado por su gerente, un administrador de empresas quien antes 
de ser empresario trabajó durante 25 años en cargos gerenciales de una importante cadena hotelera colombiana. El mercado objetivo del hotel es especialmente el corporativo y principalmente el de las empresas ubicadas en el norte de la ciudad, o de las que deben utilizar el aeropuerto, que se encuentra relativamente cerca

El gerente, que adicionalmente tiene una empresa que opera pequeños hoteles de terceros en diferentes ciudades de Colombia, está proyectando actualmente una mayor especialización de las funciones directivas de la empresa, entrar en un proceso de certificación ISO para este hotel, y abrir uno propio en Colombia u otros países cercanos tales como Ecuador o Perú.

La empresa “ $\boldsymbol{D}$ " es un hotel boutique de 12 habitaciones que inició actividades en el año 2009. Sus servicios son el alojamiento, el alquiler de espacios equipados para reuniones de trabajo (Office Hoteling) y las oficinas virtuales. Su propietario es un joven hombre de negocios que detectó en sus viajes la necesidad que tienen los ejecutivos, de disponer en su lugar de alojamiento de espacios de trabajo, pero diferentes a la habitación. Planeó su proyecto en el marco de su formación universitaria y aprovechó una ley de apoyo al sector hotelero en Colombia para iniciar el suyo. Desde la apertura del hotel, se vinculó un gerente con amplia experiencia en el sector, lo que ha facilitado los primeros años de funcionamiento, en los que se han venido ajustando aspectos de logística y del modelo empresarial.

Los directivos se han vinculado a los diferentes grupos empresariales de la región y en especial a los relacionados con el turismo, el fundador ingresó a la junta directiva en del gremio hotelero, y junto al gerente participan de eventos para aumentar el reconocimiento de la empresa. La planeación tienen una visión de largo plazo, y se analiza un modelo para entregar en un futuro próximo algunas franquicias, o conseguir socios inversionistas para expandir la marca. Actualmente proyectan la creación de una nueva sede en el mismo sector de la ciudad, y se concentran en la consolidación del modelo a nivel nacional. Consideran como sus principales fortalezas el modelo innovador del hotel, su ubicación geográfica y la atención personalizada y a la medida de los ejecutivos.

En la tabla 2 que se pueden apreciar las principales características de las empresas abordados en este estudio de casos: 
Tabla 2. Características de los casos analizados

\begin{tabular}{|l|l|l|l|l|}
\hline \multicolumn{1}{|c|}{ Características } & \multicolumn{1}{|c|}{ Empresa A } & \multicolumn{1}{|c|}{ Empresa B } & \multicolumn{1}{|c|}{ Empresa C } & \multicolumn{1}{|c|}{ Empresa D } \\
\hline Actividad & Hotelería & Hotelería & Hotelería & Hotelería \\
\hline $\begin{array}{l}\text { Ubicación } \\
\text { geográfica }\end{array}$ & $\begin{array}{l}\text { Norte de Cali, } \\
\text { Colombia. }\end{array}$ & $\begin{array}{l}\text { Norte de Cali, } \\
\text { Colombia. }\end{array}$ & $\begin{array}{l}\text { Norte de Cali, } \\
\text { Colombia. }\end{array}$ & $\begin{array}{l}\text { Norte de Cali, } \\
\text { Colombia. }\end{array}$ \\
\hline Servicios & $\begin{array}{l}\text { Alojamiento y } \\
\text { alquiler de } \\
\text { salones para } \\
\text { eventos. }\end{array}$ & $\begin{array}{l}\text { Alojamiento y } \\
\text { alquiler de salones } \\
\text { para eventos. }\end{array}$ & $\begin{array}{l}\text { Alojamiento, } \\
\text { restaurante y } \\
\text { alquiler de un } \\
\text { salón para } \\
\text { eventos. }\end{array}$ & $\begin{array}{l}\text { Alojamiento, } \\
\text { office hotelling y } \\
\text { oficinas virtuales. }\end{array}$ \\
\hline $\begin{array}{l}\text { Número de } \\
\text { habitaciones }\end{array}$ & 23 & 38 & 12 \\
\hline $\begin{array}{l}\text { Tamaño dentro del } \\
\text { sector de actividad }\end{array}$ & Pequeño. & Pequeño. & Pequeño. & Pequeño. \\
\hline $\begin{array}{l}\text { Número de } \\
\text { trabajadores }\end{array}$ & 12 & 34 & 14 & 8 \\
\hline $\begin{array}{l}\text { Antigüedad de la } \\
\text { empresa }\end{array}$ & 18 & 8 & 3 & 2 \\
\hline
\end{tabular}

Fuente: elaboración propia.

\subsubsection{Aspectos de cultura organizacional}

A continuación y desde el enfoque planteado por Cameron y Quinn (1999), se identifica y describe la cultura organizacional de cada caso:

La empresa " $A$ " tiene una cultura tipo clan, sus propietarios son percibidos por los colaboradores cómo "amigables", él más pragmático y ella más emocional y autoritaria. Hay momentos en los cuales la empresa se percibe como una gran familia, aunque siempre se mantienen las formalidades propias de la estructura organizacional. En general las relaciones son cordiales, y en la medida que se desciende en la estructura, se tornan más informales. La directora administrativa está interesada por generar un clima laboral aún más amigable pues considera que ello puede influir positivamente en el desempeño del personal. Los valores corporativos no están aún escritos, sin embargo se reconocen y promueven algunos como la honestidad, la responsabilidad y la transparencia, ya que son importantes por la naturaleza del servicio que se presta. Para el éxito de la empresa la dirección considera fundamental fortalecer el trabajo en equipo y un mayor uso de las TIC para ser más conocidos, así mismo busca mayor productividad pero con base en los servicios tradicionales que se ofrecen (más que con nuevos servicios). La gestión cotidiana se ha delegado en la directora de administrativa, las decisiones importantes se toman en reuniones mensuales de junta directiva. 
En la empresa “ $\boldsymbol{B}$ ” predomina la cultura de tipo jerárquico ya que como factores críticos para lograr el éxito se promueve la claridad, el conocimiento y el cumplimiento de los procesos y procedimientos establecidos, que sirven además para facilitar la delegación y el empoderamiento del personal, al cual se capacita en competencias laborales para el sector hotelero, buscando que tengan versatilidad funcional. Los colaboradores perciben un buen ambiente laboral en el hotel lo que les lleva a mantener la calidez con los huéspedes, lo que se considera un factor diferencial frente a la competencia. Se hacen esfuerzos por mejorar la productividad, para esto se está implementando un proceso de certificación de la calidad, y mejorar la eficiencia del trabajo en equipo, especialmente en cuanto al compromiso y rendimiento del personal temporal, difícil de manejar por su volatilidad.

La cultura predominante en la empresa “ $\boldsymbol{C}$ ” es la de mercado, pues hay en ella un claro enfoque en conseguir resultados comerciales y ganar participación en el sector, con base en un buen servicio, adecuada logística y un factor humano preparado y motivado. A través del plan estratégico la gerencia promueve la competitividad y el logro de objetivos retadores. Los valores compartidos son la honestidad, el compromiso, el sentido de pertenencia y el respeto por el cliente. El éxito se basa en la penetración del mercado y una premisa central, es que es necesario vender para poder pagar las diferentes obligaciones de la empresa, entre ellas el arrendamiento del hotel; por esto se concentran en el servicio, la eficiencia, y la capacitación y satisfacción de los colaboradores, quienes manifiestan sentirse a gusto en la organización. El liderazgo es percibido por los trabajadores como participativo.

La empresa " $\boldsymbol{D}$ " tiene una cultura que claramente se identifica con la de tipo adhocrático. Los directivos y colaboradores definen el hotel como dinámico e innovador por el tipo de servicios que ofrece y su capacidad de responder a los requerimientos de unos clientes exigentes y con necesidades muy específicas. El propietario y el gerente son percibidos por sus colaboradores cómo líderes a seguir por su proactividad, preparación y capacidad de superación, y por tener una gerencia abierta, moderna y poco jerarquizada. Los valores compartidos son la autonomía, el compromiso con la capacitación y la innovación, la originalidad y la autenticidad; los colaboradores sienten que sus intereses están alineados con los de la empresa. Hay un permanente interés por mantener y ampliar la diferenciación de los servicios, por tener elementos únicos, y a partir de ello ser más exitosos, reconocidos y lograr así mayor porción del mercado. Hay interés también por mantener la motivación y unión de los colaboradores.

En la tabla 3 se presentan las características de la cultura empresarial de cada uno de los hoteles estudiados: 
Tabla 3. Características de la cultura organizacional

\begin{tabular}{|c|c|c|c|c|}
\hline Características & Empresa A & Empresa B & Empresa C & Empresa D \\
\hline $\begin{array}{l}\text { Cultura } \\
\text { Empresarial }\end{array}$ & Clan & Jerárquica & Mercado & Adhocrática \\
\hline $\begin{array}{l}\text { Característica de la } \\
\text { empresa }\end{array}$ & $\begin{array}{l}\text { Familiar y } \\
\text { moderadamente } \\
\text { tradicionalista. }\end{array}$ & $\begin{array}{l}\text { Clásica y } \\
\text { conservadora. }\end{array}$ & $\begin{array}{l}\text { Competitiva y } \\
\text { funcional. }\end{array}$ & $\begin{array}{l}\text { Dinámica e } \\
\text { innovadora. }\end{array}$ \\
\hline $\begin{array}{l}\text { Valores } \\
\text { compartidos }\end{array}$ & $\begin{array}{l}\text { Honestidad, } \\
\text { responsabilidad y } \\
\text { transparencia. }\end{array}$ & $\begin{array}{l}\text { Orden y } \\
\text { cumplimiento, } \\
\text { servicio al cliente. }\end{array}$ & $\begin{array}{l}\text { Honestidad, } \\
\text { compromiso, } \\
\text { pertenencia, } \\
\text { respeto por el } \\
\text { cliente. }\end{array}$ & $\begin{array}{l}\text { Autonomía, } \\
\text { compromiso, } \\
\text { novedad y cambio. }\end{array}$ \\
\hline $\begin{array}{l}\text { Estilo de dirección y } \\
\text { liderazgo }\end{array}$ & Conservador. & $\begin{array}{l}\text { Empoderador pero } \\
\text { con base en los } \\
\text { procedimientos. }\end{array}$ & $\begin{array}{l}\text { Participativo y } \\
\text { competitivo. }\end{array}$ & $\begin{array}{l}\text { Proactivo, } \\
\text { participativo. }\end{array}$ \\
\hline $\begin{array}{l}\text { Ambiente de } \\
\text { trabajo }\end{array}$ & Familiar. & Formalizado. & Competitivo. & Inspirador. \\
\hline $\begin{array}{l}\text { Base del éxito } \\
\text { empresarial }\end{array}$ & $\begin{array}{l}\text { El trabajo en } \\
\text { equipo, y el uso } \\
\text { de las TICS. }\end{array}$ & $\begin{array}{l}\text { Cumplimiento de } \\
\text { los procesos, } \\
\text { mejoramiento de la } \\
\text { productividad y } \\
\text { los costos. }\end{array}$ & $\begin{array}{l}\text { Resultados } \\
\text { comerciales, } \\
\text { adecuada } \\
\text { logística, factor } \\
\text { humano } \\
\text { motivado. }\end{array}$ & $\begin{array}{l}\text { Diferenciación en } \\
\text { los servicios. }\end{array}$ \\
\hline
\end{tabular}

Fuente: elaboración propia

En cuanto a esta primera variable, en esta investigación se encuentra que los directivos de las empresas con cultura clan se interesan especialmente por impulsar el trabajo en equipo y generar un amigable ambiente laboral, coincidiendo en esto con los hallazgos de Yescas (2008) y de Wen-Chia (2007); que los de las que tienen una cultura de tipo jerárquico se preocupan especialmente por tener procedimientos claros y hacerlos cumplir, así mismo por lograr la estabilidad y la eficiencia, esto es similar a lo encontrado por Wen-Chia (2007) y Gatrell et al.(2001); que los de las empresas con cultura de mercado tienen un interés especial por mejorar sus indicadores comerciales y por lograr una mayor penetración en el mercado, coincidiendo así con los estudios de Wen-Chia (2007) y Gatrell et al.(2001). Por su parte que los de las empresas con cultura adhocrática son visionarios y centran su interés en el futuro y la innovación, y en tener servicios fuertemente 
diferenciados, coincidiendo de esta manera con los estudios de Yescas (2008) y los de Durendez y García (2007).

\subsubsection{Aspectos de innovación}

A continuación se describe el comportamiento innovador de los últimos años en las empresas analizadas:

La empresa “ $A$ ” ha tenido básicamente los mismos servicios desde su creación, sin embargo se han hecho mejoras en algunos como el de cafetería, y se comienzan a divulgar los tours que organizan otras empresas, se piensa ofrecer habitaciones temáticas acerca de personajes distinguidos de Colombia. Se han mejorado procesos como la recepción, lo cual ha sido importante, y se han adquirido nuevos inmuebles para la ampliación del hotel. En cuanto a la gestión ha habido cambios como la tercerización de la contabilidad, la comercialización a través de medios virtuales, las ventas directas en la recepción y la vinculación de representantes comerciales. No hay políticas para el fomento de la creatividad y la innovación de los trabajadores.

En la empresa “ $\boldsymbol{B}$ ” no se han presentado innovaciones importantes en los últimos años y tampoco hay o mayor interés en ello, su gerente define el hotel cómo "clásico" en cuanto a sus servicios, infraestructura física e inmobiliario. Los productos y servicios son los mismos desde el comienzo de operaciones. En cuanto a procesos se han hecho algunas renovaciones de inmobiliario tales como los televisores. En la medida que las posibilidades económicas lo permiten se trata de estar al día en el uso de las TIC, de igual manera se han implementado algunas estrategias para motivar al personal.

En la empresa “C”, se han realizado algunas mejoras en el servicio, cómo la colocación de cerraduras electrónicas, el rediseño del área de lobby, inclusión de suvenires típicos de la región en las habitaciones, contratación de recepcionistas bilingües y la variación quincenal en el menú del desayuno y del restaurante así mismo se han creado nuevos productos para el fin de semana cómo noches románticas. En cuanto a procesos se ha modernizado el circuito cerrado de televisión lo que permite mejorar la seguridad de los huéspedes, hacer mejores controles administrativos y se facilita a los vendedores mostrar el hotel en forma remota y en tiempo real; de igual manera se adquirió un equipo que a través de vapor evita que queden arrugas en los tendidos de las camas. Se han adquirido nuevas aplicaciones para la gestión contable e implementado estrategias comerciales cómo la participación en eventos y visitas a otras ciudades para ofrecer los servicios del hotel; todos los ejecutivos comerciales tienen equipos celulares que les permite comunicarse vía internet con la empresa y sus clientes, también se ha ingresado en los sistemas de reserva on line.

La empresa "D" es innovadora desde el concepto de su servicio ya que no es vender alojamiento, si no "facilitar la productividad y el bienestar de los huéspedes". Se aplican estrategias de marketing sensorial (colores, olores, sonidos agradables). Se han 
implementado recientemente nuevos servicios cómo el de lavandería y restaurante (a través de una alianza estratégica), se amplió el servicio de snacks y el de cafetería, y el desayuno se personalizó. También se inició hace poco el servicio de masajes y se otorgan servicios diferenciadores gratis cómo el lustrado de zapatos y la lavanda de ropa. Los procesos se han venido ajustando y estandarizando, se han comparado algunos equipos menores cómo la mesa de masajes y nuevas cafeteras. En cuanto a la gestión del hotel, se han realizado convenios para mejorar el aprovisionamiento de servicios cómo el restaurante y la cafetería y para comercializar las oficinas virtuales, se ha incursionando fuertemente en el internet para la venta de servicios y para hacer conocer más el hotel.

En la tabla 4 se presentan las manifestaciones de innovación en cada una de las empresas analizadas.

Tabla 4. Manifestación y características del comportamiento innovador

\begin{tabular}{|c|c|c|c|c|}
\hline Características & Empresa A & Empresa B & Empresa C & Empresa D \\
\hline $\begin{array}{l}\text { Cultura } \\
\text { Empresarial }\end{array}$ & Clan & Jerárquica & Mercado & Adhocrática \\
\hline $\begin{array}{l}\text { Innovación en } \\
\text { productos y } \\
\text { servicios }\end{array}$ & $\begin{array}{l}\text { Mejoras en el } \\
\text { servicio de } \\
\text { cafetería. }\end{array}$ & $\begin{array}{l}\text { Son los mismos } \\
\text { servicios desde la } \\
\text { apertura. }\end{array}$ & $\begin{array}{l}\text { Mejoramiento } \\
\text { área de lobby. } \\
\text { Recepcionistas } \\
\text { bilingües. } \\
\text { Variación de los } \\
\text { menús. Noches } \\
\text { románticas los } \\
\text { fines de semana. }\end{array}$ & $\begin{array}{l}\text { Afinamiento del } \\
\text { concepto } \\
\text { empresarial. } \\
\text { Implementación } \\
\text { del restaurante, } \\
\text { servicio de } \\
\text { masajes; lustrado } \\
\text { de zapatos y } \\
\text { lavandería gratis. }\end{array}$ \\
\hline $\begin{array}{l}\text { Innovación en } \\
\text { procesos }\end{array}$ & $\begin{array}{l}\text { Implementación } \\
\text { de la recepción. } \\
\text { Compra de } \\
\text { nuevo } \\
\text { inmobiliario. }\end{array}$ & $\begin{array}{l}\text { Renovación de } \\
\text { televisores. }\end{array}$ & $\begin{array}{l}\text { Modernización } \\
\text { del circuito } \\
\text { cerrado de } \\
\text { televisión. } \\
\text { Mejoras en la } \\
\text { gestión de } \\
\text { habitaciones. }\end{array}$ & $\begin{array}{l}\text { Implementación } \\
\text { del marketing } \\
\text { sensorial. Compra } \\
\text { de equipos } \\
\text { menores como } \\
\text { cafeteras. }\end{array}$ \\
\hline $\begin{array}{l}\text { Innovación en } \\
\text { gestión }\end{array}$ & $\begin{array}{l}\text { Tercerización de } \\
\text { la contabilidad. } \\
\text { Ingreso en los } \\
\text { medios virtuales. } \\
\text { Vinculación de } \\
\text { representantes } \\
\text { comerciales. }\end{array}$ & $\begin{array}{l}\text { Ingreso en los } \\
\text { medios virtuales. }\end{array}$ & $\begin{array}{l}\text { Adquisición de } \\
\text { nuevo software } \\
\text { para la } \\
\text { contabilidad y } \\
\text { modernos } \\
\text { equipos de } \\
\text { comunicación } \\
\text { para el área } \\
\text { comercial. } \\
\text { Implementación } \\
\text { reservas en línea. }\end{array}$ & $\begin{array}{l}\text { Tercerización de } \\
\text { servicios de } \\
\text { restaurante. } \\
\text { Convenio para } \\
\text { comercializar las } \\
\text { oficinas virtuales. } \\
\text { Ingreso en los } \\
\text { medios virtuales. }\end{array}$ \\
\hline
\end{tabular}

Fuente: elaboración propia 
En la investigación se observa que las cuatro empresas estudiadas han realizado en los últimos años algún tipo de innovación, apreciándose que al igual que en los estudios de Lee, Tan y Chlu (2008), Lau y Ngo (2004) y Claver et al (1998) hay relación de su desempeño innovador con el tipo de cultura organizacional prevaleciente en cada caso; así las que presentan menor nivel de innovación son las empresas con cultura tipo clan o jerárquica, y las de mayor las de tipo adhocrática o de mercado, esto está en línea con los hallazgos de Naranjo et al. (2008). De igual manera se encuentra que al igual que en los estudios de Khazanchi et al. (2007) y Martins y Terblanche (2003), valores o prácticas cómo la flexibilidad, asumir riesgos y fomentar la generación de ideas influyen positivamente en la innovación empresarial.

\subsubsection{Aspectos de rendimiento}

Las directivas de la empresa $\boldsymbol{A}$ consideran que si bien la calidad de sus servicios ha sido siempre buena, y bien organizados los procesos operativos y las tareas del personal, un proceso de certificación de calidad recientemente terminado, ha ayudado a mejorar y estandarizar aún más estos aspectos. Mediante la implementación del servicio de recepción se ha logrado atender mejor y más rápido las necesidades de los clientes y esto ha influido en su satisfacción, la utilización de los medios virtuales ha ayudado a que la empresa sea más reconocida. Ha habido un incremento del $20 \%$ en la ocupación del hotel lo que se refleja en sus cifras generales, la participación en el mercado se sostiene, la rentabilidad ha mejorado significativamente sobre todo por el control de costos, la productividad ha mejorado un poco pues se ha disminuido la cantidad de personal y continúan las actividades sin desmejorar su calidad. El nivel de motivación del personal se ha mantenido estable, la rotación del personal ha sido la normal dentro del sector, y el ausentismo ha disminuido.

En la empresa “ $\boldsymbol{B}$ ” el proceso de certificación de calidad en que se encuentran les ha permitido ser más eficientes en los procesos internos y hay interés por temas cómo la sostenibilidad ambiental aunque se dificulta por las limitaciones de la infraestructura física del hotel. El mejor desempeño se ha presentado en sus relaciones externas, ya que se ha ganado reconocimiento en el mercado y ha mejorado la imagen de sus servicios. La rentabilidad y la utilidad no ha sido la esperada para el nivel de inversión y por los altos costos de operación. El personal ha mantenido un nivel medio de motivación y compromiso.

La empresa "C" ha venido trabajando en la documentación de los procesos y se han mejorado algunos de ellos cómo el control de los amenities. Se percibe un mayor conocimiento del hotel en el mercado (ello se observa cuando se participa en convocatorias para contratar hoteles), en el incremento en la tasa de ocupación y tener actualmente una empresa nueva por semana; hay mayor satisfacción de los clientes y se esto demuestra por que frecuentemente regresan al hotel. Se ha aumentado considerablemente la tasa de ocupación y la cuota de mercado; así mismo ha mejorado la rentabilidad a través del 
control de costos, y de la productividad a través de la utilización de las TIC. La satisfacción de los trabajadores ha mejorado por los programas de capacitación e incentivos establecidos, la rotación del personal ha sido baja.

La empresa " $\boldsymbol{D}$ " es nueva por lo que ha venido afinando y estandarizando sus diferentes servicios y procesos (recepción, facturación, etc.), consecuentemente las tareas del personal se han reorganizado y se ha generado empoderamiento en los colaboradores. Ha habido un verdadero interés por entender y atender los cambios en el sector de actividad y en especial las necesidades y deseos de los clientes, esto se refleja en aspectos como la personalización del desayuno (se sirve lo que al cliente le guste) y dar un suvenir típico de la región a los clientes que lo desean; se ha podido comprobar que comienza a haber recordación de la marca. La rentabilidad ha venido mejorando cómo fruto del ajuste de los costos y la mejora de la productividad, a esto ha contribuido también el incremento en la ocupación del hotel y la participación en el mercado. La motivación del personal se ha mantenido en un buen nivel aunque dificultades del mercado ha impedido atender algunas expectativas que se crearon durante en su contratación, la rotación del personal y el ausentismo se ha mantenido en niveles bajos para el sector.

En la tabla 5 se presentan los principales aspectos del rendimiento de cada una de las empresas analizadas. 
Tabla 5. Manifestación y características del rendimiento

\begin{tabular}{|c|c|c|c|c|}
\hline Características & Empresa A & Empresa B & Empresa C & Empresa D \\
\hline $\begin{array}{l}\text { Cultura } \\
\text { Empresarial }\end{array}$ & Clan & Jerárquica & Mercado & Adhocrática \\
\hline $\begin{array}{l}\text { Rendimiento en } \\
\text { procesos internos }\end{array}$ & $\begin{array}{l}\text { Los procesos se } \\
\text { han mejorado y } \\
\text { estandarizado a } \\
\text { partir de la } \\
\text { certificación de } \\
\text { calidad obtenida. }\end{array}$ & $\begin{array}{l}\text { Los procesos } \\
\text { internos son más } \\
\text { eficientes gracias } \\
\text { al proceso de } \\
\text { certificación que } \\
\text { se adelanta. }\end{array}$ & $\begin{array}{l}\text { Mejora en los } \\
\text { procesos gracias a } \\
\text { la documentación } \\
\text { y estandarización } \\
\text { de los mismos. }\end{array}$ & $\begin{array}{l}\text { Los procesos y } \\
\text { servicios se han } \\
\text { venido afinando } \\
\text { como fruto de la } \\
\text { experiencia } \\
\text { adquirida por la } \\
\text { empresa. }\end{array}$ \\
\hline $\begin{array}{l}\text { Rendimiento } \\
\text { externo (sistema } \\
\text { abierto) }\end{array}$ & $\begin{array}{l}\text { El proceso de } \\
\text { "apertura" y el } \\
\text { uso de internet } \\
\text { ha hecho más } \\
\text { conocido el } \\
\text { hotel. } \\
\text { Los clientes } \\
\text { están más } \\
\text { satisfechos } \\
\text { gracias al } \\
\text { servicio de } \\
\text { recepción }\end{array}$ & $\begin{array}{l}\text { Ha mejorado el } \\
\text { reconocimiento de } \\
\text { la marca en el } \\
\text { mercado. }\end{array}$ & $\begin{array}{l}\text { Importante } \\
\text { mejoría en las } \\
\text { tasas de } \\
\text { ocupación y en el } \\
\text { reconocimiento } \\
\text { de la marca. }\end{array}$ & $\begin{array}{l}\text { Los clientes se } \\
\text { encuentran más } \\
\text { satisfechos por } \\
\text { servicios como el } \\
\text { desayuno } \\
\text { personalizado. } \\
\text { La marca } \\
\text { comienza a ser } \\
\text { reconocida en el } \\
\text { mercado. }\end{array}$ \\
\hline $\begin{array}{l}\text { Rendimiento } \\
\text { racional }\end{array}$ & $\begin{array}{l}\text { La rentabilidad } \\
\text { ha mejorado por } \\
\text { el control de } \\
\text { costos y el } \\
\text { aumento de } \\
\text { ocupación. }\end{array}$ & $\begin{array}{l}\text { La rentabilidad y } \\
\text { la utilidad no han } \\
\text { sido las esperadas } \\
\text { para la inversión y } \\
\text { costos. }\end{array}$ & $\begin{array}{l}\text { Mejora en la } \\
\text { rentabilidad } \\
\text { gracias al control } \\
\text { de costos, y en la } \\
\text { productividad por } \\
\text { el uso de las TIC. }\end{array}$ & $\begin{array}{l}\text { La rentabilidad ha } \\
\text { mejorado gracias } \\
\text { al ajuste de costos } \\
\text { y la mejora en la } \\
\text { tasa de } \\
\text { ocupación. }\end{array}$ \\
\hline $\begin{array}{l}\text { Rendimiento en } \\
\text { relaciones humanas }\end{array}$ & $\begin{array}{l}\text { La motivación y } \\
\text { rotación del } \\
\text { personal ha sido } \\
\text { buena y estable. } \\
\text { El ausentismo ha } \\
\text { disminuido. }\end{array}$ & $\begin{array}{l}\text { La motivación y el } \\
\text { compromiso del } \\
\text { personal han sido } \\
\text { estables. }\end{array}$ & $\begin{array}{l}\text { La motivación y } \\
\text { compromiso de } \\
\text { los colaboradores } \\
\text { ha mejorado } \\
\text { significativamente } \\
\text { por programas de } \\
\text { capacitación y } \\
\text { estímulos por } \\
\text { desempeño. }\end{array}$ & $\begin{array}{l}\text { La motivación del } \\
\text { personal se ha } \\
\text { mantenido en un } \\
\text { buen nivel. La } \\
\text { rotación del } \\
\text { personal ha sido } \\
\text { baja. }\end{array}$ \\
\hline
\end{tabular}

Fuente: elaboración propia 
En cuanto al rendimiento organizacional, en esta investigación y al igual que en los estudios de Zhang et al. (2008), O'cass y Ngo (2007), y de Kim et al. (2004), se encuentra relación de ello con la cultura organizacional prevaleciente en las empresas; así y al igual que en los estudios de Tseng (2010), Durendez y García (2008), y Deshpande y Farle (2004) respectivamente, se halla que las cultura adhocrática y de mercado generan un impacto positivo sobre el rendimiento de la empresa, y que las de tipo jerárquico y clan lo desestimulan.

En la tabla 6 se puede apreciar un resumen de las principales características de los hoteles abordados en este estudio de casos.

Tabla 6. Características de los casos analizados

\begin{tabular}{|l|c|c|c|c|}
\hline \multicolumn{1}{|c|}{ Características } & Empresa A & Empresa B & Empresa C & Empresa D \\
\hline $\begin{array}{l}\text { Cultura } \\
\text { Empresarial }\end{array}$ & Clan & Jerárquica & Mercado & Adhocrática \\
\hline Innovación & Baja & Baja & Alta & Muy alta \\
\hline Rendimiento & Medio-bajo & Bajo & Alto & Alto \\
\hline
\end{tabular}

Fuente: elaboración propia.

\subsection{CONCLUSIONES}

La presente investigación utilizó la metodología del estudio múltiple de casos, considerada como la de mayor aplicación para la consecución de objetivos de tipo cualitativo (Yin, 1989). La selección de los casos se realizó mediante muestreo teórico y no estadístico, escogiéndose aquellos que presentaban la mayor oportunidad de aprendizaje de los fenómenos estudiados. Se escogieron cuatro casos de empresas MIPYME del sector turístico de Cali, Colombia. Cada empresa fue identificada con un tipo de cultura: clan, adhocrática, jerárquica y mercado, de acuerdo con el modelo propuesto por Cameron y Quinn (1999).

Los resultados confirman que las empresas, aún estando en zonas geográficas y sectores de actividad similares (lo que les lleva a tener oportunidades y problemáticas parecidas), presentan diferentes niveles de innovación y de rendimiento; y que esto está significativamente influido por el tipo de cultura establecido en cada una mediante el tipo de liderazgo ejercido, los valores compartidos, el clima organizacional, y las prácticas gerenciales y operativas implementadas consciente o inconscientemente.

Si bien las empresas abordadas en este trabajo comparten algunas características como haber entrado en procesos de certificación y afinamiento de sus procesos, en su interés por la satisfacción del factor humano, por conocer y atender las necesidades de los 
clientes, y por ponerse al día en la implementación de las facilidades que ofrecen las TICs; en muchos otros aspectos se comportan diferente, y ello les lleva a obtener resultados disimiles.

Los hoteles con cultura clan o jerárquica presentan un pobre nivel de innovación (en especial de productos/servicios y procesos), y uno medio-bajo en cuanto a su rendimiento, tendiendo a concentrarse en mejorar sus servicios tradicionales en vez de desarrollar otros nuevos que los lleve a diversificar su portafolio y cambiar su posicionamiento. Por su parte las empresas con cultura adhocrática y de mercado manifiestan un mejor nivel general de innovación y de rendimiento, destacando en el caso de la adhocrática su innovación en productos y procesos, y en la de mercado su rendimiento en los indicadores racionales; las empresas con estos dos últimos tipos de cultura se enfocan respectivamente en diferenciarse a través de servicios innovadores y lograr una mayor cuota en el mercado.

La empresa con cultura adhocrática es la de más reciente creación y se muestra claramente como la más abierta y propensa a la innovación tanto en su concepto de negocio, como en sus servicios y prácticas gerenciales, aplicando por ello el marketing sensorial, el marketing experiencial y la tercerización de servicios ofrecidos y demandados; se puede percibir que este comportamiento está directamente relacionado con la visión del propietario y con que al igual que el gerente, tienen permanentemente relación con el mundo académico y empresarial. Por su parte, la empresa con cultura de mercado que de igual manera es joven, es la que tiene los mejores resultados en rendimiento comercial y financiero, gracias especialmente al perfil competitivo de su gerente y a la agresiva estrategia de ventas que ha implementado.

La información que proporciona este estudio es de gran utilidad ya que permite tener mayor claridad de la manera en que se manifiestan los diferentes tipos de cultura en las MIPYME de Colombia y en particular en las del sector turístico. Los empresarios y el gremio del turismo y en particular el hotelero, puede aprovecharla para impulsar entre sus colaboradores y asociados respectivamente, los valores y prácticas que generan un mayor nivel de innovación y desempeño; de igual manera la academia y las instituciones de apoyo a este tipo de empresas puede servirse de ella para revisar y reforzar sus programas para el mejoramiento de la competitividad empresarial.

Dentro de las limitaciones que tiene esta investigación están aspectos como la diferencia de antigüedad de las empresas, ya que dos son relativamente nuevas, mientras que una de ella es mucho mayor que las demás, y esto puede generar diferencias como el nivel de organización de sus procesos; de igual manera la utilización de un sólo modelo de referencia para caracterizar los tipos de cultura (el de Cameron y Quinn, 1999) y hacer el estudio con empresas de una única ciudad, pudo dificultar tener más elementos para comparar las diferentes culturas organizacionales en Colombia.

Futuros trabajo pueden retomar este estudio para analizar aspectos como el impacto de la antigüedad de la empresa en su nivel innovador y de rendimiento; así mismo se 
podrían revisar aspectos como el efecto de la zona geográfica donde se encuentre la empresa sobre el tipo de cultura que manifiesta. 
CONCLUSIONES GENERALES 
La cultura organizacional, la innovación y el intraemprendimiento son considerados factores realacionados y críticos para la supervivencia y el éxito de las empresas (Formichella, 2005; Garzón 2004; Camelo, Romero y Valle, 2000; Damanpour y Gopalakrishnan 2001; Rogers, 1983). Los objetivos planteados para esta tesis son analizar y aportar evidencia empírica en el marco de la teoría de recursos y capacidades sobre los siguientes aspectos y relaciones en las MIPYME de Colombia:

- El efecto de la cultura organizacional y de la innovación sobre el rendimiento. Para esto se observaron variables que miden percepciones acerca del clima organizacional, el estilo de dirección, los valores compartidos y los factores de éxito; la innovación en productos o servicios, en los procesos y en la gestión; y el rendimiento de la empresa en sus procesos internos, en su relación con el medio externo, en sus indicadores de gestión y en la satisfacción de sus recursos humanos.

- El impacto de la cultura de intraemprendimiento en la innovación y en el rendimiento organizacional. Para el caso de la cultura de intraempendimiento se consideraronn factores como la autonomía que tienen los empleados, la tolerancia al riesgo y a los errores, la compensación y el reconocimiento, el soporte de la gerencia y la flexibilidad en la estructura organizacional; y para medir la innovación y el rendimiento los mismos factores señalados en el punto anterior.

- La forma cómo manifiestan su cultura organizacional y el impacto de esta en la innovación y el desempeño de la firma; para esto se midieron bajo un enfoque cualitativo, respectivamente las mismas variables señaladas en los puntos anteriores

Para alcanzar los objetivos planteados se desarrollaron tres investigaciones empíricas que se relacionan a continuación:

En el primer capitulo se presenta un estudio cuantitativo de corte transversal realizado en la ciudad de Cali con 60 empresas MIPYME de mediana o alta tecnología, pertenecientes a sectores de considerable significancia económica para la región a saber: el software, la ingeniería eléctrica, las artes gráficas, y los plásticos. En cuanto a la relación entre cultura organizacional y su efecto en el rendimiento, se lograron probar aunque de manera parcial tres de las cinco hipotesis planteadas; en cuanto a la relación entre la innovación y su impacto sobre el rendimiento se pudieron probar parcialmente dos de las tres hipotesis planteadas.

Los resultados más relevantes de este capítulo muestran que la cultura de innovación es la que más favorece el desempeño de las empresas, seguida por la de tipo clan, mientras que la jerárquica lo afecta negativamente. De igual manera que la edad de la empresa influye positivamente en el rendimiento de sus procesos internos, y el recurso humano es el factor que se ve más favorablemente impactado por la cultura organizacional. Respecto a la innovación y su efecto sobre el rendimiento, se observó que la innovación en 
procesos y la innovación en productos son las que mayor impacto positivo generan en la MIPYME. De otra parte se verificó que en general la innovación impacta positivamente el desempeño externo de la empresa y a su rendimiento general.

En el segundo capítulo se presenta otro estudio cuantitativo de corte transversal en el cual se analiza el efecto que tiene la cultura de intraemprendimiento sobre la innovación y el rendimiento empresarial, para esto se desarrolló una investigación con 68 hoteles, agencias de viaje y restaurantes MIPYME del sector turístico de Colombia. El trabajo retomó las variables de innovacion y desempeño analizadas en el capitulo precedente, y en cuanto a la cultura de intraemprendimiento consideró y midió factores como la autonomía que tienen los empleados, la tolerancia al riesgo y a los errores, la compensación y el reconocimiento, el soporte de la gerencia y la flexibilidad en la estructura organizacional. Las dos hipotesis planteadas en esta investigación fueron probadas aunque parcialmente.

Entre los principales hallazgos de este trabajo se puede señalar que el soporte de la gerencia y la flexibilidad en la estructura corporativa tienen impacto positivo en el rendimiento de los procesos internos, de las relaciones con el entorno y en el desempeño general de la empresa, así como en la innovación en sus procesos internos. Por otra parte mostramos cómo el trabajo en equipo impacta positivamente en el rendimiento y en la satisfacción del factor humano, la innovación en gestión y el nivel innovador general de la empresa.

En el tercer capítulo se presenta un trabajo de tipo cualitativo adelantado mediante un estudio múltiple de casos desarrollado con cuatro hoteles de la ciudad de Cali. Para esto y siguiendo la metodología escogida, se contrastaron las proposiciones planteadas frente a la información recolectada en la revisión bibliográfica y en el trabajo de campo.

Entre los principales hallazgos de esta tercera investigación pueden señalarse cómo en las empresas con cultura de tipo adhocratico y de mercado son donde se manifiesta un mayor nivel de rendimiento y de innovación; mientras que en las que tienen cultura de tipo jerárquico y clan se puede observar respectivamente un bajo y medio-bajo nivel en los mismos aspectos.

A partir de las tres investigaciones empíricas desarrolladas en la tesis se pueden extraer las siguientes conclusiones generales:

- Gracias a los elementos conceptuales que proporciona, la teoría de recursos y capacidades genera un marco propicio para el análisis de los efectos que tienen aspectos cómo la cultura organizacional y la innovación sobre el rendimiento y éxito empresarial.

- En todas las empresas se presentan características o prácticas asociables con los tipos de cultura organizacional propuestas por Cameron y Quinn (1999), pero a través de la observación de ciertas prácticas y valores, generalmente es posible identificar que una de ellas prevalece sobre las demás. 
- Existe una marcada relación entre la cultura organizacional predominante en las empresas y la forma, frecuencia y magnitud de sus innovaciones, y de igual manera en los diferentes indicadores de su rendimiento.

- La cultura de intraemprendimiento es todavía relativamente baja en la mayoría de las MIPYME turísticas colombianas ya que implica esfuerzos y cambios de paradigmas, pero aún así en las que ya la poseen, tiene un importante impacto positivo sobre su desempeño general y sobre su innovación.

- Las MIPYME del sector hotelero de Colombia están sometidas a un fuerte proceso de competencia que las obliga a cambiar e innovar para sostenerse y tratar de ser exitosas; dichas innovaciones pueden ser sencillas como los cambios en los menús de sus cafeterías y restaurantes, hasta muy significativas al introducir nuevos conceptos de servicio como el office hotelling. De cualquier manera es palpable que el tipo de cultura establecido en las empresas hoteleras influye en su capacidad y forma de innovar y de obtener buenos rendimientos.

La información que proporciona esta tesis es pertinente porque además de la ya señalada importancia económica y social de las MIPYME en Colombia, en dicho país son aún escasos los estudios empíricos alrededor de las temáticas abordadas, y en particular en cuanto a trabajos de tipo cuantitativo se refiere.

Los resultados obtenidos en las tres investigaciones realizadas han generado una serie de implicaciones que se consideran de gran relevancia para diferentes agentes sociales y económicos tales como la academia, las entidades públicas y privadas de apoyo y fomento empresarial, los gremios y los mismos empresarios

Entre las principales limitaciones de las investigaciones realizadas en esta tesis se pueden señalar: a) en los dos primeros trabajos: el relativamente pequeño tamaño de la muestra lo que pudo limitar las posibilidades de obtener más estadísticos significativos, y el haber utilizado como única fuente de información a los directivos de las empresas, ya que incluir algunos de los colaboradores habría reducido las posibilidades de sesgos perceptuales; b) en la tercera investigación: haber incluido sólo empresas del sector hotelero y en una sola ciudad, lo que puede reducir la posibilidad de generalizar los resultados al sector turístico colombiano.

Es importante también recalcar que en esta tesis se adelantaron tareas importantes y exigentes tales como los siguientes: a) abordaje de temáticas y relaciones que han sido poco estudiadas de manera empíricia en economías emergentes como la colombiana; b) combinación de metodologías cuantitativas y cualitativas: se utilizaron para los dos primeras investigaciones metodos cuantitativos a través de estudios empíricos de corte transversal, y en la tercera investigación, de tipo cualitativo, el estudio múltiple de casos; c) utilización de diversas fuentes de información: en cada una de las investigaciones realizadas se utilizaron bases de datos construidas a través del trabajo de campo del 
investigador, ya sea mediante la aplicación de encuestas o de la información recogida minuciosamente en cada uno de los casos realizados; d) utilización de medidas $e$ instrumentos ampliamente validados: se han utilizado en el trabajo medidas e instrumentos probados en diferentes estudios internacionales tales cómo el OCAI para medir la cultura organizacional (Cameron y Quinn, 1999), el CVF para analizar el rendimiento (Quinn y Rohrbaugh, 1983), y la metodología propuesta por Hornsby, Kuratko y Zahra (2002), que se tomó como base para diseñar el instrumento empleado pra medir la cultura intraemprendedora; e) generación de implicaciones empresariales, académicas y socioeconómicas: los resultados que se presentan, plantean implicaciones tanto para los propietarios y los directivos de las empresas, cómo para los entes gubernamentales y los profesores e investigadores de las entidades de educación superior y en general de apoyo a la MIPYME. 
REFERENCIAS BIBLIOGRAFICAS 
AECA (1988). La competitividad de la empresa: concepto, características y factores determinantes. Principios de Organización de Empresas, Documento $n^{o}$. 4. Madrid: Asociación Española de Contabilidad y Administración de Empresas.

AECA (1995). La innovación en la empresa: factor de supervivencia. Principios de organización y sistemas. Madrid: Asociación Española de Contabilidad y Administración de Empresas.

Agca, V., Topal, Y., y Kaya (2009). Linking intrapreneurship activities to multidimensional firm performance in Turkish manufacturing firms: an empirical study, International Entrepreneurship Management, Online. Recuperado el 20 de mayo del 2010 de:http://www.springerlink.com.bd.univalle.edu.co/content/khgv0v7401243828/fulltext.pdf 2009

Amit, R. y Shoemaker, P (1993). Strategic assets and organizational rents. Strategic management journal, 14 (1), 33-46.

Amo, B., y Kolvereid, L. (2005). Organizational strategy, individual personality and innovation behavior. Journal of Enterprising Culture, 13 (1), 7-19.

Antoncic, B. (2003). Risk taking in intrapreneurship: Translating the individual level risk aversion into the organizational risk taking. Journal of Enterprising Culture, 11 (1), 1-23.

AntonciC, B., y Hisrich, R. (2003). Clarifying the intrapreneurship concept. Journal of Small Business and Enterprise Development, 10 (1), 7-24.

Arango, L., y Urrea, F. (2000). Culturas empresariales en Colombia. Bogotá: Colciencias y Corporación Calidad.

Barney, J. B. (1986). Organizacional culture can be a source of sustained competitive advantage. Academy of Management Review, 11 (3), 656-665.

Barney, J. B. (1991). Firm resources and sustained competitive advantage. Journal of Management, 17 (1), 99-120.

Bastida, F. y García, D. (2005). Efectos de la innovación y los sistemas de control de gestión sobre el rendimiento de la Pyme. XIII Congreso AECA. Oviedo: Recuperado el 15 de mayo de 2010, de http://dialnet.unirioja.es/servlet/articulo?codigo=2031637.

Benitez-Amado, J., Llorens-Montes F., y Perez-Arostegui, M. (2010) Information technology-enabled intrapreneurship culture and firm performance. Industrial Management y Data Systems, 110 (4), 550 - 566.

Bhaskaran, S. (2006). Incremental Innovation and Business Performance: Small and Medium-Size Food Enterprises in a Concentrated Industry Environment. Journal of Small Business Management, 44 (1), 64-80. 
Bieto, E. (2008). Aproximación al Corporate Entrepreneurship en España: Tipologías y Relación con los Resultados Empresariales. Tesis Doctoral. Barcelona: ESADE, 2008 IV.

BjØrnenak, T. (1997). Diffusion and Accounting: The case of ABC in Norway. Management Accounting Research, 8, 3-17.

Blichfeldt, B. (2009). Innovation and Entrepreneurship in Tourism: The Case of a Danish Caravan Site. Pasos. Revista de Turismo y Patrimonio Cultural, 7 (3), 415-431.

Bruns, W. J., y Waterhouse, J. H. (1975). Budgetary control and organization structure, Journal of Accounting Research, 13 (2), 177-203.

Camelo, C., Romero, P., y Valle, R. (2000). Relación entre el tipo y el grado de innovación y el rendimiento de la empresa. Economía Industrial, 333, 149-160.

Cameron, K. y Quinn, R. (1999). Diagnosing an changing organizational culture. based on the competing values framework. San Francisco: Prentice Hall Series in Organizational Developement.

Camisón, C. (1997). La competitividad de la Pyme industrial española: estrategia y competencias distintivas. Madrid: Civitas.

Castellanos, O.; Gálvez, B.; Montoya, L.; Lagos, Y. y Montoya, I. (2006). Medición del potencial de investigación y de desarrollo de las Pymes a partir de su capacidad de gestión organizacional. Revista EAN, 57, 159-172.

Chen, J., Zhu, Z. y Anquan, W. (2005). A System Model for Corporate Entrepreneurship. International Journal of Manpower, 26 (6), 529-545.

Christensen, S. K. (2005). Enabling intrapreneurship: The case of a knowledge-intensive industrial company. European Journal of Innovation Management, 8 (3), 305-318.

Claver, E., Llopis, J., García, D., y Molina, H. (1998). Organizational culture for innovation and new technological behavior. The journal of High Technology Management Reserch, 9 (1), 55-68.

Collis, D. J. (1991). A Resource-based Analysis of Global Competition: The Case of the Bearings Industry. Strategic Management Journal, 12, 49-68.

Collis, D. J. y Montgomery, C. A. (1995). Competing on resources: strategy in the 1990's. Harvard Business Review; 73 (4), 118-128.

Conner, K. (1991). A historical comparision of resource-based theory and five schools of thought within industrial organization economics: Do we have a new theory of the firm? Journal of Management, 17 (1), 121-154. 
CONPES (2007). Documento CONPES 3484. Consejo Nacional de Política Económica y Social. República de Colombia. Política nacional para la transformación productiva y la promoción de las micro, pequeñas y medianas empresas: Un esfuerzo público y privado. Bogotá.

CONPES. (2005). Documento CONPES 3397 "Política Sectorial de Turismo". Bogotá:

Consejo Nacional de Política Económica y Social. Departamento Nacional de Planeación. Recuperado el 24 de enero de 2011 de: http://www.snc.gov.co/Es/Institucionalidad/Documents/Conpes/3397.pdf

Cornejo, M., y Muñoz, E. (2009). Percepción de la innovación: cultura de la innovación y capacidad innovadora. Pensamiento Iberoamericano. Recuperado el 05 de octubre del 2010 de:http://www.pensamientoiberoamericano.org/xnumeros/5/pdf/pensamientolberoamericao -118.pdf .

Covin, J. G., y Slevin O. P. (1991) A conceptual model of entrepreneurship as firm behavior, Entrepreneurship Theory and Practice. 16(1), 7-25.

Cuervo, G. A. (1993). El papel de la empresa en la competitividad. Papeles de Economía Española, 56, 363-377.

Damanpour, F., y Gopalakrishnan, S. (2001). The dynamics of the adoption of products and process innovations in organizations. Journal of Management Studies, 38, 45-65.

DANE (2005). Censo general 2005. Bogotá: Recuperado el 07 de abril de 2010, de http://www.dane.gov.co/censo/files/libroCenso2005nacional.pdf.

Darroch, J. (2005). Knowledge management, innovation and firm performance. Journal Of Kwnoledge Management, 9 (3), 101-115.

Davidson, G., Coetzee, M., yVisser, D. (2007). Organisational Culture and Financial Performance in a South African Investment Bank, Journal of Industrial Psychology, 33 (1), $38-48$.

Dávila, A. (1999). Cultura Organizacional en una Escuela Católica Mexicana: Un Estudio de Caso, en Cultura en Organizaciones Latinas. México: ITESM,.

Davis, S. (1993). Cultura corporativa y Estrategia, dos piezas que deben ir juntas. Management y Gestión, 2 (112), 32-34.

Deshpande, R., y Farle, J. (2004). Organizational culture, market orientation, innovativeness, and firm performance: an international research odyssey. International Journal of Research in Marketing, 21, 3-22.

Dierickx, I. y Cool, K (1989). Asset Stock, Acumulation and Sustainability of Competitive Advantage. Management Science, 35, 1504-1511. 
Dobbs, R. y Koller, T. (2006). La medición del rendimiento a largo plazo. Harvard-Deusto Finanzas y Contabilidad, 69, 4-12.

Drucker, P. (1985). La Innovación y el empresario innovador. México: Edhasa.

Duréndez, A. yGarcía, D. (2008). Innovative culture, management control systems and performance in young smes. Doctoral track in Entrepreneurship, culture, finance and economic developement. Recuperado el 26 de mayo de 2010, de http://www.unicaen.fr/colloques/Entrepreneurship_Conference_2008/Innovative_culture_m anagement_control_systems_and_performance_in_young_smes.pdf.

Eisenhardt, K.M., 1989. Building therories from case study research. Academy of Management Rreview, 14(4), 532-550.

Esparza, J. L. (2010). La gestión integral de las empresas familiares turísticas mexicanas cómo factor estratégico y sostenible de competitividad empresarial. Tesis doctoral. Facultad de Ciencias Económicas y Empresariales. Universidad de Cantabria.

Esparza, J. L., y García, D. (2011). La cultura de las empresas familiares turísticas mexicanas y su influencia en la gestión estratégica. Cuadernos de Administración, 24 (42), 295-313.

Estrada, R. y Sánchez, V. G. (2009). Herramientas estratégicas en la Pyme y su efecto en la planeación y el rendimiento: una evidencia empírica. Recuperado el 1 de junio de 2010, de http://www.economia.uady.mx/Revista/2009/XXVI/73/03.pdf.

Fernández, M. y Peña, I. (2009). Estrategia de innovación cómo factor determinante del éxito de las cooperativas vitivinícolas de Castilla la Mancha. Revesco, 98, 70-96

Fernández, Z. (1993). La organización interna cómo ventaja competitiva para la empresa. Papeles de Economía Española, 1 (56), 178-193.

Freeman, C. (1987). Technology and Economic Performance: Lessons from Japan. London: Pinter Publisher.

Foba, T., yDe Villiers, D. (2007). The Integration of Intrapreneurship into a Performance Management Model. Journal of Human Resources Management, 5 (2), 1-8.

Formichella, M. (2005). Innovación del concepto de desarrollo y su relación con el desarrollo. Recuperado el 29 de mayo de 2010, de:

http://190.41.189.210/oficinas/investigaciones/Evolucion\%20del\%20Concepto\%20de\%20I nnovacion\%20y\%20Desarrollo.pdf

Gordon, G., y Di Tomaso, N. (1992). Predicting corporate performance from organizational culture. Journal of Management Studies, 29 (6), 783-799. 
Foro Económico Mundial. (2009). Reporte global de competitividad 2009-2010. Génova: Foro Económico Mundial.

Franco, M., y Urbano, D (2010). El éxito de las Pymes en Colombia: Un estudio de casos en sector salud. Estudios Gerenciales, 26 (114), 77-97.

Freel, M. (2000). Do Small Innovating Firms Outperform Non-Innovators? Small Business Economics, 14, 195-210.

Garzón, M. A. (2004). La innovación intraemprendedora liderada por los gerentes de las Pymes. Universidad Empresa, 3 (6), 74-109.

Garzón, M. A. (2005). Modelo intraemprendedor para la innovación. Bogotá: Universidad del Rosario.

Gatrell, J., Jenkins, H., y Tucker, J. (2001). Family values in family business, en G. Corbetta y D. Montemerlo (Eds): The role of family in family business, $12^{\text {th }}$ Annual FBN World Conference. Rome. EGEA S.p.A FBN. Milano.

Gasalla, J. M. (1999). Cultura de la creatividad y de la innovación. Revista electrónica. http://www.madrimasd.org. Recuperada el 02 de junio del 2010, 1-6.

Girard, J. (1989). Un leadership transparent et combatiff. Colloque de la Fondation de L'entrepreneurship. Montreal. Canadá.

Grant, R. M. (1991). The Resource-based Theory of Competitive Advantage: Implications for Strategy Formulation. Management Review, 33 (1) 3, 114-135.

Grant, R. M. (1996). Dirección Estratégica. Conceptos, Técnicas y Aplicaciones. Madrid: Civitas.

Hair, J.F., Anderson, R. E., Tatham, R. L., y Black, W. C. (1999). Análisis Multivariante. Quinta Edición. España: Prentice Hall.

Hall, R. (1993). A Framework Linking Intangible Ressources and Capabilities to Sustainable Competitive Advantage. Strategic Management Journal, 14 (18), 607-618.

Hartley, J. (1994). Case study in organizational research, en Cassel, C. y Simon, G. Londres: (Eds) Qualitative Methods in Organizational Research: a Practical Guide. Sage.

Henri, J. F. (2006). Organizational culture and performance measurement systems. Accounting, Organizations and Society, 31, 77-103.

Hernández, J., Yescas, M. y Domínguez, M. L. (2007). Factores de éxito en los negocios de artesanía en México. Estudios Gerenciales, 23(104), 77-99. 
Hernández, R., Fernández, C., y Baptista, P. (2006). Metodología de la investigación. México: Mc Graw Hill.

Heunks, F. (1998). Innovation, Creativity and Success. Small Business Economics, 10, 263272.

Holmes, S., y Nicholls, D. (1989). Modelling the Accounting Information Requirements of Small Business. Accounting and Business Research, 19 (74), 143-150.

Homsby, J. S., Kuratko, D. F., y Zahra, S. A. (2002). Middle managers perception of the internal environment for corporate entrepreneurship: Assessing a measurement scale. Journal of Business Venturing, 17 (3), 253-273.

Hsueh, L. y Tu, Y. (2004). Innovation and the Operational Performance of Newly Established Small and Medium Enterprises in Taiwan. Small Business Economics, 23 (2), 99-113.

Huges, A. (2001). Innovation and Business Performance: Small Entrepreneurial Firms in the UK and the EU. New Economy, 8, 157-163.

Igo, T., y Skitmore, M. (2006). Diagnosing the organizational culture of an Australian engineering consultancy using the competing values framework. Construction Innovation, 6, 121-139.

INE. (2000). Encuesta sobre Innovación Tecnológica en las empresas. Madrid. Servicio de Publicaciones del Instituto de Estadísticas.

James, C., y Connolly, M. (2009). An analysis of the relationship between the organizational culture and the performance of staff work groups in schools and the development of an explanatory model. School Leadership, Management and Administration, 12 (4), 389-407.

Jeuchter, W.; Fisher, C. y Alford, R. (1998). Five conditions for high performance cultures. Training and Development, 52, (5), 63-67.

Julien, P. A. (2003). Las PYME: Balance y perspectiva. Cali: Universidad ICESI.

Kamoche, K. (1996). Strategic Human Resource Management Within a ResourceCapability View of the Firm. Journal of Management Studies, 33 (2), 213-233.

Kaplan, R. y Norton, D. (1993). Evaluación de resultados: algo más que números. HarvardDeusto Business Review, 55, 18-25.

Khazanchi, S., Lewis, M., y Boyer, K. (2007). Innovation-supportive culture: The impact of organizational values on process innovation. Journal of Operations Management, 25, 871884. 
Kim, J., Lee, J., y Yu, K. (2004). Corporate culture and organizational performance. Journal of Managerial Psychology, 19 (4), 340-359.

Kotter, J., y Heskett, J. (1992). Corporate culture and perfomance. New York: Free Press.

Kuratko, D. F., Ireland, R. D., Covin, J. G., y Hornsby, J. S. (2005). A Model of Midddle Level Managers, Entrepreneurial Behavior. Entrepreneurship Theory and Practice, 29 (6), 699-716.

Kuz, D. (2010). Exploration of Intrapreneurship and Innovation in Advanced Technology Organizations in the Western United States. Recuperado el 24 de enero de 2011, de: http://proquest.umi.com/pqdlink?Ver=1\&Exp=01-23-

2016\&FMT=7\&DID=2168222101\&RQT=309\&attempt=1\&cfc=1

Kyriakopoulos, K., Meulenber, M., y Nilsson, J. (2004). The Impact of Cooperative Structure and Firm Culture on Market Orientation and Performance. Agrobusiness, 20 (4), 379-396.

La Rovere, R. Hasenclever, L. (2003). Innovación, competitividad y adopción de tecnologías de la información y de la comunicación en pequeñas y medianas empresas: algunos estudios de caso sobre Brasil. Recuperado el 08 de 02 del 2011 de: http://www.littec.ungs.edu.ar/eventos/renata\%20la\%20rovere\%20y\%20lia\%20hasenclever. pdf.

Lau, C., yNgo, H. (2004). The HR system, organizational culture, and product innovation. International Business Review, 13 (6), 685-703.

Lee, C. K., Tan, B., y Chlu, J. Z. (2008). The impact of organizational culture and learning on innovation performance. International Journal of Innovation and Learning, 5 (4), 413428.

Lin, Y,. yChen, Y.C. (2007). Does innovation lead to performance? An empirical study of SMEs in Taiwan. Management Research News, 30 (2), 115-132.

Lippman, S. y Rumelt, R. P. (1982). Uncertain Imitability: An Analysis of Interfirm Differences in Efficiency under Competition. The Bell Journal of Economics, 13 (2), 418438.

López, C. (2008). Influencia del comportamiento emprendedor de los mandos medios en el fomento del corporate entrepreneurship. Tesis doctoral. Universidad Ramón Llull. Departamento de Política de Empresa, Dirección de Recursos Humanos y Sistemas de Información. 
López, J., y Sabater R. (1998). La Teoría de Los Recursos y Capacidades de la Empresa. Una revisión. Recuperado el 01 de 02 de 2011 de: https://www.um.es/fee/documentos/dt200.pdf

Lopez, N., Montes, J. y Vázquez, C. (2003). Fuentes tecnológicas para la innovación. Algunos datos para la industria española. Madrid .

Lusthaus, C.; Adrien, M.; Anderson, G.; Carden, F. y Montalvan G. (2002). Evaluación Organizacional. Washington DC: BID.

Maidique, M., y Zirger, B. (184). A Study of Success and Failure in Product Innovation: The Case of the U.S. Electronics Industry. IEEE Transactions on Engineering Management, Vol. 31 (4), 192-203.

McGinnis, M., y Verney, T. (1987). Innovation Management an Intrapreneurship. Sam Advanced Management Journal, 19-23.

Macmillan, I., yMcgrath, R. (2000). The entrepreneurial Mind-set. Boston: Harvard Business School Press.

Malaver, F. Vargas, (2004). Innovation process in Colombian industry: results from different case studies. Cuadernos de Administración, 17 (28), 9-51

Maldonado, G., Madrid, A., Martinez, M. y Aguilera, L. (2009). Los efectos de la innovación en el rendimiento de las MIPYMES de Aguasclientes: una evidencia empírica. Recuperado el 25 de junio del 2010, de: http://www.revista.economia.uady.mx/2009/XXVI/73/02.pdf

Malmi, T. (1999). Activity-based costing diffusion across organizations. An exploratory empirical analysis of Finnish firms. Accounting, Organizations and Society, 24, 649-672.

Manimala, M. J. (2006). Organizational Constraints on Innovation and Intrapreneurship:Insights from Public Sector. Vikalpa, 31, 49-60.

Marcus, M. H., y Zimmerer, A. 2003 Longitudinal Study of the Impact of Intrapreneurial programs in Fortune 500 firms, Journal of Management Research, 3 (1), 11-22.

Martínez, P. C. (2006). El método de estudio de caso: Estrategia metodológica de la investigación científica. Pensamiento y Gestión, 20, 165-193.

Martins, E., y Terblanche, F. (2003). Building organizational culture that stimulates creativity and Innovation. European Journal of Innovation Management, 6 (1), 64-74.

Maxwell, J. A. (1996). Qualitative Research Design: An Interactive Approach. California: Sage Publications, Thousand Oaks, 
Medina, C. y Espinoza, M. (1994). La innovación en las organizaciones modernas. Recuperado el 12 de junio del 2010, de:

http://www.azc.uam.mx/publicaciones/gestion/num5/doc06.htm

Menéndez, J., López, J., Rodríguez, A. y Francesco, S. (2007). El impacto del uso efectivo de las TIC sobre la eficiencia técnica de las empresas españolas. Estudios Gerenciales, 23(103), 65-84.

Merchant, K. (1984). Influences on departmental budgeting: An empirical examination of a contingency model. Accounting, Organizations and Society, 9 (34), 291-307.

Miles, R., y Snow, C. (1978). Organizational strategy, structure and process. New York: McGraw Hill.

MINCOMERCIO. (2010). En 10,3\% aumentó número de viajeros extranjeros a Colombia. Recuperado el 24 de 01 de 2011 de: http://www.mincomercio.gov.co/eContent/NewsDetail.asp?ID=8449\&IDCompany=1

Morcillo, P. (2007). Cultura e innovación empresarial: la conexión perfecta. España: Thomson.

Moreno, M., Munera, J. L.,y García, D. (2011). La innovación como factor de competitividad de la empresa española. Información Comercial Española, 860, 99-113.

Moriano, J., Topa, G., Valero, E. y Levy, J. (2009). Identificación organizacional y conducta "intraemprendedora". Anales de Psicología, 25 (2), 277-287.

Morris, M. A., Avila, R., y Allen, J. (1993). Individualism and the modern coporation: Implicacions for innovation and entrepreneurship. Journal of Management, 3 (19), 595612.

Morris, M., y Kuratko, D. F. (2002). Corporate Entrepreneurship. Harcourt: College Publishers.

Naranjo, J. C., Sanz, R. y Jiménez, D. (2008). Cultura organizacional e innovación: un estudio empírico. En J. Pindado García. Estableciendo puentes en una economía global. Salamanca.

Nelson, R. y Winter. S.G. (1982). An evolutionary theory of economic change. En D.C NORTH, 1994. Economic performance through time. The American Economic Review, 84(3), 359-368.

North, D. (1990). Institutions, institutional change, and economic performance. Cambridge: Cambridge University Press. 
O'cass, A., y Ngo, L. (2007). Market orientation versus innovative culture: two routes to superior brand performance. European Journal of Marketing, 41 (78), 868-887.

Obenchain, A., yJohnson, W. (2004). Product and process innovation in service organizations: The influence of org. Journal of Applied Management and Entrepreneurship, 9 (3), 91-113.

OECD y EUROSTAT. (2005). Manual de Oslo. Noruega: Organización para la Cooperación y Desarrollo Económico y Oficina de Estadística de las Comunidades Europeas.

Ogbonna, E., y Harris, L. (2000). Leadership style, organizational culture and performance: empirical evidence from UK companies. Internationa Journal of Human Resources Management, 11 (4), 766-788.

Penrose, E. T. (1962). Teoría del crecimiento de la empresa. Madrid: Editorial Aguilar.

Pérez, R.; Garzón, M., y Nieto, M. (2009). Análisis empírico de la aplicación del modelo de modernización de la gestión para organizaciones en Pymes colombianas. Revista EAN, 65, 77-105.

Pinchot III, G. (1985). Intrapreneuring. New York: Harper y Row.

Prahalad, C. K. yHamel, G. (1991). La organización por unidades estratégicas de negocio ya no sirve. Harvard-Deusto Business Review, primer trimester 1991, 47-64.

Quinn, R. yRohrbaugh, J. (1983). A spatial model of effectiveness criteria: towards a competing values approach to organizational analysis. Management Science, 29 (3), 363377

Rialp, A. (1998). El método del caso como técnica de investigación y su aplicación al estudio de la función directiva, ponencia presentada en el IV Taller de Metodología ACEDE, 23-25 de abril, Arnedillo, La Rioja.

Restrepo, D. (2007). Las Pymes y el crecimiento económico en Colombia (años 19902000). Recuperado el 20 de mayo de 2010, de: http://www.javeriana.edu.co/biblos/tesis/economia/tesis11.pdf.

Rhoads, G. R. (2005). Initiating an Entrepreneurial Mindset in the Department of Defense (DoD): Testing a Comprehensive Model. Master's thesis. Air Force Inst of Tech WrightPatterson Afb Oh School Of Engineering And Management.

Rodriguez, A. (2007). Transferencia de conocimiento en relaciones inter-organizacionales: su efecto sobre el desempeño de la firma receptora. Estudios gerenciales, 23 (103), 13-37.

Rogers, E. (1983). Diffussion and Innovation. New York: Free Press. 
Ross, J. (1987). Intrapreneurship and Corporate Culture. Industrial Management, 29 (1), 22-25.

Samuelsson, M. y Dahlqvist, J. (2005). Which Schumpeter is right? Comparing nascent exploitation processes. En P. D. Reynolds et al. (Eds.), Frontiers of entrepreneurial Research (pp. 1-10). Babson Park: Babson College Center.

Sathe, V. (2003). Corporate entrepreneurship: top managers and new business creation. Inglaterra: Cambridge University Press.

Schein, E. (1985). Organizational Culture and Leadership. San Francisco: Jossei-Bass.

Schein, E. (1988). Organisational culture. Working Paper. Massachussets: Sloan School of Management MIT.

Schumpeter, J. (1935). Análisis del cambio económico. Recuperado el 29-05-2010, de http://eumed.net/cursecon/textos/schump-cambio.pdf

Smircich, L. (1983). Concepts of culture and organizational analysis. Administrative Science Quarterly, 28 (3), 339-358.

Sonrensen, J. (2002). The strength of corporate culture and the reliabiity of firm performance. Administrative Science Quarterly, 47, 70-91.

Stake, R. E. (2005). Investigación con estudio de casos. Madrid: Ed. Morata, 3era edición.

Stock, G., McFaddena, K., yGowen, Ch. (2007). Organizational culture, critical success factors, and the reduction of hospital errors. International Journal Production Economics, 106, 368-392.

Teece, D., Pisano, G., y Shuen A. (1997): Dynamic capabilities and strategic management. Strategic Management Journal, 18(7), 509-533.

Torres, N., Vallejo, B., Rivera, J., y Salamanca, A. (2005). Estudio descriptivo del sector productor y comercilizador de cosméticos en Bogotá, Colombia. Revista Colombiana de Ciencias Químicas y Farmaceúticas, 34, 172-180.

Trujillo, M. A., y Guzmán, A. (2008). Intraemprendimiento: Una revisión al constructo teórico, sus implicaciones y agenda de investigación futura. Cuadernos de Administración, 21 (35), 37-63.

Tseng, S. M. (2010). The correlation between organizational culture and knowledge conversion on corporate performance. Journal of Knowledge and Management, 14 (2), 269284.

Urbano, D. y Toledano, N. (2007). El estudio de casos cómo estrategia de investigación en creación de empresas: cuestiones preliminares. Revista OIKOS, 11 (24), 145 - 160. 
Van Auken, H., Madrid, A., yGarcía, D. (2008). Innovation and performance in Spanish manufacturing SMEs. International Journal of Entrepreneurship and Innovation Management, 8 (1), 36-56.

Van Brusel, G., y Ulijn, J. (2008). Developing Intrapreneurship as a Career Perspective for Senior Professionals: Towards an Innovative HRM and Career Management Approach, The 5th international conference on innovation and management. The Netherlands.

Varela, J., e Irizar, I. (2009). Caracterización de los Intraemprendimientos en el Grupo Mondragón de España y en las empresas de Ibagué en Colombia. Recuperado el 21 de enero de 2011 de: http://www.clee2008.ufsc.br/31.pdf

Velásquez, F. (2004). La estrategia, la estructura y las formas de asociación: fuentes de ventaja competitiva para las PYMES colombianas. Estudios Gerenciales, 93, 73-97.

Veysel, A. Y. (2009). Linking intrapreneurship activities to multidimensional firm performance in Turkish manufacturing firms: an empirical study, International Entrepreneurship Management, 32, 1-19.

Wade, M. y Hulland, J. (2004). The resource-based view and information systems research: Review, extension and suggestions for future research. MIS Quarterly, 28, 107-142.

Wen-Chia, H. (2007). Using the competing values framework to compare leaders roles, managerial activities behaviours, and organizational culture between generations of family business in Taiwan, Tesis Doctoral, School of Graduate Studiesf, University of the Incarnate Word.

Wernerfelt, B. (1984). A resource based view of the firm. Strategic Management Journal, 5 (2), 171-180.

Winter, S. G. (1995). Four Rs of Profitability: Rents, Resources, Routines and Replication. en C. A. Montgomery (ed.): Resource-based and Evolutionary Theories of the Firm. Boston: Ed. Kluwer Academic Publishers, 147-178.

Wood, C. (2004). Entrepreneurial Mindset in Department of Defense (DoD) Organizations Antecedents and Outcomes, Tesis de Maestría para la Air Force Inst Of Tech WrightPatterson Afb Oh School Of Engineering And Management. Recuperado el 19 de enero del 2011,de:

http://www.dtic.mil/cgibin/GetTRDoc?AD=ADA423134\&Location=U2\&doc=GetTRDoc. pdf

World Economic Forum. (2009). Evaluación de la competitividad en el sector de viajes y turismo en Colombia. Washington: World Economic Forum. 
Yamin, S.; Gunasekaran, A. y Mavondo, F. (1999). Innovation index and its implications on organizational performance: a study of Australian manufacturing companies. International Journal of Technology Management, 17 (5), 495-503.

Yasuda, T. (2005). Firm growth, size, age and behavior in Japanese manufacturing. Small Business Economics, 24, 1-15.

Yescas, M (2008). La cultura organizacional y el desempeño de los negocios de artesanías. Tesis de Posgrado, CIIDIR Unidad Oaxaca, Instituto Politécnico Nacional, México.

Yin, R. K. (1989). Case Study Research: Design and Methods. California: Sage Publications Inc, Thousand Oaks,.

Zapata, A., y Rodriguez, A. (2008). Gestión de la Cultura Organizacional, bases conceptuales para su implementación. Cali, Colombia.: Facultad de Ciencias de la Administración. Universidad del Valle.

Zapata, E. (2004). Las Pymes y su problemática empresarial. Análisis de casos. Revista EAN, 52, 119-135.

Zhang, M., Li, H. y Wei, J. (2008). Examining the relationship betwen organizational cuture and performance. The perspectives of consistency and balance. Science of science and management of $S y T, 28$ (8), 140-148.

Zhao, F. (2005). Exploring the synergy between entrepreneurship and innovation, International Journal of Entrepreneurial Behaviour Research, 1 (1), 25 - 41. 
ANEXOS 


\section{Anexo 1. Encuesta primera investigación}

BLOQUE I.- DATOS GENERALES

1.- Indique los valores de las siguientes variables, así como la tendencia para el año 2010.

\begin{tabular}{|c|c|c|c|c|c|}
\hline & \multirow[b]{2}{*}{2008} & \multirow[b]{2}{*}{2009} & \multicolumn{3}{|c|}{ Tendencia 2010} \\
\hline & & & Aumento & Igual & $\begin{array}{c}\text { Disminu } \\
\text { ción }\end{array}$ \\
\hline $\begin{array}{l}\text { Ingresos por } \\
\text { ventas } \\
\text { (millones de } \\
\text { pesos } \\
\text { colombianos) }\end{array}$ & $\begin{array}{l}\mathbf{1} \square \text { Entre } 1-20 \\
\mathbf{2} \square \text { Entre } 21-50 \\
\mathbf{3} \square \text { Entre } 51-100 \\
\mathbf{4} \square \text { Entre } 101-200 \\
\mathbf{5} \square \text { Más de } 200\end{array}$ & $\begin{array}{l}\mathbf{1} \square \text { Entre } 1-20 \\
\mathbf{2} \square \text { Entre } 21-50 \\
\mathbf{3} \square \text { Entre } 51-100 \\
\mathbf{4} \square \text { Entre } 101-200 \\
\mathbf{5} \square \text { Más de } 200\end{array}$ & $\mathbf{1} \square$ & $\mathbf{2} \square$ & 3 \\
\hline $\begin{array}{l}\mathrm{N}^{\mathrm{o}} \text { medio de } \\
\text { empleados }\end{array}$ & $>=0$ & $>=0$ & $1 \square$ & $2 \square$ & $3 \square$ \\
\hline
\end{tabular}

2.-¿Cuántos años lleva funcionando su empresa?............. .>=0 años

3.- ¿El control mayoritario de su empresa es familiar? (Un grupo familiar tiene más del $50 \%$ del capital y el gerente es familiar):
SI 1
NO O(Continúe en la P7)

4.- Los puestos de dirección, ¿están ocupados mayoritariamente por miembros de la familia?
SI 1
NO 0

5.- El género del director general / gerente de su empresa, es:

Masculino 1

Femenino 2

6.- ¿Cuál es el nivel de formación del director general / gerente de su empresa?:

\begin{tabular}{ll|ll}
\hline Estudios Primarios, Bachiller o Técnico & $\square \mathbf{1}$ & Estudios universitarios & $\square \mathbf{2}$ \\
\hline
\end{tabular}

7.- Si el director general/gerente tiene estudios universitarios. ¿Qué carrera posee?:

8. - Indique su grado de acuerdo con las siguientes afirmaciones respecto de su sector:

\begin{tabular}{|l|c|c|c|c|c|}
\hline Es fácil que entren nuevas empresas & $\mathbf{1}$ & $\mathbf{2}$ & $\mathbf{3}$ & $\mathbf{4}$ & $\mathbf{5}$ \\
\hline $\begin{array}{l}\text { Existe una elevada competencia entre las empresas del } \\
\text { sector en el que opera }\end{array}$ & $\mathbf{1}$ & $\mathbf{2}$ & $\mathbf{3}$ & $\mathbf{4}$ & $\mathbf{5}$ \\
\hline $\begin{array}{l}\text { Los clientes tienen más poder en la negociación que las } \\
\text { empresas de su sector }\end{array}$ & $\mathbf{1}$ & $\mathbf{2}$ & $\mathbf{3}$ & $\mathbf{4}$ & $\mathbf{5}$ \\
\hline $\begin{array}{l}\text { Los proveedores tienen más poder en la negociación que } \\
\text { las empresas de su sector }\end{array}$ & $\mathbf{1}$ & $\mathbf{2}$ & $\mathbf{3}$ & $\mathbf{4}$ & $\mathbf{5}$ \\
\hline
\end{tabular}




\begin{tabular}{|l|l|l|l|l|l|l|}
\hline $\begin{array}{l}\text { Existe facilidad para crear productos sustitutos de los } \\
\text { fabricados por su sector }\end{array}$ & $\mathbf{1}$ & $\mathbf{2}$ & $\mathbf{3}$ & $\mathbf{4}$ & $\mathbf{5}$ \\
\hline
\end{tabular}

BLOQUE II.- INNOVACIÓN, ESTRATEGIA Y TECNOLOGÍA

\begin{tabular}{|c|c|c|c|c|c|c|c|}
\hline \multirow{2}{*}{\multicolumn{3}{|c|}{$\begin{array}{l}\text { 9.- ¿Ha realizado algún cambio o mejora en sus productos, procesos } \\
\text { o sistemas de gestión en los últimos dos años? En caso afirmativo } \\
\text { indique el grado de importancia de estos cambios para su empresa: }\end{array}$}} & \multicolumn{5}{|c|}{$\begin{array}{l}\text { Grado de } \\
\text { importancia }\end{array}$} \\
\hline & & & \multicolumn{3}{|c|}{$\begin{array}{l}\text { Poco } \\
\text { Importante }\end{array}$} & \multicolumn{2}{|c|}{$\begin{array}{l}\text { Muy } \\
\text { Importa } \\
\text { nte }\end{array}$} \\
\hline $\begin{array}{l}\text { Productos/servicios } \\
\text {-Cambios o mejoras en productos/servicios }\end{array}$ & & & 1 & 2 & 3 & 4 & 5 \\
\hline -Comercialización nuevos productos/servicios & No & $\mathrm{S}$ & 1 & 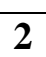 & 3 & 4 & 5 \\
\hline \begin{tabular}{|l} 
Procesos \\
-Cambios o mejoras en los procesos de \\
producción/servicios \\
-Adquisición de nuevos equipos
\end{tabular} & No 0 & Sí 1 & 1 & 2 & 3 & 4 & 5 \\
\hline $\begin{array}{l}\text { Sistemas de gestión } \\
\text {-Dirección y gestión } \\
\text {-Compras y aprovisionamientos } \\
\text {-Comercialización/Ventas }\end{array}$ & $\begin{array}{l}\text { No } 0 \\
\text { No } 0 \\
\text { No } 0\end{array}$ & $\begin{array}{l}\text { Sí } 1 \\
\text { Sí } 1 \\
\text { Sí } 1\end{array}$ & $\begin{array}{l}1 \\
1 \\
1\end{array}$ & $\begin{array}{l}2 \\
2 \\
2\end{array}$ & $\begin{array}{l}\mathbf{3} \\
\mathbf{3} \\
\mathbf{3}\end{array}$ & $\begin{array}{l}4 \\
4 \\
4\end{array}$ & $\begin{array}{l}5 \\
5 \\
5\end{array}$ \\
\hline
\end{tabular}

10. A continuación se le presentan cuatro TIPOS DE EMPRESAS. Indique con cuál de ellas se identifica la suya atendiendo a su actuación en los dos últimos años (MARQUE SÓLO UNA RESPUESTA):

Tipo A.- Suele realizar cambios y mejoras en los productos y mercados con relativa frecuencia, tratando de ser la primera en desarrollar nuevos productos, aun con el riesgo de que estas innovaciones no tengan éxito.

$\underline{\text { Tipo B. }}$ - Mantiene una base relativamente estable de productos y mercados, mientras que al mismo tiempo desarrolla de forma selectiva nuevos productos y mercados, tratando de imitar a las empresas que ya los desarrollaron y tuvieron éxito.

Tipo C.- Ofrece un conjunto relativamente estable de productos para un mercado relativamente estable. No está interesada en las modificaciones sino que se concentra en la mejora continua del trabajo dentro de su campo de actuación.

Tipo D.- No cuenta con un área de producto-mercado duradera y estable.

Normalmente actúa forzada por las presiones del entorno y de la competencia.

11.- La POSICIÓN TECNOLÓGICA de su empresa se puede considerar (SÓLO UNA RESPUESTA):

\begin{tabular}{|l|l|}
\hline$\square$ Tipo A 1 & $\bullet \begin{array}{l}\text { Desarrollo interno de la tecnología que utilizamos con el fin de obtener } \\
\text { mejores resultados que la competencia. }\end{array}$ \\
\hline$\square$ Tipo B 2 & $\bullet \begin{array}{l}\text { La tecnología adquirida por la empresa o el uso que se hace de ella nos } \\
\text { posiciona por delante de la competencia. }\end{array}$ \\
\hline$\square$ Tipo C 3 & $\begin{array}{l}\text { La tecnología que utilizamos es la misma que se utiliza en la mayoría de } \\
\text { empresas del sector y sólo realizamos nuevas inversiones cuando } \\
\text { comprobamos que la competencia obtiene buenos resultados. }\end{array}$ \\
\hline$\square$ Tipo D 4 & $\begin{array}{l}\text { Nuestros principales competidores tienen una tecnología más eficiente o } \\
\text { moderna que la nuestra. }\end{array}$ \\
\hline
\end{tabular}


12.- Para cada una de las cuatro cuestiones siguientes, reparta 100 puntos entre las 4 respuestas $(\mathbf{a}, \mathbf{b}, \mathbf{c}, \mathbf{d})$ que reflejan lo más apegado a su realidad en los distintos aspectos de la cultura actual de su empresa:

Defina SU EMPRESA >=0 y <=100

Actual

a) Es como una gran familia. La gente comparte mucho con los demás

b) Es una entidad muy dinámica y emprendedora. La gente está dispuesta a apostar por sus ideas y asumir riesgos

c) Es una entidad orientada a resultados. La gente es muy competitiva y enfocada fundamentalmente a conseguir los objetivos

d) Es una entidad muy jerarquizada, formalizada y estructurada. Para cualquier actividad existen procedimientos y normas previamente definidos

TOTAL

Defina el ESTILO DE DIRECCIÓN EN SU EMPRESA: >=0 y <=100

Actual

a) Se caracteriza por promover el trabajo en equipo, el consenso y la participación

b) Se caracteriza por promover la iniciativa del individuo, la asunción de riesgos, la innovación y la singularidad

c) Se caracteriza por promover la competitividad agresiva y la consecución de objetivos ambiciosos

d) Se caracteriza por promover la seguridad en el empleo, la permanencia en el puesto y la existencia de poca incertidumbre

TOTAL

\section{Defina los VALORES COMPARTIDOS POR EL PERSONAL DE SU Actual
EMPRESA: $>=0 \mathrm{y}<=100$}

a) Los valores compartidos son la lealtad, el compromiso con la empresa, la confianza mutual y el trabajo en grupo

b) Los valores compartidos son el compromiso con la innovación y el cambio continuo

c) Los valores compartidos son la agresividad, el espíritu ganador y la consecución de los objetivos previstos

d) Los valores compartidos con la empresa son el respeto por las normas y políticas formales y el cumplimiento con la jerarquía

TOTAL

Defina en qué basa EL ÉXITO DE SU EMPRESA: >=0 y <=100

Actual

a) El éxito se basa en el trabajo en equipo, el compromiso e interés por los trabajadores

b) El éxito se basa en el desarrollo de productos únicos y novedosos. Ser líder en productos e innovación

c) El éxito se basa en la penetración en el mercado y la cuota de mercado. Ser el número uno respecto a los competidores

d) El éxito se basa en la eficiencia. La adecuada programación de la producción y los bajos costes son aspectos críticos

TOTAL 


\section{BLOQUE IV.- RENDIMIENTO}

13.- Indique cuál ha sido la evolución de los siguientes aspectos en su empresa en los dos últimos años.

Muy

Desfavorable

a) Calidad del producto / servicio

-Eficiencia de los procesos operativos internos

- Organización de las tareas del personal

-Satisfacción de los clientes

- Rapidez de adaptación a las necesidades de los mercados

-Imagen de la empresa y de sus productos/servicios

- Incremento de la cuota de mercado

-Incremento de la rentabilidad

- Incremento de la productividad

-Motivación / satisfacción de los trabajadores

-Reducción de la rotación de personal (abandono voluntario trabajadores)

-Reducción del ausentismo laboral

\begin{tabular}{|c|c|c|c|c|}
\multicolumn{4}{|c|}{ able } \\
\hline 1 & 2 & 3 & 4 & 5 \\
\hline 1 & 2 & 3 & 4 & 5 \\
\hline 1 & 2 & 3 & 4 & 5 \\
\hline 1 & 2 & 3 & 4 & 5 \\
\hline 1 & 2 & 3 & 4 & 5 \\
\hline 1 & 2 & 3 & 4 & 5 \\
\hline 1 & 2 & 3 & 4 & 5 \\
\hline 1 & 2 & 3 & 4 & 5 \\
\hline 1 & 2 & 3 & 4 & 5 \\
\hline 1 & 2 & 3 & 4 & 5 \\
\hline 1 & 2 & 3 & 4 & 5 \\
\hline 1 & 2 & 3 & 4 & 5 \\
\hline
\end{tabular}




\section{Anexo 2. Encuesta segunda investigación}

Objetivo: conocer como la cultura organizacional influye en la innovación y el desempeño de las empresas.

Nota de confidencialidad: la información recolectada será utilizada únicamente para fines académicos y de preparación de acciones de intervención en favor de las empresas.

\section{BLOQUE I.- DATOS GENERALES}

\begin{tabular}{|c|c|c|c|c|}
\hline \multicolumn{5}{|c|}{ DATOS BÁSICOS DE LA EMPRESA } \\
\hline \multirow[t]{2}{*}{ Razón social: } & \multirow[t]{2}{*}{ NIT: } & \multicolumn{3}{|c|}{ Sector de actividad: } \\
\hline & & $\begin{array}{l}\square \\
\text { HOTEL }\end{array}$ & $\begin{array}{l}\text { ㅁ } \\
\text { AGE. } \\
\text { VIAJES }\end{array}$ & $\begin{array}{l}\text { ㅁ } \\
\text { RESTAURANTES }\end{array}$ \\
\hline Dirección: & \multicolumn{4}{|c|}{ Teléfono: } \\
\hline \multicolumn{5}{|l|}{ Página Web: } \\
\hline Nombre Contacto: & \multicolumn{4}{|c|}{ Cargo: } \\
\hline
\end{tabular}

1. Indique el número de trabajadores en la empresa en los siguientes años.

\begin{tabular}{|l|l|c|}
\hline 2009: & 2010: & $\begin{array}{c}\text { Tendencia. } \\
\text { 2011: }\end{array}$ \\
\hline & & \\
\hline
\end{tabular}

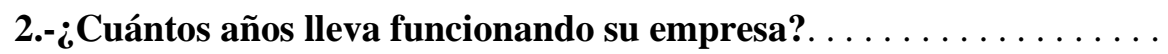

3.- ¿El control mayoritario de su empresa es familiar? (Un grupo familiar tiene más del $50 \%$ del capital y el gerente es familiar):

NO(Continúe en la P5)

4.- Los puestos de dirección, ¿están ocupados mayoritariamente por miembros de la familia?

$$
\text { SI } \quad \square \text { NO }
$$

5.- El género del director general / gerente de su empresa, es:

$$
\square \text { Masculino } \square \text { Femenino }
$$

6.- ¿Cuál es el nivel de formación del director general / gerente de su empresa?:

\begin{tabular}{|l|l|l|l|}
\hline Estudios Primarios, Bachiller o Técnico & $\square$ & Estudios universitarios & $\square$ \\
\hline
\end{tabular}

7.- Si el director general/gerente tiene estudios universitarios. ¿Qué carrera posee?: 


\begin{tabular}{|c|c|c|c|c|c|c|c|}
\hline \multirow{2}{*}{\multicolumn{3}{|c|}{$\begin{array}{l}\text { 8.- ¿Ha realizado algún cambio o mejora en sus productos, procesos } \\
\text { o sistemas de gestión en los últimos dos años? En caso afirmativo } \\
\text { indique el grado de importancia de estos cambios para su empresa: }\end{array}$}} & \multicolumn{5}{|c|}{$\begin{array}{l}\text { Grado de } \\
\text { importancia }\end{array}$} \\
\hline & & & \multicolumn{3}{|c|}{$\begin{array}{l}\text { Poco } \\
\text { Importante }\end{array}$} & \multicolumn{2}{|c|}{$\begin{array}{l}\text { Muy } \\
\text { Importa } \\
\text { nte }\end{array}$} \\
\hline Productos/servicios & & & & & & & \\
\hline -Cambios o mejoras en productos/servicio & No 0 & Sí 1 & 1 & 2 & 3 & 4 & 5 \\
\hline -Comercialización nuevos productos/servicios & No ( & & $\mathbf{1}$ & 2 & 3 & 4 & 5 \\
\hline $\begin{array}{l}\text { Procesos } \\
\text {-Cambios o mejoras en los procesos de } \\
\text { producción/servicios }\end{array}$ & & Sí 1 & 1 & 2 & 3 & 4 & 5 \\
\hline ción de nuevos equipos & & & 1 & 2 & 3 & 4 & 5 \\
\hline $\begin{array}{l}\text { Sistemas de gestión } \\
\text {-Dirección y gestión } \\
\text {-Compras y aprovisionamientos } \\
\text {-Comercialización/Ventas }\end{array}$ & $\begin{array}{l}\text { No } 0 \\
\text { No } 0 \\
\text { No } 0\end{array}$ & $\begin{array}{l}\text { Sí } 1 \square \\
\text { Sí } 1 \square \\
\text { Sí } 1 \square\end{array}$ & $\begin{array}{l}\mathbf{1} \\
\mathbf{1} \\
\mathbf{1}\end{array}$ & $\begin{array}{l}2 \\
2 \\
2\end{array}$ & $\begin{array}{l}3 \\
3 \\
3\end{array}$ & $\begin{array}{l}4 \\
4 \\
4\end{array}$ & $\begin{array}{l}5 \\
5 \\
5\end{array}$ \\
\hline
\end{tabular}

\section{BLOQUE III.- CULTURA ORGANIZACIONAL INTRAEMPRENDEDORA}

9.- Para cada una de las cuatro cuestiones siguientes, reparta 100 puntos entre las 4 respuestas $(\mathbf{a}, \mathbf{b}, \mathbf{c}, \mathbf{d})$ que reflejan lo más apegado a su realidad en los distintos aspectos de la cultura actual de su empresa:

\section{Defina SU EMPRESA}

a) Es como una gran familia. La gente comparte mucho con los demás

b) Es una entidad muy dinámica y emprendedora. La gente está dispuesta a apostar por sus ideas y asumir riesgos

c) Es una entidad orientada a resultados. La gente es muy competitiva y enfocada fundamentalmente a conseguir los objetivos

d) Es una entidad muy jerarquizada, formalizada y estructurada. Para cualquier actividad existen procedimientos y normas previamente definidos

TOTAL

100

\section{Defina el ESTILO DE DIRECCIÓN EN SU EMPRESA:}

a) Se caracteriza por promover el trabajo en equipo, el consenso y la participación

b) Se caracteriza por promover la iniciativa del individuo, la asunción de riesgos, la innovación y la singularidad

c) Se caracteriza por promover la competitividad agresiva y la consecución de objetivos ambiciosos

d) Se caracteriza por promover la seguridad en el empleo, la permanencia en el puesto y la existencia de poca incertidumbre

TOTAL

100

Defina los VALORES COMPARTIDOS POR EL PERSONAL DE SU

EMPRESA:

a) Los valores compartidos son la lealtad, el compromiso con la empresa, la 
confianza mutual y el trabajo en grupo

b) Los valores compartidos son el compromiso con la innovación y el cambio continuo

c) Los valores compartidos son la agresividad, el espíritu ganador y la consecución de los objetivos previstos

d) Los valores compartidos con la empresa son el respeto por las normas y políticas formales y el cumplimiento con la jerarquía

TOTAL

Defina en qué basa EL ÉXITO DE SU EMPRESA:

\begin{tabular}{|c|c|}
\hline $\begin{array}{l}\text { a) El éxito se basa en el trabajo en equipo, el compromiso e interés por los } \\
\text { trabajadores }\end{array}$ & \\
\hline $\begin{array}{l}\text { b) El éxito se basa en el desarrollo de productos únicos y novedosos. Ser líder en } \\
\text { productos e innovación }\end{array}$ & \\
\hline $\begin{array}{l}\text { c) El éxito se basa en la penetración en el mercado y la cuota de mercado. Ser el } \\
\text { número uno respecto a los competidores }\end{array}$ & \\
\hline $\begin{array}{l}\text { d) El éxito se basa en la eficiencia. La adecuada programación de la producción y los } \\
\text { bajos costes son aspectos críticos }\end{array}$ & \\
\hline TOTAL & 100 \\
\hline
\end{tabular}

\begin{tabular}{|c|c|c|c|c|c|}
\hline \multirow{3}{*}{\begin{tabular}{|l|} 
10.- Indique su grado de acuerdo o desacuerdo con las \\
siguientes afirmaciones, según se hayan dado las situaciones \\
\\
-Pueden los trabaiadores iniciar algunos provectos sin tener que
\end{tabular}} & \multicolumn{5}{|c|}{ Grado deacuerdo } \\
\hline & \multicolumn{3}{|c|}{$\begin{array}{l}\text { Nada de } \\
\text { Acuerdo }\end{array}$} & \multicolumn{2}{|c|}{$\begin{array}{l}\text { Totalmente } \\
\text { de acuerdo }\end{array}$} \\
\hline & 1 & 2 & 3 & 4 & 5 \\
\hline $\begin{array}{l}\text {-La participación de los trabajadores en nuevos proyectos se } \\
\text { persuade más que se obliga. }\end{array}$ & 1 & 2 & 3 & 4 & 5 \\
\hline $\begin{array}{l}\text {-Los trabajadores pueden tomar ciertas decisiones autónomamente } \\
\text { en el desarrollo de proyectos institucionales. }\end{array}$ & 1 & 2 & 3 & 4 & 5 \\
\hline $\begin{array}{l}\text { - Los trabajadores que asumen riesgos moderados en favor de la } \\
\text { organización son valoradas aunque algunas veces se equivoquen. } \\
\text { - La empresa estimula que los trabajadores tomen riesgos } \\
\text { calculados. }\end{array}$ & 1 & 2 & 3 & 4 & 5 \\
\hline $\begin{array}{l}\text {-A los trabajadores que generan o impulsan proyectos novedosos } \\
\text { se les reconoce públicamente. } \\
\text {-Se recompensa económicamente a los trabajadores que generan } \\
\text { nuevas ideas o proyectos. }\end{array}$ & 1 & 2 & 3 & 4 & 5 \\
\hline $\begin{array}{l}\text {-Está bien vista la generación espontáneade equipos de trabajo } \\
\text { para asuntos laborales. }\end{array}$ & 1 & 2 & 3 & 4 & 5 \\
\hline $\begin{array}{l}\text {-Se fomenta con frecuencia el trabajo entre personas de diferentes } \\
\text { áreas y/o niveles jerárquicos. }\end{array}$ & 1 & 2 & 3 & 4 & 5 \\
\hline $\begin{array}{l}\text { - Es frecuente que los directivos se la jueguen por los proyectos de } \\
\text { sus trabajadores. }\end{array}$ & 1 & 2 & 3 & 4 & 5 \\
\hline $\begin{array}{l}\text { - Existe un programa institucional para fomentar la iniciativa de los } \\
\text { trabajadores. }\end{array}$ & 1 & 2 & 3 & 4 & 5 \\
\hline $\begin{array}{l}\text { - Es frecuente que se asignen recursos a nuevos proyectos así no } \\
\text { estén en el plan estratégico y/o en el presupuesto. }\end{array}$ & 1 & 2 & 3 & 4 & 5 \\
\hline $\begin{array}{l}\text { - Los directivos permiten que los trabajadores usen parte de su } \\
\text { tiempo laboral para el desarrollo de proyectos auto-iniciados. }\end{array}$ & 1 & 2 & 3 & 4 & 5 \\
\hline
\end{tabular}


11.- A continuación se le presentan cuatro TIPOS DE EMPRESAS. Indique con cuál de ellas se identifica la suya atendiendo a su actuación en los dos últimos años (MARQUE SÓLO UNA RESPUESTA):

Tipo A.-No existen actividades ni se destinan recursos que estimulen la generación o desarrollo de ideas o proyectos por parte de los colaboradores.

Tipo B.- Se tienen algunos recursos disponibles para apoyar proyectos que puedan aparecer, pero no se hace gran divulgación de esto.

Tipo C.- Se tiene establecido un programa y algunos recursos para convertir ideas en proyectos.

Tipo D.-Se cuenta con una estructura, un programa de actividades y capacitación, y unos recursos que incentivan fuertemente las actividades emprendedoras e innovadoras de los trabajadores.

\section{BLOQUE IV.- ESTRATEGIA}

12. Indique si su empresa realiza habitualmente planeación estratégica formal (por escrito) y, en su caso, a que tiempo la realiza:

\begin{tabular}{|l|l|l|l|}
\hline & \multicolumn{3}{c|}{ ¿A qué tiempo? } \\
\hline Realiza Plan estratégico & \multicolumn{1}{|c|}{ ¿NO $\square$ SÍ } & 1 año & Más de 1 año $\square$ \\
\hline
\end{tabular}

\section{BLOQUE V.- RENDIMIENTO}

13.- Indique cuál ha sido la evolución de los siguientes aspectos en su empresa en los dos últimos años.

\begin{tabular}{|l|r|}
\hline Muy & Muy \\
Desfavorable & able \\
\hline
\end{tabular}

b) Calidad del producto / servicio

-Eficiencia de los procesos operativos internos

- Organización de las tareas del personal

- Satisfacción de los clientes

- Rapidez de adaptación a las necesidades de los mercados

-Imagen de la empresa y de sus productos/servicios

-Incremento de la cuota de mercado

- Incremento de la rentabilidad

- Incremento de la productividad

-Motivación / satisfacción de los trabajadores

-Reducción de la rotación de personal (abandono voluntario trabajadores)

-Reducción del ausentismo laboral

Desfavorable

able

\begin{tabular}{|l|l|l|l|l|}
\hline 1 & 2 & 3 & 4 & 5 \\
\hline 1 & 2 & 3 & 4 & 5 \\
\hline 1 & 2 & 3 & 4 & 5 \\
\hline 1 & 2 & 3 & 4 & 5 \\
\hline 1 & 2 & 3 & 4 & 5 \\
\hline 1 & 2 & 3 & 4 & 5 \\
\hline 1 & 2 & 3 & 4 & 5 \\
\hline 1 & 2 & 3 & 4 & 5 \\
\hline 1 & 2 & 3 & 4 & 5 \\
\hline 1 & 2 & 3 & 4 & 5 \\
\hline 1 & 2 & 3 & 4 & 5 \\
\hline 1 & 2 & 3 & 4 & 5 \\
\hline
\end{tabular}




\section{Anexo 3. Protocolo de entrevista tercer investigación}

\section{GUÍA DE ENTREVISTA A EMPRESARIOS Y/O DIRECTIVOS Y} COLABORADORES

\section{Objetivos del trabajo de investigación:}

1. Determinar los tipos de cultura organizacional que existen dentro de las empresas de sector turístico en Colombia.

2. Conocer los posibles rasgos de cultura de intraemprendimiento.

3. Analizar los tipos de innovación que se presentan en estas empresas.

4. Conocer y analizar el desempeño de las empresas partiendo de la tipología de su cultura, sus manifestaciones de intraemprendimiento e innovación.

\section{Objetivo de la entrevista:}

Conocer desde la percepción del propietario y/o directivo el tipo de cultura establecido en la empresa, los tipos de innovación y comportamiento intraemprendedor que se practican, y el rendimiento obtenido.

Nota: La información será tratada de manera anónima y con estricta confidencialidad.

\section{SECCIÓN I. ANTECEDENTES Y EVOLUCIÓN DE LA EMPRESA}

\section{Por favor, describa los servicios que presta su empresa:}

Descripción :

\section{Por favor, describa el proceso de creación y la evolución de la empresa hasta la fecha:}

Descripción (fecha de creación, quien o quienes la crearon (perfil de esta(s) persona(s)), motivaciones para crearla, figura jurídica empleada, entorno general y del sector turístico en el momento de la creación; principales etapas en la vida de la empresa (hitos), situación y perspectivas actuales:

\section{Describa la situación actual de su empresa para competir en el mercado:}

Descripción: (Perspectivas del sector de actividad, fortalezas y debilidades de la empresa en el sector).

\section{Describa el perfil personal y profesional del director o gerente de la empresa: \\ Descripción: (es el mismo propietario(a), género, nivel de formación.).}




\section{SECCIÓN II. CULTURA ORGANIZACIONAL}

5. Por favor describa la cultura organizacional de su empresa:

Descripción: (forma de relacionamiento de las personas, grado de formalidad en las relaciones y procesos internos, clima organizacional, perspectivas y orientación y objetivos de los individuos; que tan marcada o fuerte es la cultura organizacional).

6. ¿Por favor describa el estilo de dirección en su empresa?:

Descripción: (¿Qué aspectos promueve el líder: el trabajo en equipo, la iniciativa del individuo, la competitividad agresiva, la seguridad en el empleo y poca incertidumbre?).

\section{7. ¿Por favor describa cuales son los valores compartidos en la empresa?:}

Descripción (Describa los valores más importantes en la empresa, , como se establecen, como se transmiten, como se manifiestan, como impactan a la empresa):

8. ¿Por favor describa en que se basa el éxito de la empresa?:

Descripción (factores clave en el éxito de la empresa: trabajo en equipo, innovación, penetración en el mercado, eficiencia y bajos costos):

\section{SECCIÓN III. CULTURA DE INTRAEMPRENDIMIENTO}

9. Por favor, describa el grado de autonomía que se da a los colaboradores:

Descripción (para iniciar y mantener proyectos, para tomar decisiones en sus actividades normales, para decidir su participación en proyectos):

\section{Por favor describa que tan tolerante al riesgo y a los errores es su empresa:}

Descripción (Que tipo de riesgos pueden tomar los colaboradores, que ocurre cuando se equivoca uno):

11. Por favor describa la compensación y el reconocimiento que se brinda a los colaboradores en su empresa:

Descripción (Aspectos que se consideran dignos de reconocimiento público, formas en que se realiza, frecuencia con que se hace, cuando se hizo por última vez): 


\section{Por favor describa algunos aspectos del trabajo en equipo en su empresa:}

Descripción (cuáles son las características en su empresa?, como se estimula, cómo?, hay relaciones frecuentes entre funcionarios de diferente rango y departamento?) :

13. Por favor describa el soporte que se brinda al colaborador y la flexibilidad en la estructura de su empresa:

Descripción (se estimula la creatividad del colaborador, cómo?, flexibilidad en el uso de recursos para proyectos presentados por colaboradores?) :

\section{SECCIÓN IV. INNOVACIÓN}

\section{Por favor indique si ha innovado en productos o servicios.}

Descripción (¿Ha realizado mejoras en productos o servicios?, si es así dé ejemplos concretos. ¿Ha comercializado nuevos productos o servicios?, si es así presente ejemplos concretos):

\section{Por favor indique si ha innovado en procesos.}

Descripción (¿Ha realizado mejoras en los procesos de producción o servicios?, si es así dé ejemplos concretos. ¿Ha adquirido nuevos equipos?, si es así presente ejemplos concretos) :

\section{Por favor indique si ha innovado en gestión.}

Descripción (¿Ha realizado mejoras en dirección o gestión?, si es así dé ejemplos concretos. ¿Ha realizado mejoras en el proceso de comparas o aprovisionamiento?, si es así presente ejemplos concretos. ¿Ha realizado mejoras en el proceso de comercialización /ventas?, si es así por favor presente ejemplos concretos.) :

\section{SECCIÓN V. RENDIMIENTO}

17. ¿Cómo describe y evalúa el desempeño de la empresa en razón de la evolución de sus productos y/o servicios y de sus procesos internos?

\section{1: Nada satisfactoria}

5: Completamente satisfactoria

Descripción (calidad de los productos y /o servicios, eficiencia en procesos operativos internos, organización de las tareas del personal):

\section{8. ¿Cómo describe y evalúa el desempeño de la 1 1: Nada satisfactoria empresa en razón de la evolución de sus relaciones con el medio externo? \\ 5: Completamente satisfactoria

\begin{tabular}{l|l|l|l|l|}
$\mathbf{1}$ & $\mathbf{2}$ & $\mathbf{3}$ & $\mathbf{4}$ & $\mathbf{5}$ \\
\hline
\end{tabular}

Descripción (evolución de la satisfacción de los clientes, adaptación a las necesidades del mercado, imagen de la empresa y sus productos): 
19. ¿Cómo describe y evalúa el desempeño de la 1 : Nada satisfactoria empresa en razón de la evolución de sus principales indicadores?

5: Completamente satisfactoria

Descripción (evolución de cuota de mercado, rentabilidad, productividad), en lo posible de ejemplos que permitan entender mejor sus afirmaciones:

20. ¿Cómo describe y evalúa el desempeño de la empresa en razón de la evolución de sus relaciones humanas?

1: Nada satisfactoria 5: Completamente satisfactoria

Descripción (evolución de motivación de los trabajadores, de la rotación del personal, del ausentismo laboral):

21. ¿Cómo describe y evalúa el desempeño de la empresa en razón de la evolución de sus relaciones humanas?

1: Nada satisfactoria

5: Completamente satisfactoria

\begin{tabular}{l|l|l|l|l|}
$\mathbf{1}$ & $\mathbf{2}$ & $\mathbf{3}$ & $\mathbf{4}$ & $\mathbf{5}$ \\
\hline
\end{tabular}

Descripción (evolución de motivación de los trabajadores, de la rotación del personal, del ausentismo laboral):

\section{DATOS DEL CASO}

Nombre de la empresa:

Giro de la empresa:

Domicilio :

\begin{tabular}{|l|l|l} 
Teléfono: & Fax: & Correo electrónico: \\
\hline
\end{tabular}

Objeto Social

Principales producto que comercializa y participación en los ingresos (\%):

\begin{tabular}{|l|l|l|}
\hline Promedio de trabajadores: & Ventas anuales promedio: & $\begin{array}{l}\text { Importe promedio de } \\
\text { activos: }\end{array}$ \\
\hline
\end{tabular}




\section{Anexo 4. Guía de observación tercera investigación}

\section{Observador:}

\section{Fecha:}

\section{Objetivos del trabajo de investigación:}

1. Determinar los tipos de cultura organizacional que existen dentro de las empresas de sector turístico en Colombia.

2. Conocer los posibles rasgos de cultura de intraemprendimiento.

3. Analizar los tipos de innovación que se presentan en estas empresas.

4. Conocer y analizar el desempeño de las empresas partiendo de la tipología de su cultura, sus manifestaciones de intraemprendimiento e innovación.

\begin{tabular}{|l|}
\hline Aspecto a observar: \\
\hline Descripción: \\
\\
\end{tabular}

\section{Comentarios:}

Descripción: 